Central Washington University

ScholarWorks@CWU

All Master's Theses

Master's Theses

Summer 2021

\title{
Tsunami Deposits and Tsunami Modeling of the 900 AD Seattle Fault Event in Northern Puget Sound
}

Andrew A. Raulerson

Central Washington University, drew.raulerson@gmail.com

Follow this and additional works at: https://digitalcommons.cwu.edu/etd

Part of the Geology Commons, and the Stratigraphy Commons

\section{Recommended Citation}

Raulerson, Andrew A., "Tsunami Deposits and Tsunami Modeling of the 900 AD Seattle Fault Event in Northern Puget Sound" (2021). All Master's Theses. 1551.

https://digitalcommons.cwu.edu/etd/1551

This Thesis is brought to you for free and open access by the Master's Theses at ScholarWorks@CWU. It has been accepted for inclusion in All Master's Theses by an authorized administrator of ScholarWorks@CWU. For more information, please contact scholarworks@cwu.edu. 
TSUNAMI DEPOSITS AND TSUNAMI MODELING OF THE 900 AD

SEATTLE FAULT EVENT IN NORTHERN PUGET SOUND

A Thesis
Presented to
The Graduate Faculty
Central Washington University
In Partial Fulfillment
of the Requirements for the Degree
Master of Science
Geology

by

Andrew Auvell Raulerson

August 2021 


\section{CENTRAL WASHINGTON UNIVERSITY}

Graduate Studies

We hereby approve the thesis of

Andrew Auvell Raulerson

Candidate for the degree of Master of Science

APPROVED FOR THE GRADUATE FACULTY

Dr. Breanyn MacInnes, Committee Chair

Dr. Lisa Ely, Committee Member

Dr. Megan Walsh, Committee Member

Dean of Graduate Studies 


\begin{abstract}
TSUNAMI DEPOSITS AND TSUNAMI MODELING OF THE 900 AD

SEATTLE FAULT EVENT IN NORTHERN PUGET SOUND

by
\end{abstract}

Andrew Auvell Raulerson

August 2021

Puget Sound has a history of earthquakes and tsunamis with an ever-expanding knowledge of these events. The focus of this study is the Seattle fault earthquake and resulting tsunami 1100 years ago. This study aimed at refining the extent of tsunami inundation north of the fault using a two-phased approach: a field study at Elger Bay and tsunami modeling. Tsunami deposits dating to this event have been observed in six sites total sites in Puget Sound, and four of them are in northern Puget Sound. At Elger Bay I found one tsunami deposit in cores from the southwest corner of the marsh, near the inlet, however, ${ }^{14} \mathrm{C}$ dates of charcoal near the deposit range from $1478-1664$ cal AD - too young to be from the Seattle fault tsunami. Other possible sources within the last 500 years could be the 1820 's Camano Head landslide, 1700 Cascadia event, or nearby local fault earthquakes, or undiscovered landslides. Environmental analysis of Elger Bay sediments suggests that at the time of the Seattle fault rupture, the site was a tidal lagoon and therefore would have been unlikely to preserve a tsunami deposit.

Tsunami modeling consisted of three earthquake scenarios run at three tide levels for the 4 published northern Puget Sound Seattle fault tsunami deposit sites (West Point, Cultus Bay, Deer Lagoon, the Snohomish delta) and Elger Bay, resulting in 45 total models. All models agreed that the tide needed to be at or near mean higher high water 
(MHHW) to get inundation at all locations - no significant inundation occurred at NAVD88 (0 m) or mean lower low water (MLLW) datums. At Elger Bay, tsunami wave heights ranged from $\sim 0.6 \mathrm{~m}$ to $0.75 \mathrm{~m}$, which is at the threshold of whether it could leave a deposit or not. However, as the field study concluded, even if the tsunami left a deposit in Elger Bay, it would not have been preserved because it was a lagoonal environment. The data and conclusions from this study can be used by hazard mitigation programs such as the Island County Department of Emergency Management to further their knowledge and improve their plans for future tsunami events. 


\section{ACKNOWLEDGMENTS}

First I would like to say thank you to Central Washington University that gave me the opportunity to pursue this degree while providing me with financial assistance through teaching and research assistantships. I have a lot of great memories from my time on campus that I will carry with me the rest of my life. Thank you to the PADI Foundation, the Geological Society of America, and the CWU School of Graduate Studies for funding my project. I would like to give a big thank you to Eric Brooks and the Island County Department of Emergency Management, who helped me get access to Elger Bay marsh and paid for the lodging and facilities used during my field work. This funding was crucial to the completion of my project.

I had an enormous amount of help while doing the field portion of my project from CWU graduate students Brian Ostrom and Colin Bloom, as well as CWU undergraduate students Kevin Knapp, Rebeca Beccera, Clairissa De La Vergne, and Jasmine Bates. Thank you all for sacrificing a week of your summer to trudge through the hot marsh in chest waders. Thank you to professors Joanne Bourgeois from the University of Washington and my committee member Megan Walsh from CWU for spending time with me in the field and imparting your knowledge and experience to me. I also appreciate the amazing group of local volunteers that helped throughout my fieldwork.

I would like to thank my committee members Lisa Ely and Megan Walsh for your efforts in supporting my project - whether it was through courses taught, allowing me to process samples in your lab, or helping me with fieldwork - it was all extremely helpful and greatly appreciated. A big thank you is owed to my advisor and committee chair Bre. 
Without your infinite amount of help and advice I would not be at this point in my project. Thank you for being patient with me when I would get bogged down in the minor details of things and for when I would disappear on you. You have always been there when I needed you and I can't imagine anyone else would be able to fill your shoes.

Most of all, I have to thank my wife, Mila, for pushing me to get through this. You put up with too many of my half-attempts at getting this done over the past few years. You dealt with my various excuses for not having completed my thesis and for wanting to give up. And even when I had given up, you didn't. It is ultimately because of you (and Archer, and Calvin coming soon!) that I was able to push it this far and overcome the barriers that I had built for myself. This is dedicated to you. 


\section{TABLE OF CONTENTS}

Chapter

Page

I INTRODUCTION 1

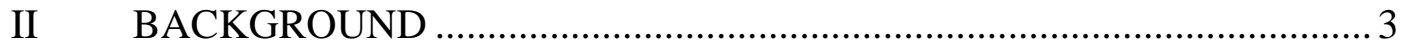

Tectonic Setting and Seattle Fault Zone ........................................... 3

900 AD Seattle Fault Tsunami .................................................................. 4

Puget Sound Marsh Stratigraphy ....................................................... 6

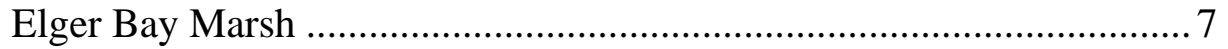

III $\quad$ METHODS .............................................................................. 9

Field Methods.......................................................................... 9

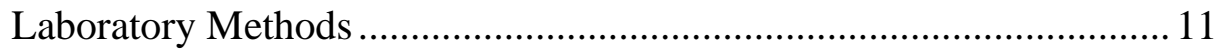

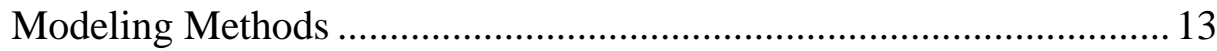

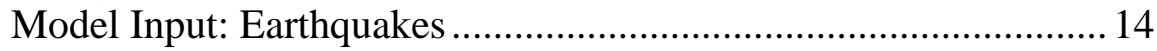

Model Input: Bathymetry ..................................................... 14

Model Input: Gauges and Maximum Inundation Map.................. 15

Model Input: Tidal Range ........................................................ 16

Comparing Model Results to Field Data.......................................... 17

IV ELGER BAY FIELDWORK RESULTS AND DISCUSSION ................ 19

Lithostratigraphic Facies and Their Environmental Interpretation....... 19

Radiocarbon Results and Interpretation ........................................... 34

Environmental Change Through Time at Elger Bay.......................... 36

A Tsunami in Elger Bay.................................................................... 41

Could We Have Seen a Seattle Fault Tsunami Deposit in Elger

Bay If It Was There? ......................................................... 45

V TSUNAMI MODELING RESULTS AND DISCUSSION ....................47

Field Sites for Modeling the Seattle Fault Tsunami............................ 47

Seafloor Deformation.............................................................. 47

Snohomish Delta Model Results .................................................... 48

Cultus Bay Model Results..............................................................50

Deer Lagoon Model Results........................................................... 50

West Point Model Results .............................................................. 52

Elger Bay Model Results ................................................................. 53

Discussion of Model Results............................................................. 54

The Seattle Fault Tsunami Occurred Near High Tide .................... 54

The Koshimura Source Produced a More Accurate Tsunami......... 60

Sources of Error ...............................................................................6 61 
TABLE OF CONTENTS (CONTINUED)

VI CONCLUSIONS

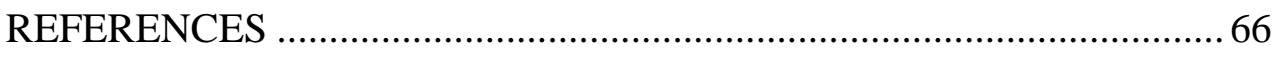

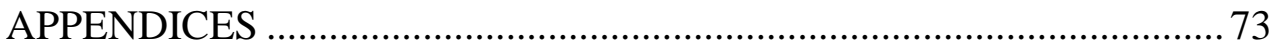

Appendix A-STRATIGRAPHY ILLUSTRATIONS..........................73

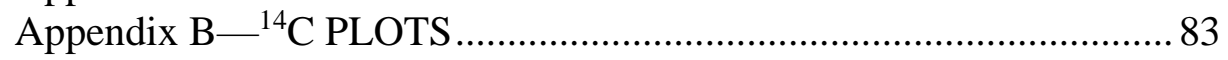




\section{LIST OF TABLES}

Table $\quad$ Page

$1 \quad$ Earthquake Parameters .................................................................... 15

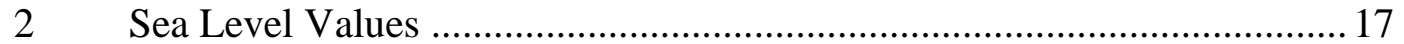

3 Livingstone Core Data ................................................................. 24

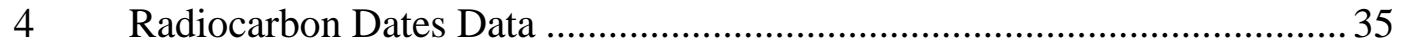

$5 \quad$ Summary of Tsunami Simulations ….................................................. 50

6 Summary of Tsunami Deposit Likelihood..............................................56 


\section{LIST OF FIGURES}

Figure

1 Puget Sound Background ............................................................. 3

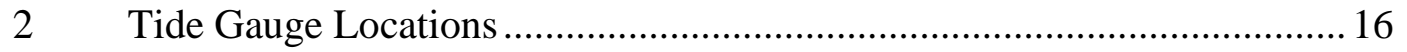

3 Elger Bay Stratigraphy Zones Map ................................................... 20

$4 \quad$ Examples of Stratigraphy.......................................................... 21

$5 \quad$ Gravel Grainsize Data...................................................................... 22

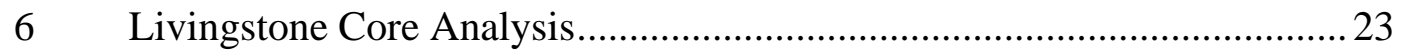

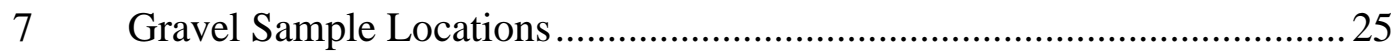

8 Muddy Sand and Gray Mud Grainsize Data........................................ 26

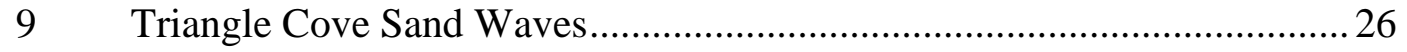

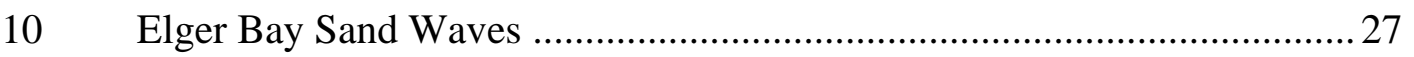

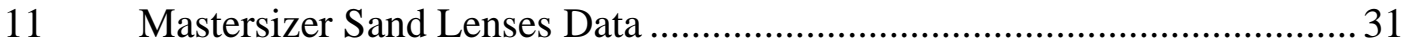

12 CAMSIZER Sand Lenses and Channel Sand Data................................. 31

13 Sand Layers Locations Map.............................................................. 32

$14 \quad$ Tsunami Deposit Location and Stratigraphy ..................................... 33

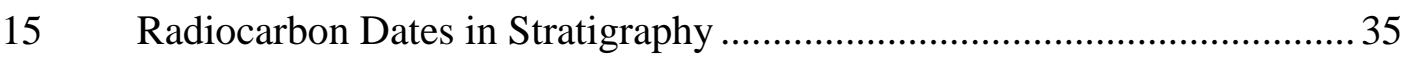

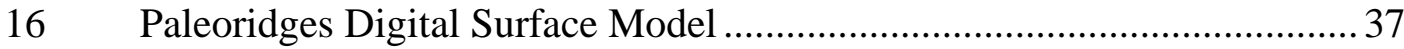

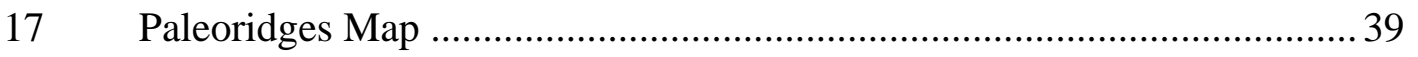

18 Protective Ridge in Historic Elger Bay Maps and Photographs ................. 39

19 Main Waterflow Channel Locations ...................................................... 40

20 Exposure 272 Surrounding Stratigraphy ........................................ 41

21 Aerial Photographs of Elger Bay ................................................... 42 


\section{LIST OF FIGURES (CONTINUED)}

22 Camano Head Landslide Location.......................................................... 44

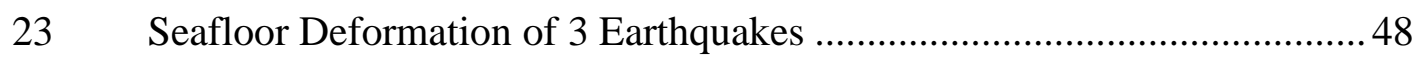

$24 \quad$ Snohomish Delta Modeling Results ...........................................................4 49

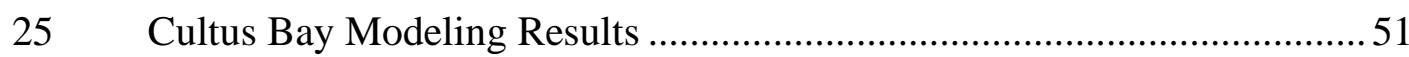

26 Deer Lagoon Modeling Results .......................................................52

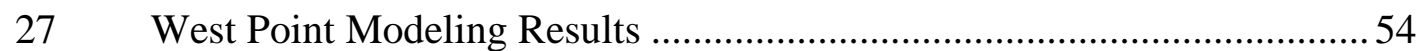

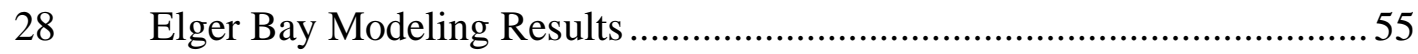

29 Maximum Flow Depths in Elger Bay .................................................59 


\section{CHAPTER I}

\section{INTRODUCTION}

Puget Sound is vulnerable to tsunamis that could cause catastrophic infrastructure damage and potential fatalities. In 900-930 AD (hereafter be referred to as $900 \mathrm{AD}$ ) an earthquake on the Seattle fault generated a tsunami that flooded low-lying areas in at least six known sites in eastern Puget Sound (Nelson, et al., 2003). The deposits have been found as far north as the Snohomish delta in Everett and as far south as Gorst near Bremerton (Adams, 1992; Atwater \& Moore, 1992; Bucknam et al., 1992; Bourgeois \& Johnson, 2001; Arcos, 2012). These few paleotsunami field sites begin to illustrate the hazard posed by a rupture of the Seattle fault, yet they do not fully define the extent of coastline inundated by that tsunami. The purpose of this project is to improve our understanding of the 900 AD tsunami in Puget Sound with new field investigations and modeling of multiple earthquake scenarios to compare the models against observed tsunami deposit field sites. Understanding the behavior and extent of the $900 \mathrm{AD}$ tsunami will improve predictions of the impact of a future Seattle fault tsunami that can be used for hazard planning throughout Puget Sound.

My project consisted of a week-long field study in Elger Bay, Camano Island in conjunction with computer modeling. Elger Bay is an ideal field study location based on multiple criteria: (1) it is a south-facing marsh, which is important because the tsunami had a direct impact from the south, (2) there are no previous tsunami studies at this marsh, and importantly (3) Elger Bay lies within a long span of coastline between locations where a Seattle fault tsunami deposit has been observed and where it was not found. Cores and exposures were observed to describe the stratigraphy of Elger Bay 
marsh and sediment and organic material was collected for lab analysis. Using the GeoClaw tsunami modeling program, I compared wave height calculations from simulations with Elger Bay and published data of tsunami deposits from Cultus Bay (Atwater and Moore, 1992), Snohomish Delta (Bourgeois and Johnson, 2001), Deer Lagoon (Bruce, 2020), and West Point (Atwater and Moore, 1992). I focused on one hypothetical and two published scenarios of the Seattle fault rupture (Venturato et al., 2007; Koshimura et al., 2002). I used multiple scenarios to cover a range of possible solutions to evaluate their reliability for reproducing the tsunami deposit record because the exact rupture solution of the earthquake is unresolved.

This project was a collaboration with the Island County Department of Emergency Management (ICDEM), who could use my results to evaluate and/or revise their current hazard mitigation plan and to add to their community outreach programs. The ICDEM hosts a number of events to promote awareness of the local hazards including hazard mitigation plan workshops and safety fairs. Hazard maps are readily available on their website as well as the "Where Are My Hazards?" app hosted by ArcGIS.com. 


\section{CHAPTER II}

\section{BACKGROUND}

\section{Tectonic Setting and the Seattle Fault Zone}

Puget Sound lies in an area where north-south crustal compaction in the Pacific Northwest region has created a series of reverse and transform fault zones crossing Puget Sound (McCaffrey et al., 2000; Wells et al., 1998), including the Tacoma fault zone, Seattle fault zone (SFZ), South Whidbey Island fault zone, and Devils Mountain fault (Figure 1).

The SFZ is a series of three or more south-dipping blind-thrust faults extending $\sim 70 \mathrm{~km}$ from the Hood Canal eastward to the Cascadia Range foothills (Nelson et al., 2003). The known faults that make up the SFZ are the Blakely Harbor fault, the Orchard Point fault, and the Seattle fault (Blakely et al., 2002). The SFZ also has at least one known backthrust fault, known as the Toe Jam Hill fault on Bainbridge Island (Nelson et al., 2003).

Although there have been multiple smaller events along the western end of the SFZ, the only known large $\left(>M_{w}=7.0\right)$ rupture occurred near 900-930 AD (Bucknam et al., 1992; Kelsey et al., 2008; Sherrod et al., 2000). Raised shoreline terraces at Restoration Point and Alki Point, tree ring correlation of primarily Douglas firs between Lake Washington and Alki Point, and rock avalanches in the Olympic Mountains are all evidence of this large rupture (Adams, 1992; Bucknam et al., 1992; Jacoby et al., 1992; Schuster et al., 1992). 

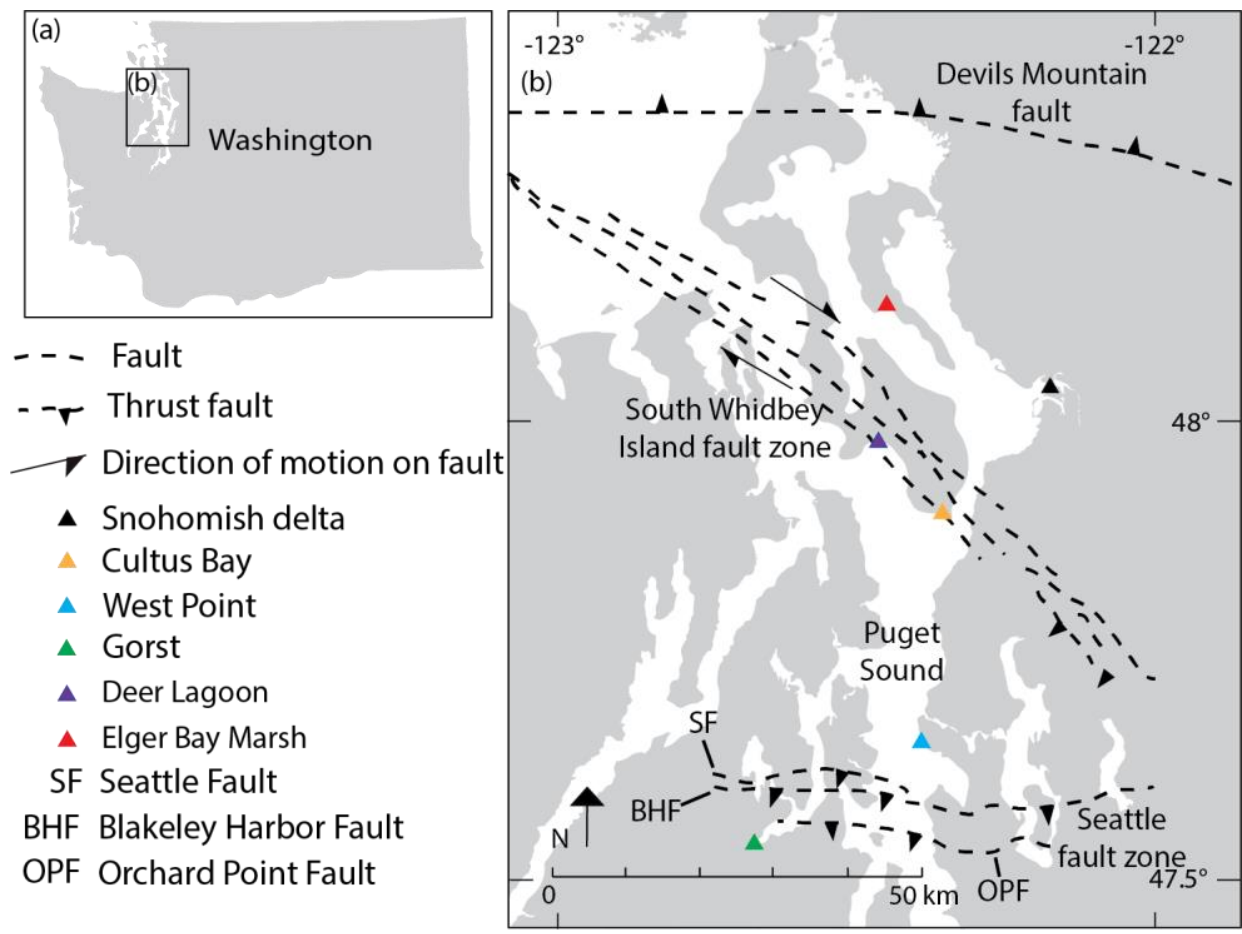

- Snohomish delta

A Cultus Bay

$\triangle$ West Point

- Gorst

- Deer Lagoon

A Elger Bay Marsh

SF Seattle Fault

BHF Blakeley Harbor Fault OPF Orchard Point Fault

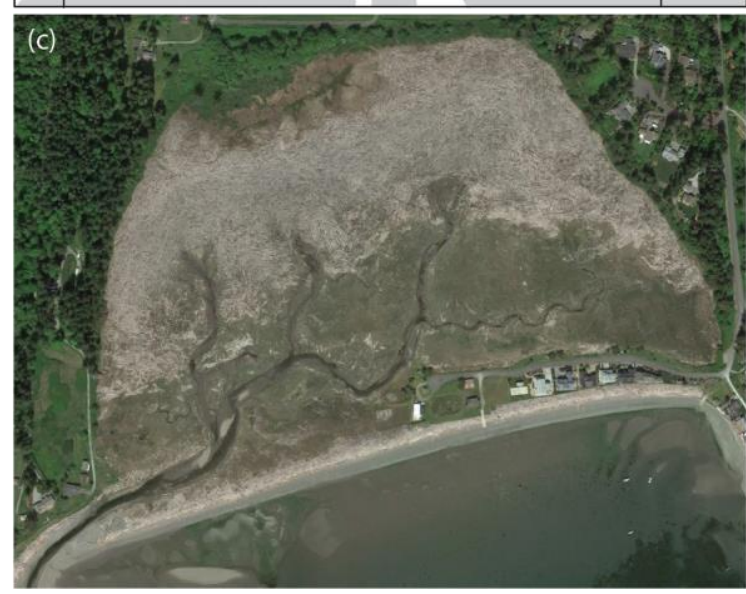

Figure 1 Puget Sound Background. (a) Washington State with inset of Puget Sound; (b) major faults of northern Puget Sound (Tacoma fault not shown, south of Seattle fault zone), faults that make up the SFZ are the Seattle Fault (SF), Blakeley Harbor Fault (BHF), and Orchard Point Fault (OPF), and locations of known AD 900 SFZ tsunami deposits. Triangles pointed up indicate tsunami deposit, triangles pointed down indicate lack of tsunami deposit. Modified from Arcos (2012); (c) satellite image of Elger Bay.

\section{AD Seattle Fault Tsunami}

The 900 AD earthquake produced a tsunami that left a sandy deposit at multiple coastal sites throughout Puget Sound, including the Snohomish delta (Bourgeois and Johnson, 2001), Cultus Bay on Whidbey Island (Atwater and Moore, 1992), West Point 
in Seattle (Atwater and Moore, 1992), and Gorst on the southern Kitsap Peninsula (Arcos, 2012). A detailed discussion of the possible earthquake sources for the tsunami can be found in the Methods chapter.

The Snohomish delta experienced flooding that deposited a sand layer up to $5 \mathrm{~cm}$ thick (Bourgeois and Johnson, 2001). At this location, there was a $2 \mathrm{~cm}$ thick sand layer coupled with a $15-20 \mathrm{~cm}$ thick grey clay layer that was extensively traceable through four channel beds. They used the disappearance of fossil vegetation and later reappearance to interpret a sudden subsidence paired with a gradual buildup of sediment afterward. They used Triglochin rhizomes in growth position to date the event at around $900 \mathrm{AD}$.

The Cultus Bay deposit consists of a sheet of sand that ranges from $5-15 \mathrm{~cm}$ thick, covering at least a $100 \mathrm{~m}$ by $200 \mathrm{~m}$ area (Atwater and Moore, 1992), although a larger area was not explored. The sediment within the deposit fined upward and landward, which is indicative of a tsunami (Morton et al., 2007). They found plant remains in growth position within the deposit that dated as $700-1100 \mathrm{AD}$, which encompasses the date of the 900 AD Seattle Fault tsunami.

The other tsunami deposit reported by Atwater and Moore (1992) at West Point, Seattle is a widespread, tabular body of sand buried within a salt marsh. Where the deposit overlies a pre-existing marsh surface, the sand ranges from $4-6 \mathrm{~cm}$ thick, while it thickens to $40 \mathrm{~cm}$ in depressions of the prior surface and disappears on higher elevations at the edge of the marsh. The deposit shows little to no basal scour and grades stratigraphically upward from $0.5-0.1 \mathrm{~mm}$ grains and contains angular clasts of local material and rounded pebbles. The area became a tidal flat due to approximately $1 \mathrm{~m}$ of 
subsidence. This subsidence prohibited the decay of the saltgrass and other plants as they were buried by tidal-flat mud. Radiocarbon dating of these plants indicates the 900 AD event and came from the bark of a Douglas fir log buried within the sand sheet.

At Deer Lagoon cores were taken on the east side, west side, and south side of the marsh. Bruce (2020) found grey mud overlying peat throughout the marsh, as well as a traceable deposit just below the mud/peat contact. There are other sand layers that were

found deeper in the cores but they were unable to be traced laterally. He used ${ }^{14} \mathrm{C}$ dating to determine the age of the deposit to likely be from the Seattle fault tsunami.

The tsunami deposit at Gorst is also a normally graded sand deposit with a sharp basal contact and a gradational upper contact that thins landward (Arcos, 2012). It is typically $5-7 \mathrm{~cm}$ thick although it is observed to thicken up to $24 \mathrm{~cm}$ into depressions. Arcos (2012) found no material within this layer for radiocarbon dating, but samples were taken immediately above and below the sandy bed indicate deposition around 900 AD.

\section{Puget Sound Marsh Stratigraphy}

The Puget Sound area has been carved and shaped by the Puget Lobe of the Cordilleran Ice Sheet. The last glaciation of this area was the Fraser glaciation that occurred $\sim 14$ ka (Porter and Swanson, 1998). When the Puget Lobe receded, it left behind a thick layer of glacial till and outwash that blankets the Puget Lowland. After recession, the region began a period of rapid isostatic rebound, which caused local sea level to fluctuate drastically (Thorson, 1981; Eronen et al., 1987). At 13,600 years ago, relative sea level in Puget Sound was above 25 m (Engelhart et al., 2015), however by 
$\sim 2,000 \mathrm{BC}$ relative sea level had fallen to around $-5.5 \mathrm{~m}$ and by $\sim 500 \mathrm{BC}$ it was about -2 m. Since $\sim 1200$ AD relative sea level had been within $1 \mathrm{~m}$ of current median sea level. Puget Sound marshes in an world with steady aggradation and sea level change would have a stratigraphic column as follows: a thick layer of peat, representing deposition of highly organic matter in a protected intertidal environment, overlying finer sediments such as muds and clays, representing deposition in a protected lower intertidal to subtidal environment, overlying increasing amounts of sand and possible pebbles deposited by coastal longshore drift cells and wave action before a barrier protected the area. Since Puget Sound is crisscrossed by multiple faults, earthquakes can disrupt this natural succession of marshy deposits. Earthquakes can cause stratigraphy to have mud overlying peat or vegetated surfaces by way of abrupt subsidence (Bourgeois and Johnson, 2001; Atwater, 1987; Sherrod, 2001). They can also cause marine sediments and flora and fauna to be found above sea level by way of abrupt uplift (Atwater and Moore, 1992; Bucknam et al., 1992). Liquefaction, tsunami, and storm events can also add sandy layers to the stratigraphy (Bourgeois and Johnson, 2001; Martin and Bourgeois, 2012; Atwater and Moore, 1992; Morton et al., 2007).

\section{Elger Bay Marsh}

Elger Bay marsh has been historically referred to as Elgers Bay, Algers Bay, and Algiers Bay. Little is known of the land use of Elger Bay, other than the knowledge of a wood mill that was located on the eastern side of the inlet from 1902-1910 (Prasse, 2006). Shipman (2008) describes Elger Bay marsh as a glacial depression embayment, a shallow valley flooded by rising sea levels, protected by a barrier beach. 
Previous studies at Elger Bay include a Master's thesis on driftwood and vegetation, and detailed work on salmon assemblages. MacLennan (2005) concluded the majority of the large woody debris, that today covers about 30 of the 70 acres of the marsh surface, is of anthropogenic origin. She also found the dominant species of vegetation growing today in the marsh (10 or more observations) are as follows: Distichlis spicata, Salicornia virginica, Triglochin maritima, Atriplex patula, Jaumea carnosa, Grindelia integrifolia car. Macrophylla, Potentilla anserina, and Spartina anglica. Kagley et al. (2007) studied the dominant salmon assemblages in Elger Bay from February through June 2005-2007 and noted the substrate of the areas in which they were sampling the fish. They labeled the sediment into four categories: mud, mixed fines, mixed coarse, and gravel, although the paper did not mention what criteria was used to classify the sediment. Inside the marsh, every location was designated as either mud or mixed fines. On the nearshore, they found sediment in all four categories, with mixed fines and mixed coarse being dominant. 


\section{CHAPTER III}

\section{METHODS}

I used a combination of field, laboratory, and modeling methods to determine if the 900 AD Seattle fault tsunami affected Elger Bay marsh. In the field I established whether the 900 AD Seattle fault tsunami deposit was preserved in Elger Bay and in doing so resolved the evolutionary history of Elger Bay marsh. Field methods included standard auger coring, Livingstone coring, and cutbank analysis to view marsh stratigraphy. Laboratory analysis of field samples included Loss on Ignition (LOI) and Magnetic Susceptibility (MS) methods to examine cores, grainsize analysis, and ${ }^{14} \mathrm{C}$ dating. My modeling methods included comparing modeling results from three earthquake sources with published and unpublished field observations, using the tsunami modeling code GeoClaw.

\section{Field Methods}

The field team, consisting of CWU professors and students, UW professors, and local volunteers, worked in the marsh June 14-20, 2015, coring and analyzing cut banks along tidal channels. I also used a DJI Phantom 2 unmanned aircraft system (UAS) paired with a GoPro Hero3+ camera to take a large series of aerial photographs of the marsh for creating a digital surface model. We worked at low tide to ensure as much vertical exposure as possible. We used a total station to track the locations of the cutbanks and where cores were taken. Handheld GPS units were used as backup units if there was an error with the total station. While in the field we collected samples for radiocarbon dating 
and grainsize analysis. Samples included sections of cores, bulk samples taken from cutbank exposures, and individual plant macrofossil samples.

At cut banks, we would clean the vertical surface and describe the stratigraphy in detail, including noting the surface vegetation and subsurface vegetation (if identifiable), sand and mud content, gravel content, woody debris, and clean sand layers. Where cut banks were not available, we used a gouge auger to view stratigraphy and described these cores in the same manner. This method requires less time searching for an ideal location because the main requirement is that the location not be in standing water to ensure retrieval. Coring is not as reliable as cut banks at accurately representing the local stratigraphy because the core is only 1 inch diameter; as such, the stratigraphy can be compressed due to the friction of the core being pressed in the ground, and patchy layers can be missed, such as a thin sand layer or slight changes in composition. There is also the risk of having no retrieval, which is most common when coring in sandy unconsolidated sediments, but can occur in all settings.

In addition to a gouge auger, we also used a Livingstone corer in two locations in the marsh. A Livingstone corer is a lightweight piston corer that is typically used for collecting lake sediments as it minimally disturbs the sediment (Livingstone, 1955). It allowed us to more precisely measure the depths of the stratigraphy because it retrieves undisturbed samples. The samples are easily packaged and preserved for describing in a lab setting as well as for use in other lab methods described below. 


\section{Laboratory Methods}

In the laboratory I analyzed the magnetic susceptibility and organic content of the two Livingstone cores and measured the grainsize distribution of individual samples taken throughout the marsh. I used a Bartington whole core magnetic susceptibility system to analyze the two Livingstone cores (EB15A and EB15B), comprised of four total drives, approximately $1 \mathrm{~m}$ each. During magnetic susceptibility analysis, sediment was introduced to a small magnetic field that induced a small, temporary magnetization within the sediment (Nowaczyk, 2002; Sandgren and Snowball, 2002). This magnetization was then measured and recorded relative to the ambient magnetic field of the environment. I took measurements in $1 \mathrm{~cm}$ increments for the entirety of the two cores.

I analyzed the same cores to determine organic content using LOI methods. I sliced the Livingstone core in half length-wise in order to preserve half of the core for potential future study, as well as to get a clean view of the stratigraphy of the core. I then made a detailed description of the core and sampled $2 \mathrm{cc}$ of sediment at $1 \mathrm{~cm}$ intervals. LOI requires a series of three baking sessions of $90^{\circ} \mathrm{C}$ for $\sim 24$ hours, $550^{\circ} \mathrm{C}$ for $\sim 2$ hours, and $900^{\circ} \mathrm{C}$ for $\sim 2$ hours (Heiri et al., 2001). Sample weight is recorded before and after every session of baking in order to calculate accurate organic and carbonate loss. I calculated the percent loss of organics using the following equation (Heiri et al., 2001):

$$
L O I_{550}=\left(\left(D W_{90}-D W_{550}\right) / D W_{90}\right) \times 100
$$

where $D W_{90}$ represents the dry weight of the sample after being cooked at $90^{\circ} \mathrm{C}, D W_{550}$ represents the dry weight of the sample after being cooked at $550^{\circ} \mathrm{C}$, and $\mathrm{LOI}_{550}$ represents the percentage of organics lost during the procedure. 
Calculating the percent of carbonates required a slight variation in the formula due to the remaining oxide once carbon dioxide has left the sample. The weight of carbon is $44 \mathrm{~g} / \mathrm{mol}$ and the weight of carbonate $\left(\mathrm{CO}_{3}^{-2}\right)$ is $60 \mathrm{~g} / \mathrm{mol}$. Hypothetically, this means that for every mol of carbonate in a sample, $16 \mathrm{~g}$ of oxide will be left behind, thus the equation needed to account for this. The weight of the carbonate loss must then be multiplied by 1.36 in order to find the actual value of carbonate loss in the sample (Heiri et al., 2001):

$$
L O I_{900}=\left(\left(\left(D W_{550}-D W_{900}\right) \times 1.36\right) / D W_{90}\right) \times 100
$$

where $D W_{900}$ represents the dry weight of the sample after being cooked at $900^{\circ} \mathrm{C}$ and $\mathrm{LOI}_{900}$ represents the percentage of carbonates lost during the procedure.

All radiocarbon and grainsize samples were prepared in a CWU lab. Preparation of radiocarbon samples consisted of picking through bulk and core samples for seeds, wood, or charcoal. Most samples were collected to date sand layers, but one was collected at depth to determine the minimum age of the marsh. The materials were then dried in an oven set at $80^{\circ} \mathrm{C}$ until dehydrated and sent to Direct AMS in Bothell, WA. Special care was taken during this process to ensure that no carbon contamination occurred. Dates were calibrated using OxCal v.4.3.2, IntCal13 atmospheric curve. Grain size analysis of samples was completed using a CAMSIZER (at the University of Washington in Seattle, WA) and a Mastersizer 2000 at CWU. A CAMSIZER measures particle size through image analysis of falling grains and can measure sediment from $30 \mu \mathrm{m}$ to $3 \mathrm{~cm}$. A Mastersizer uses laser diffraction to measure grain size and can interpret grain sizes $0.02 \mu \mathrm{m}$ to $2 \mathrm{~mm}$. Both methods are necessary to measure the full range of grain sizes present in Elger Bay. Since the two machines 
measure grain size using a different methodology, the results could not be compared directly and were analyzed separately.

Finally, with images taken using the UAS I created digital surface models (DSM) and orthophotos of the marsh using Agisoft Photoscan Pro Structure from Motion (SfM) software. I took several series of photographs at a consistent height while maintaining $\sim 30 \%$ overlap per photo. I then georeferenced the models and orthophotos with ground control points that were measured in the field with GPS and the total station. The orthophotos and DSM's were used to create figures.

\section{Modeling Methods}

I used the GeoClaw code (www.clawpack.org/geoclaw, versions 5.4.1 and 5.6.1) to model the 900 AD Seattle fault tsunami in Puget Sound. GeoClaw is an open-source program that solves two-dimensional, shallow-water wave equations using a finite volume method (Berger and LeVeque, 1998; Berger et al., 2011; LeVeque et al., 2011; Mandli et al., 2016). The program calculates seafloor deformation from an input of several fault parameters and propagates tsunamis across input bathymetries. To reduce computation time, the program uses a technique called adaptive mesh refinement. This means that the simulation runs at coarse resolution and, depending on sea surface slope, will run at a more fine resolution only where the tsunami currently is located. This method reduces simulation run time by only allowing high-resolution calculations where high-resolution calculations are needed, immediately around the tsunami.

There are five sites in Puget Sound where I ran simulations, so in order to reduce run time (which is based on computer calculation speed) I coupled Cultus Bay with 
Snohomish Delta, and Elger Bay with West Point. I ran Deer Lagoon on its own because it required a much larger area of refinement due to its large size. Doing this allowed a greater allotment of memory and CPU usage per model, which cut down on run time.

\section{Model Input: Earthquakes}

GeoClaw calculates seafloor deformation based on an input of several fault parameters (Table 1) using the Okada (1985) equations (Berger et al., 2011), including fault segment length, width, dip, rake, strike, depth, and slip. I ran two earthquake scenarios from published models: Venturato from Venturato et al. (2007), which includes varying slip over 7 subfaults with values based on field observations of uplift, and Koshimura from Koshimura (2002), which had six shallow subfaults and six deep subfaults with varying slip, strike, and dip. The third earthquake scenario was a simplistic one subfault, uniform slip scenario, Uniform Venturato, that I created by normalizing and averaging the strike and slip of the subfaults in the Venturato scenario.

\section{Model Input: Bathymetry}

Bathymetry files were downloaded from NOAA's National Centers for Environmental Information website. The Puget Sound Digital Elevation Model (DEM) and Port Townsend DEM were used for all simulations. All bathymetry was in NAVD88 vertical datum and WGS84 horizontal datum and was $1 / 3$ arc sec resolution. I trimmed the bathymetry files to make them a smaller size with the help of Dr. Loyce Adams. 
Table 1 Earthquake Parameters. List of parameters used to simulate the three earthquake scenarios.

\begin{tabular}{|c|c|c|c|c|c|c|c|c|c|}
\hline Lat $\left(^{\circ}\right)$ & Long $\left(^{\circ}\right)$ & Depth $(\mathrm{km})$ & Rake $\left(^{\circ}\right)$ & $\mathrm{L}(\mathrm{km})$ & $\mathrm{W}(\mathrm{km})$ & Strike $\left(^{\circ}\right)$ & Dip $\left(^{\circ}\right)$ & $\mathrm{D}(\mathrm{m})$ \\
\hline \multicolumn{8}{|c|}{ Koshimura } \\
\hline 47.526 & -122.75 & 1.82886 & 90 & 15.2 & 6 & 87.9 & 60 & 4 \\
\hline 47.531 & -122.61 & 1.82886 & 90 & 6.3 & 6 & 86.6 & 60 & 6 \\
\hline 47.528 & -122.509 & 1.82886 & 90 & 8.9 & 6 & 96 & 60 & 8 \\
\hline 47.516 & -122.43 & 1.82886 & 90 & 3.3 & 6 & 128.8 & 60 & 8 \\
\hline 47.497 & -122.339 & 1.82886 & 90 & 11.5 & 6 & 99.3 & 60 & 6 \\
\hline 47.498 & -122.166 & 1.82886 & 90 & 14.9 & 6 & 81 & 60 & 4 \\
\hline 47.499 & -122.749 & 7.02501 & 90 & 15.2 & 38 & 87.9 & 25 & 2 \\
\hline 47.504 & -122.608 & 7.02501 & 90 & 6.3 & 38 & 86.6 & 25 & 4 \\
\hline 47.501 & -122.513 & 7.02501 & 90 & 8.9 & 38 & 96 & 25 & 6 \\
\hline 47.489 & -122.436 & 7.02501 & 90 & 3.3 & 38 & 128.8 & 25 & 6 \\
\hline 47.47 & -122.345 & 7.02501 & 90 & 11.5 & 38 & 99.3 & 25 & 4 \\
\hline 47.471 & -122.16 & 7.02501 & 90 & 14.9 & 38 & 81 & 25 & 2 \\
\hline \multicolumn{7}{|c|}{ Venturato } \\
\hline 47.526 & -122.75 & 0.5 & 90 & 15.2 & 35 & 87.9 & 60 & 1 \\
\hline 47.531 & -122.61 & 0.5 & 90 & 6.3 & 35 & 86.6 & 60 & 1 \\
\hline 47.528 & -122.509 & 0.5 & 90 & 8.9 & 35 & 96 & 60 & 12 \\
\hline 47.516 & -122.43 & 0.5 & 90 & 2.0 & 35 & 128.8 & 60 & 11 \\
\hline 47.497 & -122.339 & 0.5 & 90 & 11.5 & 35 & 99.3 & 60 & 4 \\
\hline 47.498 & -122.166 & 0.5 & 90 & 14.9 & 35 & 81 & 60 & 1 \\
\hline \multicolumn{7}{|c|}{ Uniform Venturato } \\
\hline 47.516 & -122.467 & 0.5 & 90 & 58.8 & 35 & 91.9833 & 60 & 5 \\
\hline
\end{tabular}

\section{Model Input: Gauges and Maximum Inundation Map}

I placed tide gauges that recorded surface levels from start to end of the simulation at

Elger Bay and sites with published observation of the Seattle fault tsunami deposit: West

Point, Cultus Bay, Snohomish Delta, and Deer Lagoon (Figure 2). The gauges record water surface elevation as the tsunami propagates through the Sound. At West Point, Elger Bay, and Snohomish River, the gauges (3, 9, and 27 respectively) were placed just offshore and recorded a waveform regardless of whether the land floods or not. However, the gauges at Cultus Bay and Deer Lagoon (gauges 20 and 31) are located on the marsh 
(Cultus) and tide flat (Deer Lagoon) surfaces, so did not record a waveform if the site was not inundated. At Elger Bay I also created maximum inundation maps that detail maximum flow depths inside the marsh.
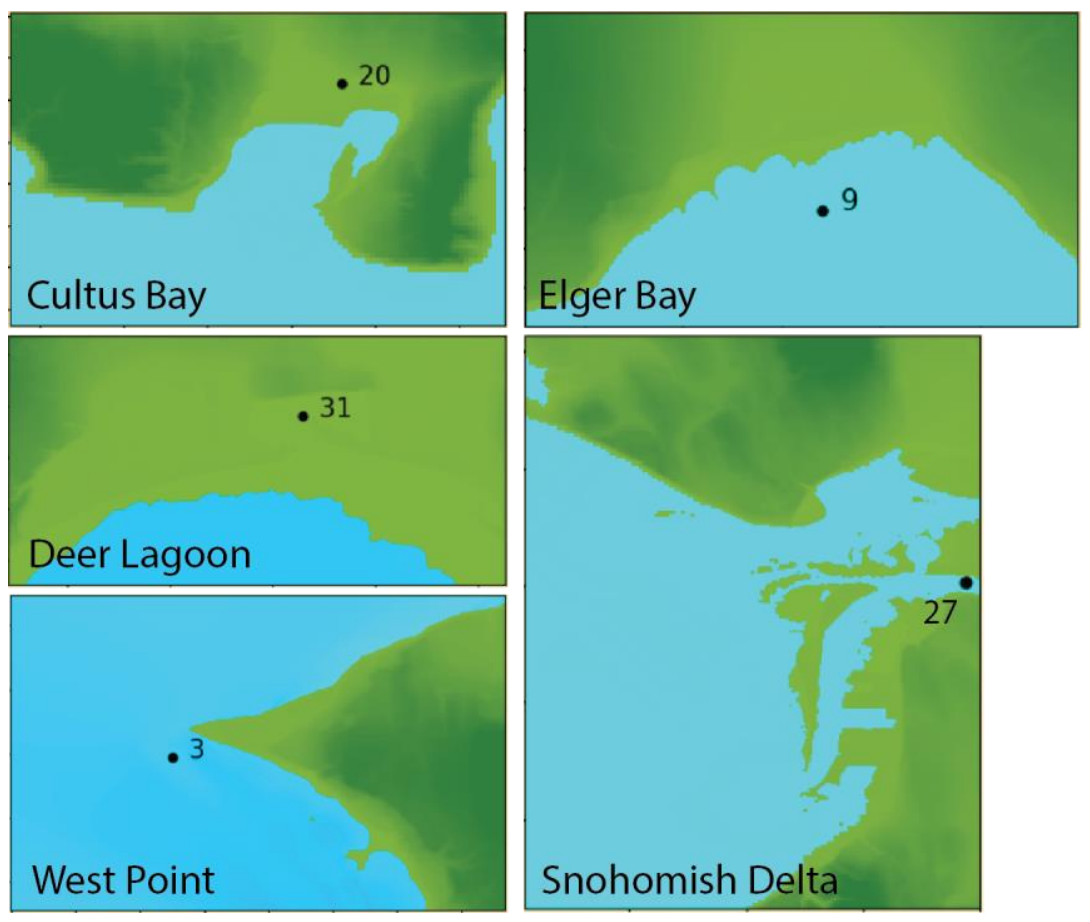

Figure 2 Tide Gauge Locations. Locations of synthetic tide gauges at each site. Tide levels are set at NAVD88 in these figures.

\section{Model Input: Tidal Range}

Puget Sound tides are mesotidal, with a range that varies spatially (Mofjeld et al., 2002). Each of the 5 sites was assigned its own unique water surface elevation representing mean lower low water (MLLW) and mean higher high water (MHHW) values, as well as the NAVD88 value that is $0 \mathrm{~m}$ in the bathymetry (Table 2). I determined MLLW and MHHW at each of the 5 sites by finding MLLW and MHHW levels relative to NAVD88 at Seattle, WA, and extrapolated from there using data from Mofjeld et al., (2002) to all five sites. The sites were then paired up and averaged to come 
up with one value for each tide level for every two sites. This way I was able to pair up sites to be run together on each tide level to limit the number of simulations run simultaneously. The tide levels were accounted for by changing the sea level value in GeoClaw's input files. I ran simulations for each site at each tide level for each earthquake scenario. For example, Elger Bay has nine different runs: three for Koshimura (MLLW, NAVD88, and MHHW), three for Venturato, and three for Uniform Venturato. Recall that Puget Sound tide range varies spatially (Table 2).

Table 2 Sea Level Values. Sea level values relative to NAVD88 assigned to each tide at all locations. Values in meters.

\begin{tabular}{|c|c|c|c|}
\hline Site & MLLW & NAVD88 & MHHW \\
\hline Cultus Bay & -0.67 & 0.0 & 2.69 \\
\hline Snohomish Delta & -0.67 & 0.0 & 2.69 \\
\hline Deer Lagoon & -0.53 & 0.0 & 2.38 \\
\hline Elger Bay & -0.81 & 0.0 & 2.635 \\
\hline West Point & -0.81 & 0.0 & 2.635 \\
\hline
\end{tabular}

\section{Comparing Model Results to Field Data}

Results from each simulated tide gauges were correlated with what was observed in the field. I devised a simple system to organize the results where YES means the model correlates with field observations, NO means the model does not correlate with field observations, and MAYBE means comparison is inconclusive but agreement is possible. Since there are no prior field studies done at Elger Bay to correlate with, YES means the tsunami was big enough to leave a deposit and therefore should have been observed, NO means that the tsunami was not big enough to leave a deposit and should 
not have been observed, and MAYBE means that the data is inconclusive whether the tsunami was large enough to leave a deposit.

In order to define the YES, NO, and MAYBE parameters, I estimated the land surface elevation for all sites based on information in the associated publication, from my own digital surface model for Elger Bay, or from total station data collected at Elger Bay: Snohomish delta - just above MHHW, $2.69 \mathrm{~m}$ above NAVD88 (Bourgeois and Johnson, 2001), Cultus Bay - 1.8 m above NAVD88 (Atwater and Moore, 1992), Deer Lagoon at $0 \mathrm{~m}$ in NAVD88, West Point - just above MHHW, $2.635 \mathrm{~m}$ above NAVD88 (Atwater and Moore, 1992), and Elger Bay - $2.7 \mathrm{~m}$ above NAVD88. Sediment transport modeling in tsunamis shows that a $10 \mathrm{~cm}$ deposit would require unrealistically high flow speeds at flow depths $\leq 1 \mathrm{~m}$ for deposition (Jaffe and Gelfenbaum, 2007). Using this information I designate a wave height of $1 \mathrm{~m}$ above land surface to be the minimum for a YES designation, $0.5 \mathrm{~m}-1 \mathrm{~m}$ above land surface for MAYBE, and less than $0.5 \mathrm{~m}$ above land surface for NO. These same ranges were applied to the Elger Bay results as well, but instead of wave heights from a gauge, I used flow depth in the marsh from the maximum inundation mapping results. 


\section{CHAPTER IV}

\section{ELGER BAY FIELDWORK RESULTS AND DISCUSSION}

During fieldwork in Elger Bay we collected data from 49 cutbanks/excavations, 66 gouge auger cores (Figure 3), and took 81 samples for sediment analysis, macrofossil identification, and radiocarbon dating. The deepest excavation recorded was excavation 399 at $1.35 \mathrm{~m}$ and the deepest core recorded was core 401 at $2.81 \mathrm{~m}$. The majority of the data collected were located in the southern half of the marsh, contained tidal channels for excavations, and contained much less driftwood, which made gouge auger coring more feasible. We categorized the sediment into seven facies: gravel, muddy sand, grey mud, organic-rich mud, orange peat, modern soil, and sand lenses (Figure 4). Stratigraphy from all cores and cutbanks can be found in Appendix A.

\section{Lithostratigraphic Facies and Their Environmental Interpretation}

Gravel: This facies was found everywhere throughout the marsh. Its color varied from grey to dark grey. It is typically composed of medium to coarse sand and often contained pebbles ranging from $<1 \mathrm{~cm}$ to $\sim 5 \mathrm{~cm}$ with occasional larger pebbles (Figure 5) and rarely contained mud-sized sediment. Due to the auger core barrel being 1 inch diameter, pebbles greater than $2.54 \mathrm{~cm}$ would not be retrieved by gouge auger coring, such as in core 249. We always found this facies at or near the bottom of a exposure or core. We did not dig or core through the gravel, but found it up to $0.64 \mathrm{~m}$ thick. In core EB15A where this facies was sampled, it had an average \% organics of $2.3 \%$ with a range of 0.9 14.2\% (Figure 6; Table 3) and an average magnetic susceptibility (MS) value of $4.18 \mathrm{x}$ $10^{-7} \mathrm{emu}$ with a range of $1.98 \times 10^{-7}-6.49 \times 10^{-7} \mathrm{emu}$. 


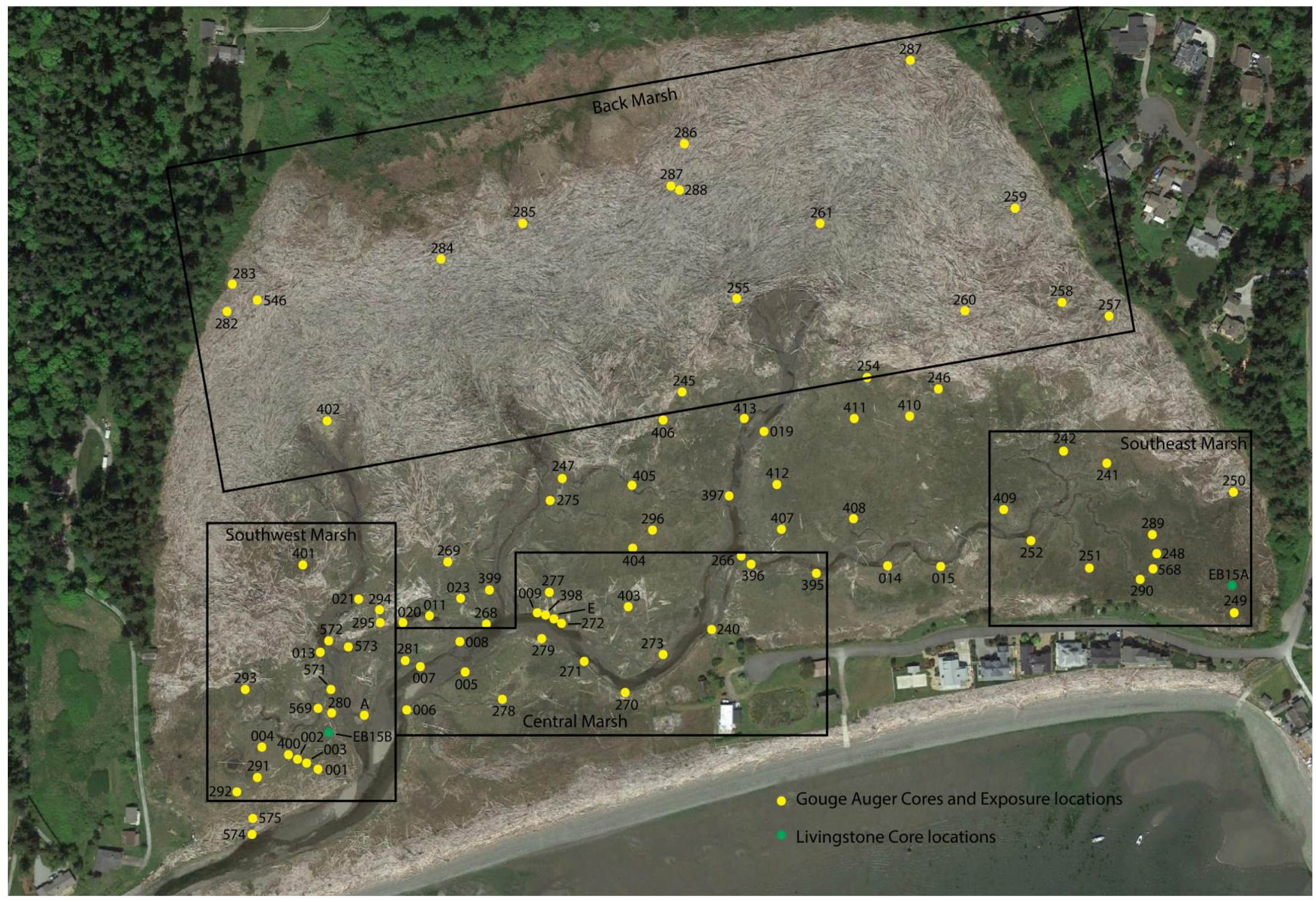

Figure 3 Elger Bay Stratigraphy Zones Map. Map of all cores and cutbank locations collected during fieldwork at Elger Bay. Boxes indicate zones of the marsh referred to in the text. 


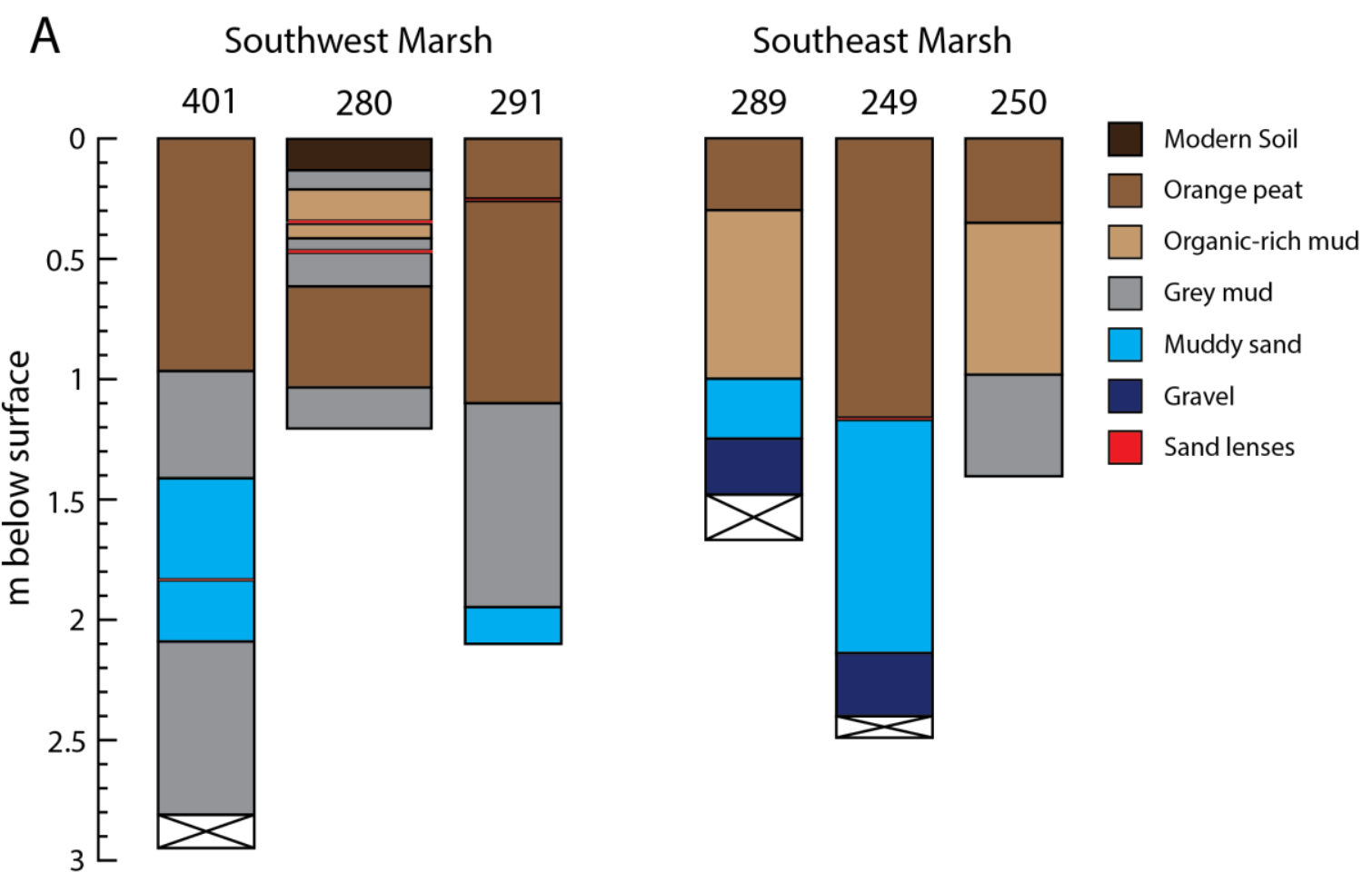

B

Central Marsh

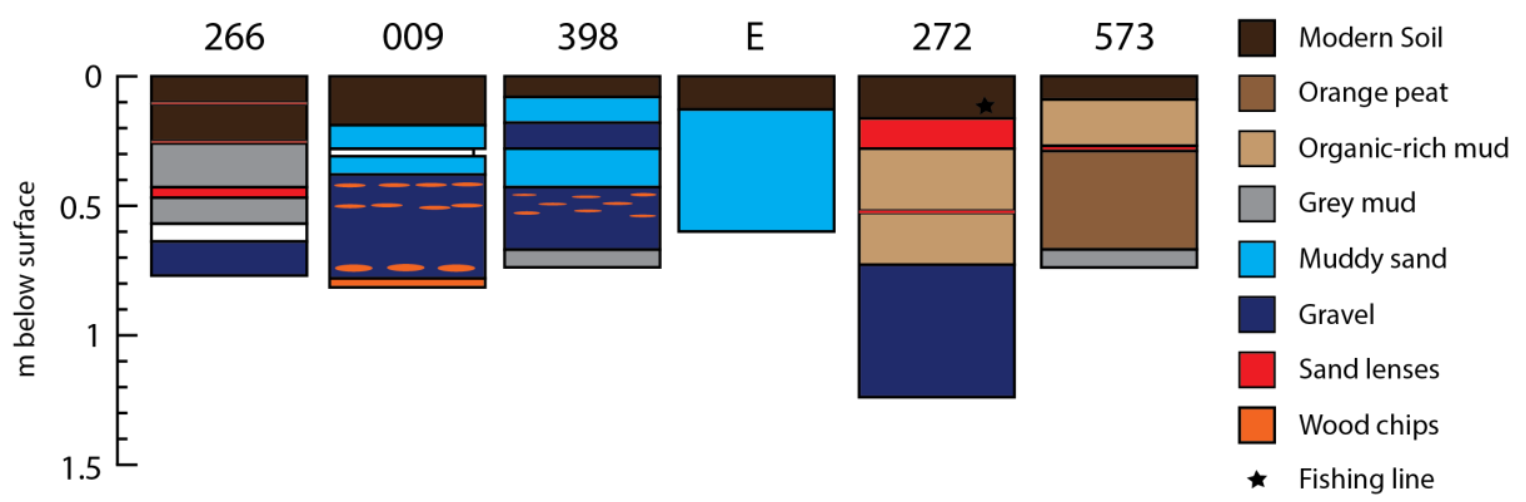

Figure 4 Examples of Stratigraphy. Example stratigraphy from cores (narrower columns) and cutbanks (wider columns) in (A) southwest and southeast marsh, (B) central marsh, and $(\mathrm{C})$ back marsh. Facies are described in Chapter IV. 


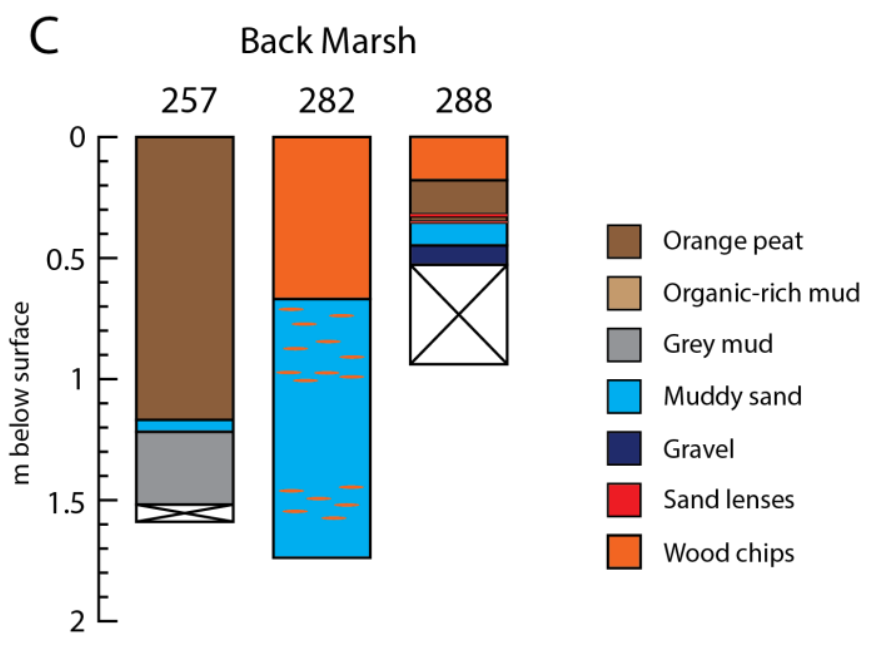

Figure 4 Examples of Stratigraphy. Example stratigraphy from cores (narrower columns) and cutbanks (wider columns) in (A) southwest and southeast marsh, (B) central marsh, and $(\mathrm{C})$ back marsh. Facies are described in Chapter IV.

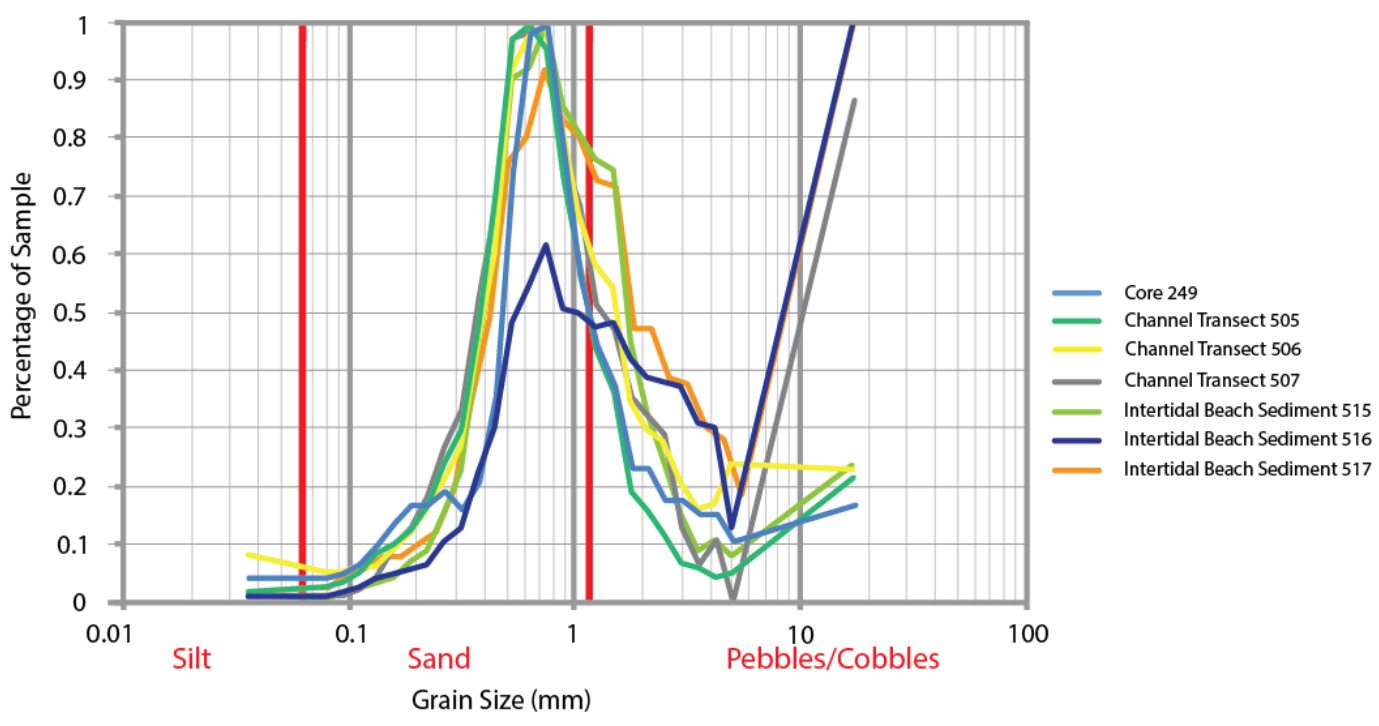

Figure 5 Gravel Grainsize Data. Grain size distribution measured by a CAMSIZER for Gravel from core 249 (blue line) compared with modern analogs. Vertical red lines show the grainsize distinctions between silt, sand, and grains larger than sand. 

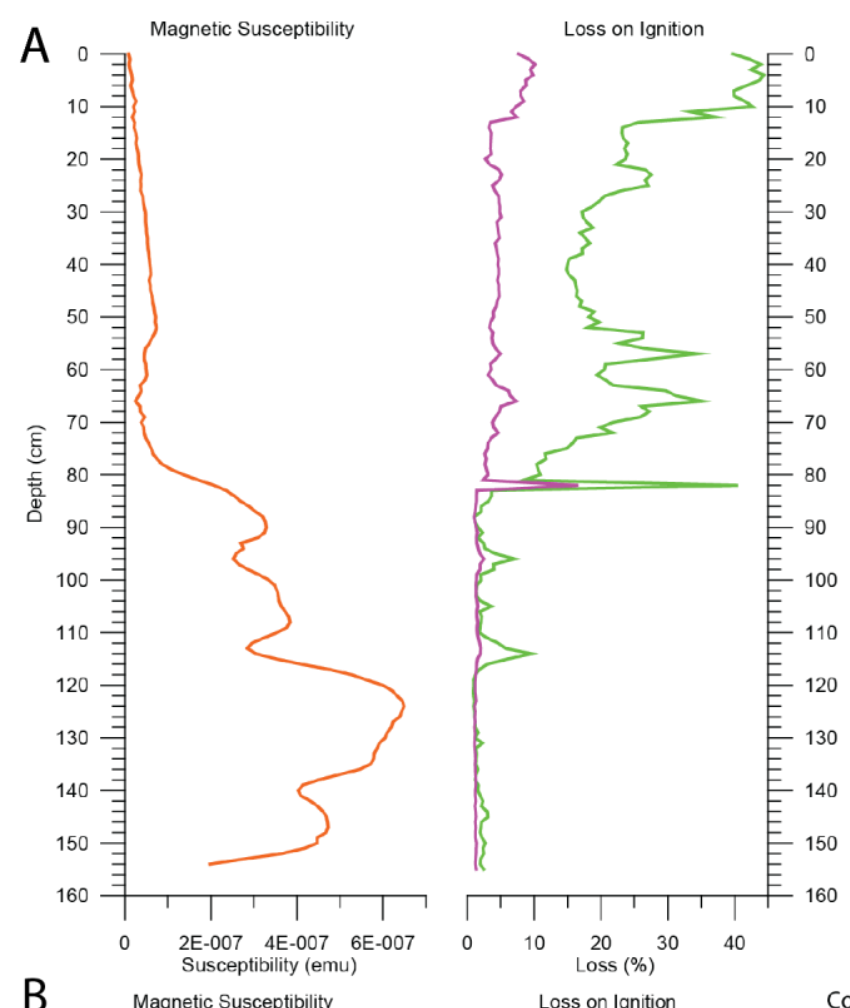

Core Stratigraphy
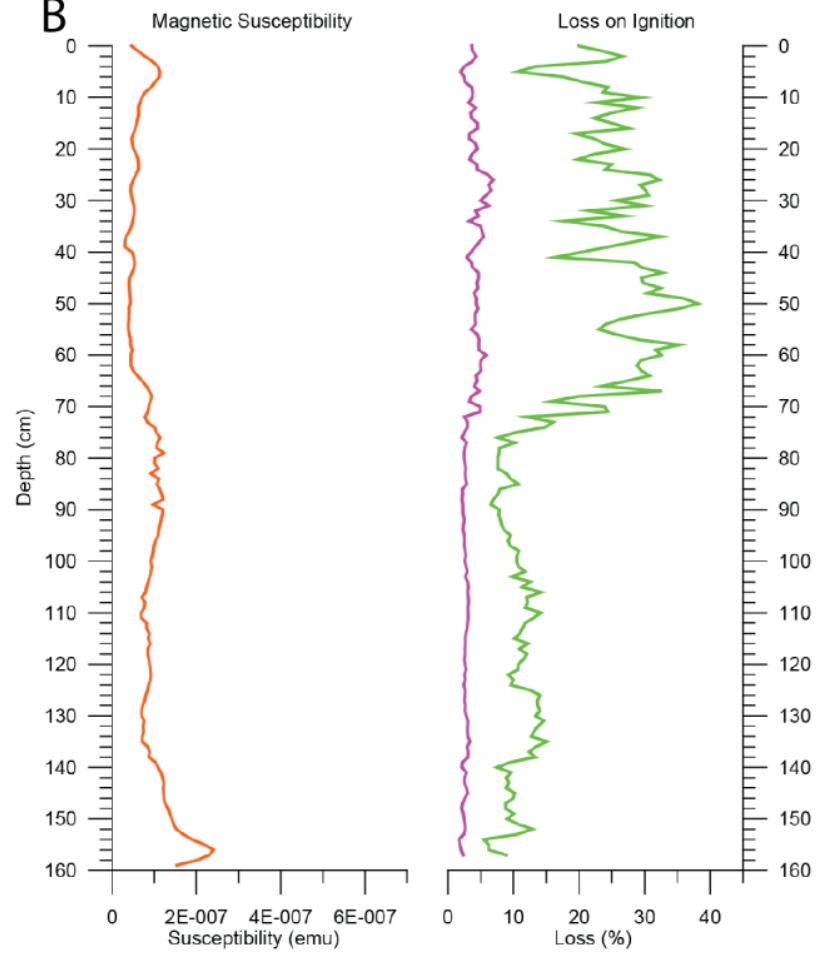

Core Stratigraphy

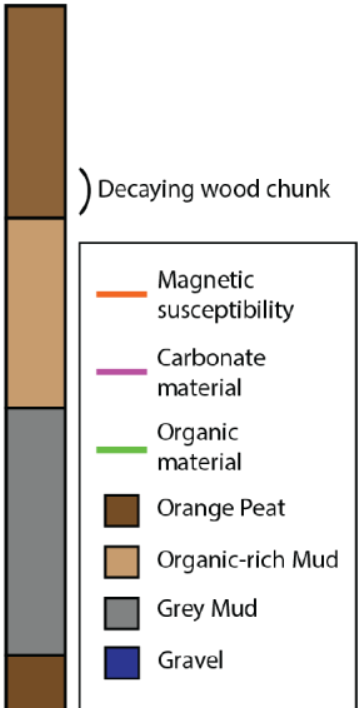

Pebbles

Figure 6 Livingstone Core Analysis. (A) MS, LOI, and stratigraphic data from Livingstone core EB15A from the southeast marsh, (B) MS, LOI, and stratigraphic data from Livingstone core EB15B from the southwest marsh. 
Table 3 Livingstone Core Data. Minimum, maximum, and average magnetic susceptibility and \% organics values of facies present in Livingstone cores EB15A and EB15B.

\begin{tabular}{|l|c|c|c|c|c|c|}
\hline \multirow{2}{*}{ Facies } & \multicolumn{3}{|c|}{ Magnetic Susceptibility (emu) } & \multicolumn{3}{c|}{ \% Organics } \\
\cline { 2 - 7 } & Min & Max & Average & Min & Max & Average \\
\hline $\begin{array}{l}\text { Orange } \\
\text { Peat }\end{array}$ & $8.75 \times 10^{-9}$ & $1.52 \times 10^{-7}$ & $7.13 \times 10^{-8}$ & 5.5 & 44.3 & 22.5 \\
\hline $\begin{array}{l}\text { Organic-rich } \\
\text { Mud }\end{array}$ & $2.44 \times 10^{-8}$ & $1.71 \times 10^{-7}$ & $6.06 \times 10^{-8}$ & 7.6 & 40.5 & 22.9 \\
\hline Gray Mud & $6.85 \times 10^{-8}$ & $1.22 \times 10^{-7}$ & $8.03 \times 10^{-8}$ & 6.6 & 34.4 & 13.8 \\
\hline Gravel & $1.98 \times 10^{-7}$ & $6.49 \times 10^{-7}$ & $4.18 \times 10^{-7}$ & 0.9 & 14.2 & 2.3 \\
\hline
\end{tabular}

Environmental interpretation: The Gravel is the basal stratigraphic unit within the marsh. It is interpreted as currently depositing at the present-day beach and in the main channel based on samples taken from the main channel near the inlet and within the intertidal zone of the beach (Figure 7). The sediment source is likely the nearby eroding cliffs that have been reworked and deposited by longshore drift from the east and the west as each side converges on the marsh, found using the Washington State Department of Ecology's Coastal Atlas Map (apps.ecology.wa.gov/coastalatlas/tools/Map.aspx). One observation to note is that there are no fines in these samples as wave action and peak tide channel flow have enough energy to remove them.

Muddy Sand: This typically grey facies was widespread at various depths throughout the marsh although it was not present in the cores analyzed by LOI and MS methods. Grain size spanned clay to medium/coarse sand (Figure 8) and ranged from approximately 
50/50\% mud/sand to about $90 \%$ sand. Occasionally the Muddy Sand contained roots, shells, driftwood, and few pebbles and sometimes it exhibited clear lamination.

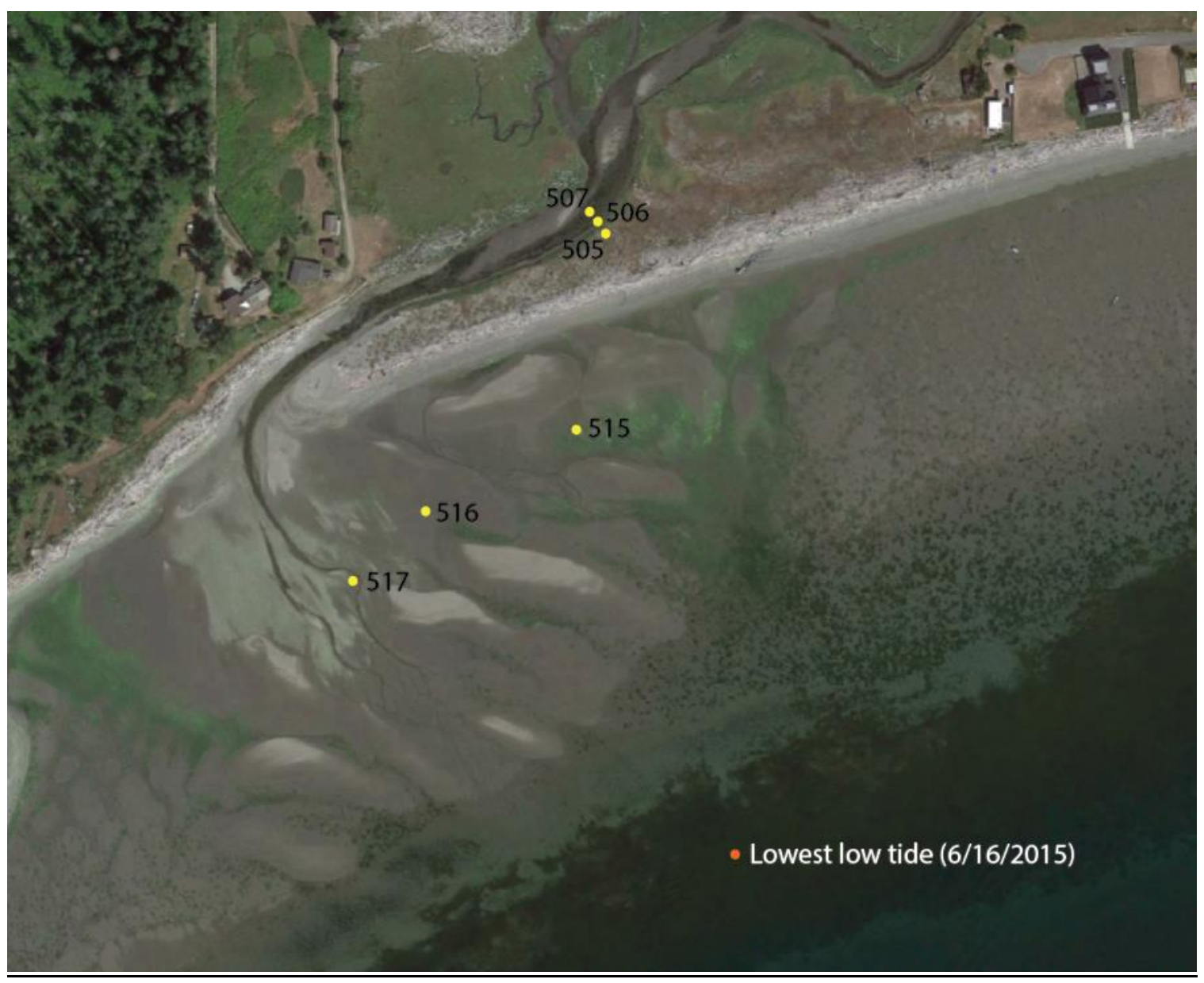

Figure 7 Gravel Sample Locations. Yellow dots show locations of modern gravel samples from the main tidal channel $(505,506$, and 507) and intertidal beach transect $(515,516$, 517). Orange dot is the location for the lowest low tide observed in the field on $6 / 16 / 2015$.

Environmental interpretation: I interpret this facies as currently being deposited in the tide channels of Elger Bay, as well as at Triangle Cove (a lagoon on the east side of Camano Island; Figure 9). Triangle Cove is a protected, intertidal mud flat where the sand is likely mobilized through meandering and avulsing tide 


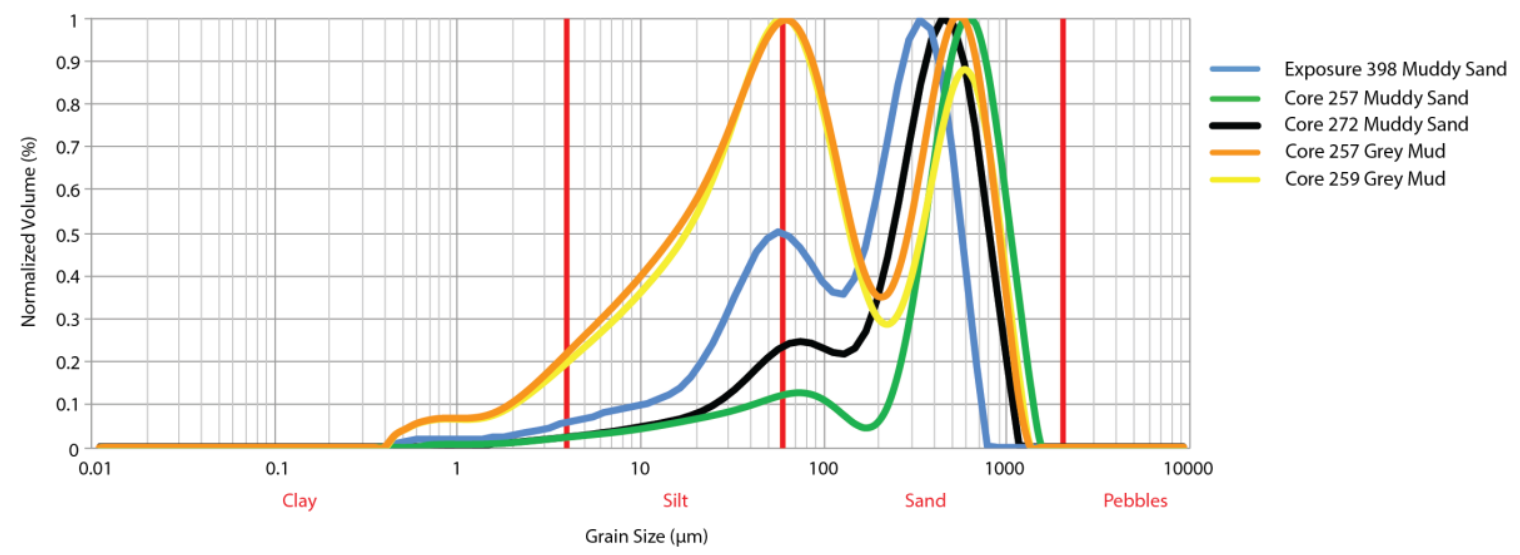

Figure 8 Muddy Sand and Gray Mud Grainsize Data. Grain size distribution measured with a Mastersizer showing differences between the Muddy Sand (blue and green lines) and Gray Mud (orange and yellow lines) facies. Vertical red lines show the grainsize distinctions between silt, sand, and grains larger than sand.
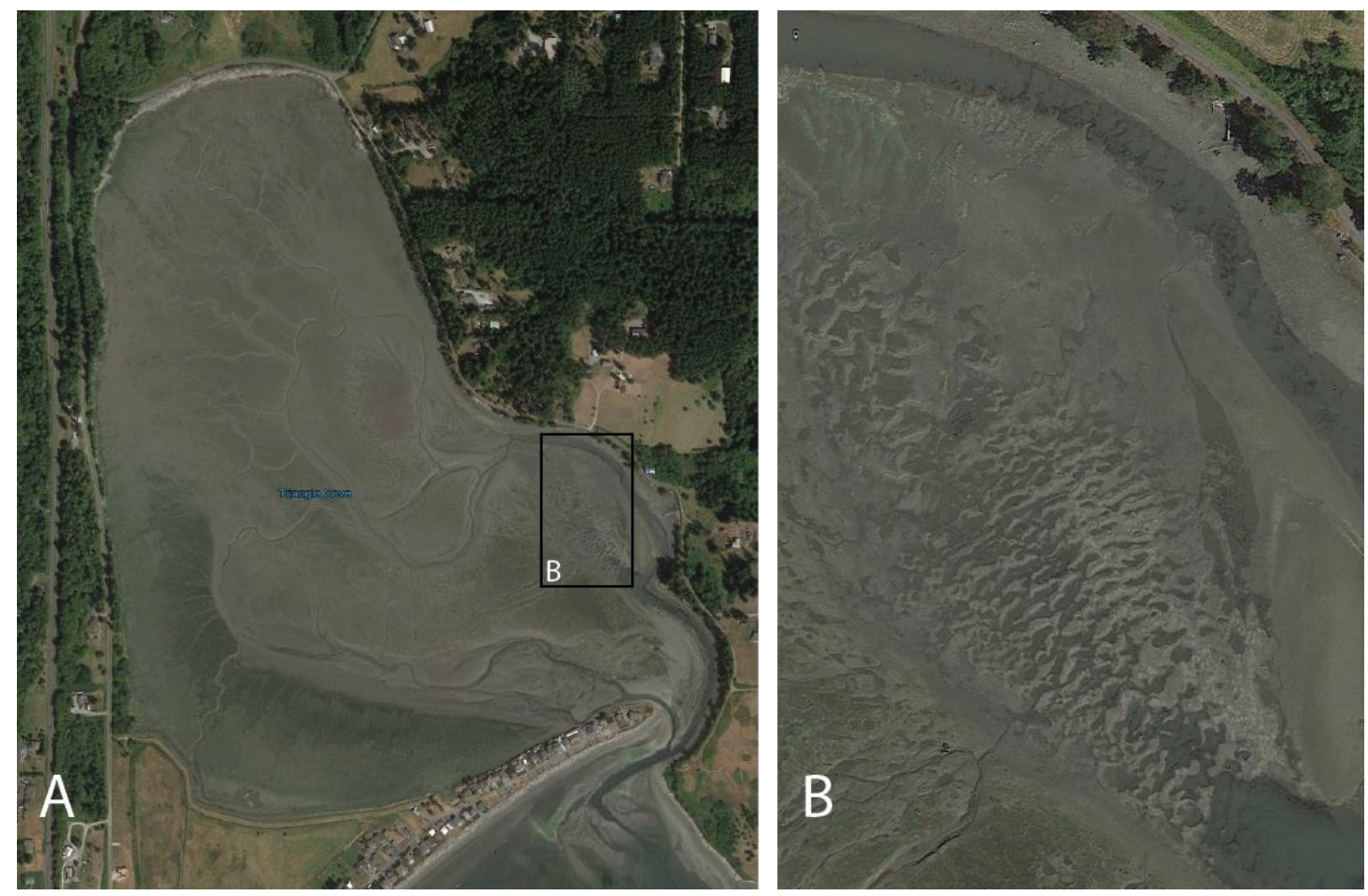

Figure 9 Triangle Cove Sand Waves. (A) Triangle Cove. The west side of the lagoon is interpreted as the depositional environment of the Grey Mud facies. (B) Within tide channels is my interpretation of the depositional environment associated with the Muddy Sand facies. Inset shows sand waves. 
channels, like at Elger Bay marsh. At Elger Bay we witnessed sand migration in tide channels in large sand waves and ripples (Figure 10). Sand and mud is transported through the tide channels and as the tide changes from incoming to outgoing the sediment settles leaving behind Muddy Sand facies. The presence of shells indicates an intertidal to subtidal environment. It is likely the observed roots grew down into this facies at a later time and are not a good indicator of surface environment during deposition. Laminations are evidence of pulses of sediment or from the ebb and flow of the tide in tide channels. Given this evidence, I interpret this facies as having been deposited in a tide channel of an intertidal environment.

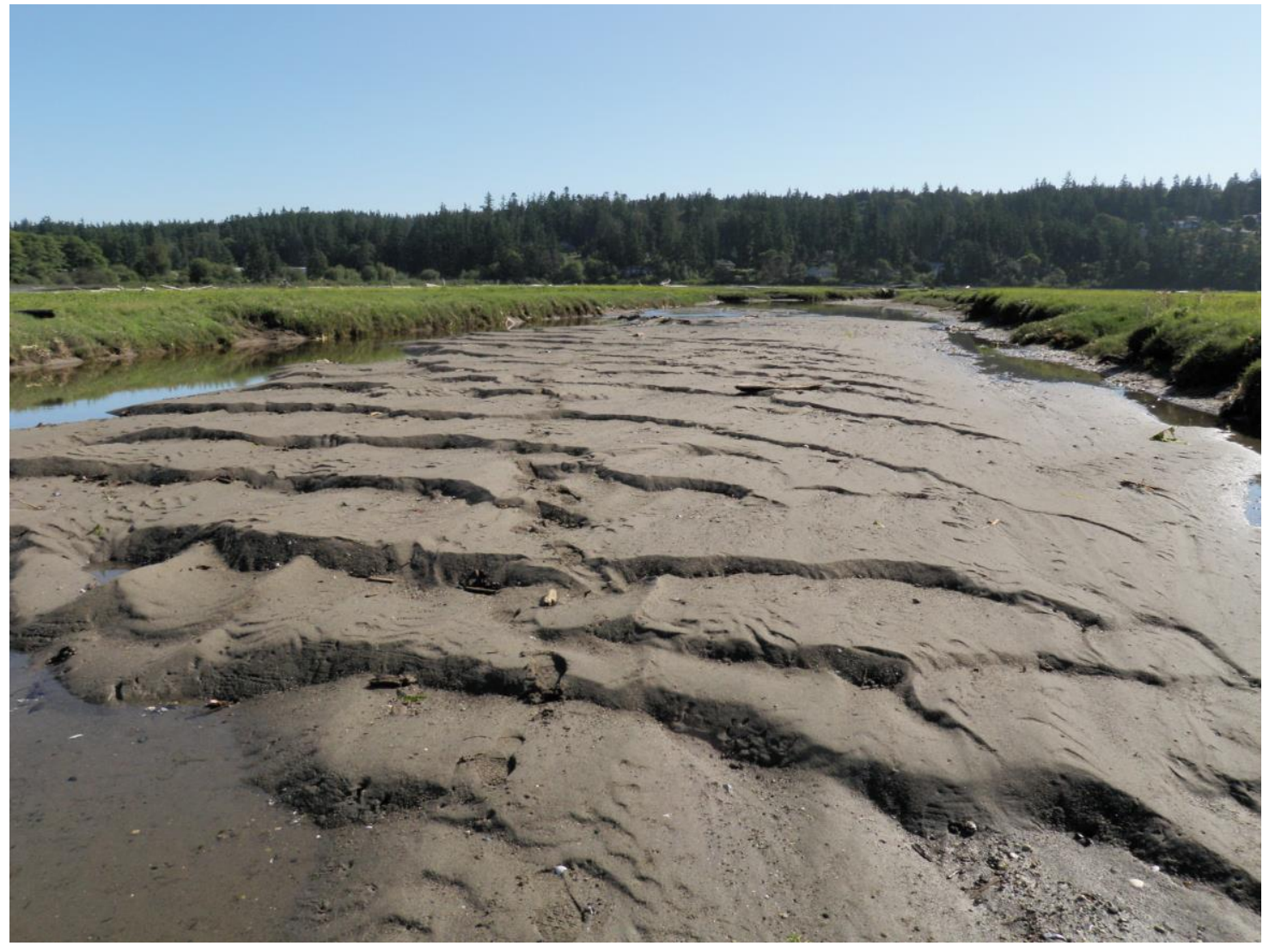

Figure 10 Elger Bay Sand Waves. Photograph showing sand waves and ripples in a tide channel at Elger Bay marsh. 
Grey Mud: The light grey to dark grey mineral mud was generally uniform in texture, but often contained scattered sand. It rarely contained roots but had occasional shells. It ranged from $100 \%$ mud content to $50 / 50 \% \mathrm{mud} / \mathrm{sand}$. This facies was found throughout the marsh, but most frequently near the mouth of the marsh and almost always immediately below Orange Peat or Organic-Rich Mud facies, which will be described below. In the two Livingstone cores EB15A and EB15B, this facies was found to have an average of $13.8 \%$ organics with a range of $6.6-34.4 \%$ and an average MS value of 8.03 $\mathrm{x} 10^{-8} \mathrm{emu}$ and a range of $6.85 \times 10^{-8}-1.22 \times 10^{-7} \mathrm{emu}$.

Environmental interpretation: The Grey Mud was interpreted as not currently depositing in Elger Bay marsh. The lack of roots and presence of shells indicates that it was subtidal to lower intertidal. No sand lenses indicates that the environment was low energy, with little sediment mobilization. This evidence indicates that it was deposited during a time when Elger Bay was a lagoonal tide flat, like Triangle Cove is today.

Organic-rich Mud: The brown to dark brown color and the average $22.9 \%$ organics (range of 7.6-40.5\%) from the two Livingstone cores shows that the Organic-Rich Mud had a high composition of organic material. Typically this facies was found near the top of the stratigraphic column throughout the entirety of the marsh, just below Orange Peat and in gradational contact with the Grey Mud. In a few locations, this facies was topped by Modern Soil (described below) which could indicate that those locations were at a lower elevation that did not allow peat to form. The salt-tolerant plant Triglochin maritima was identified in this facies in a few locations. The average MS value of this 
facies was $6.06 \times 10^{-8} \mathrm{emu}$ with a range of $2.44 \times 10^{-8}-1.71 \times 10^{-7} \mathrm{emu}$. Descriptions note it contained few to many roots.

Environmental interpretation: The Organic-Rich Mud represents the transition from intertidal where plants cannot survive to uppermost intertidal where plants can survive. Although the facies often contained roots, there was not enough fibrous organic matter to be considered a peat. The modern analog for this facies is the zone of colonizing plants along the upper banks of the tidal channels in Elger Bay marsh.

Orange Peat: This orangey to brownish-grey facies was more fibrous than the OrganicRich Mud, with a higher organic content. This facies is found throughout the entirety of the marsh and was found as the uppermost facies in the stratigraphic column in about half of the sample locations. It had a gradational contact with Organic-Rich Mud. At locations with Orange Peat as the uppermost facies, Distichlis spicata, Salicornia virginica, Triglochin maritima, and Jaumea carnosa were observed. In the two Livingstone cores, the average organics was $22.5 \%$ with a range of $5.5-44.3 \%$. Lower values were from the potentially misidentified "lower peat" in Livingstone core EB15B, which ranged from 5.5 - $15.1 \%$ and had an average of $10.6 \%$ so was more likely Organic-Rich Mud; this core was described in a lab setting where conditions were different than in the field. The average MS value of $7.13 \times 10^{-8} \mathrm{emu}$, with a range of $8.75 \times 10^{-9}-1.52 \times 10^{-7} \mathrm{emu}$.

Environmental interpretation: The vegetation identified in this facies are all salt tolerant and prefer damp or wet conditions, which indicates upper intertidal environment. The Orange Peat facies is interpreted as being deposited in a low- 
marsh environment, such as the modern surface at Elger Bay, where it is regularly wet.

Modern Soil: The light brown to dark brown Modern Soil was primarily comprised of a high abundance of roots along with other organics, with a range of sand (fine to coarse) between little and abundant and was crumbly. It graded downward in color from darker to lighter and it appeared to have soil horizons forming. When present, the Modern Soil was always found at the top of the stratigraphy. This facies was found in approximately half of the sample locations although was not encountered in the cores EB15A and EB15B that were analyzed for organics and MS.

Environmental interpretation: This facies is interpreted as being a supratidal environment as it is composed of decomposing organic materials above water level (meaning they are not forming peat). The darker color of this unit is suggestive of a seasonally dry surface.

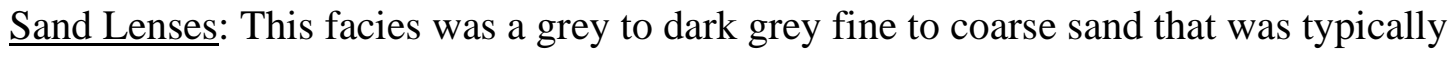
moderate to well sorted with little to no mud (Figure 11 and Figure 12), with a thickness ranging from $0.5 \mathrm{~cm}$ to $12 \mathrm{~cm}$. Most, but not all, sand lenses were found in the southern half of the marsh (Figure 13). Some sand lenses were able to be correlated between adjacent cores/cutbanks; for example, one sand layer was confidently traced through six cores near the inlet in the southwest area of the marsh (Figure 14). At other locations sand lenses were isolated; even over such a short distance as a few meters the sand lenses would pinch out. Isolated sands were observed mostly in the central marsh region where the main tidal channel branches in several places. This facies was not present in cores EB15A and EB15B that were analyzed for organics and MS. 


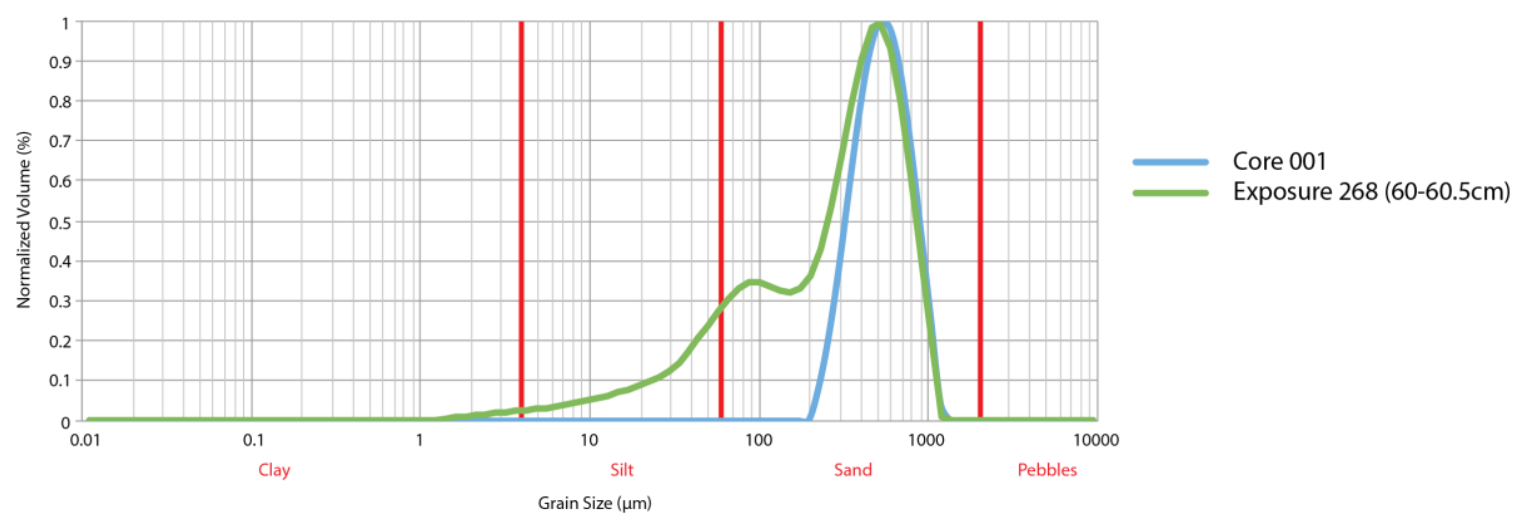

Figure 11 Mastersizer Sand Lenses Data. Grain size distribution measured with a Mastersizer of Sand Lenses facies from two samples. The silty tail on Exposure 268 is likely because the sandy layer was contaminated by overlying Grey Mud. Vertical red lines show the grainsize distinctions between silt, sand, and grains larger than sand.

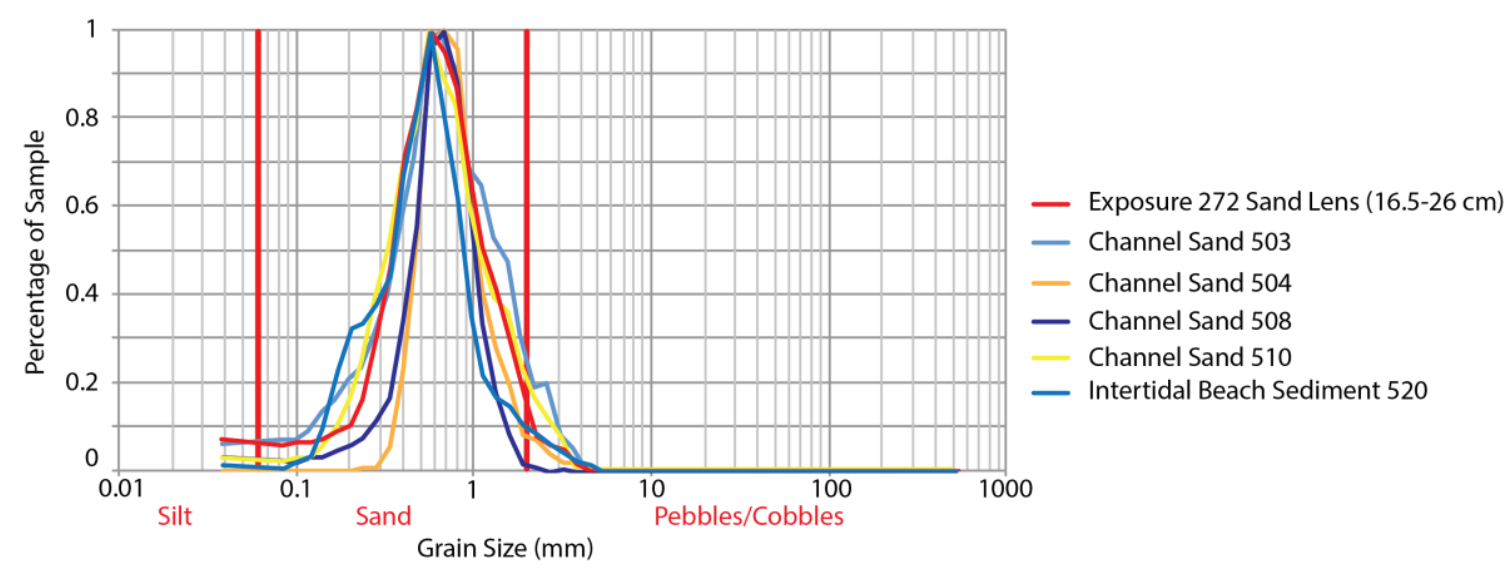

Figure 12 CAMSIZER Sand Lenses and Channel Sand Data. Grain size distribution measured with a CAMSIZER of a Sand Lenses facies sample from Exposure 272 compared to sand found in the intertidal beach area and channels.

Environmental interpretation: Untraceable/isolated sand lenses associated with the Grey Mud and Muddy Sand facies I interpret as being deposited in the meandering channel beds within the marsh. Sandy layers are expected in these lagoonal and tide channel facies related to higher velocity flow during tidal exchange. When not associated with the Grey Mud and Muddy Sand facies, 


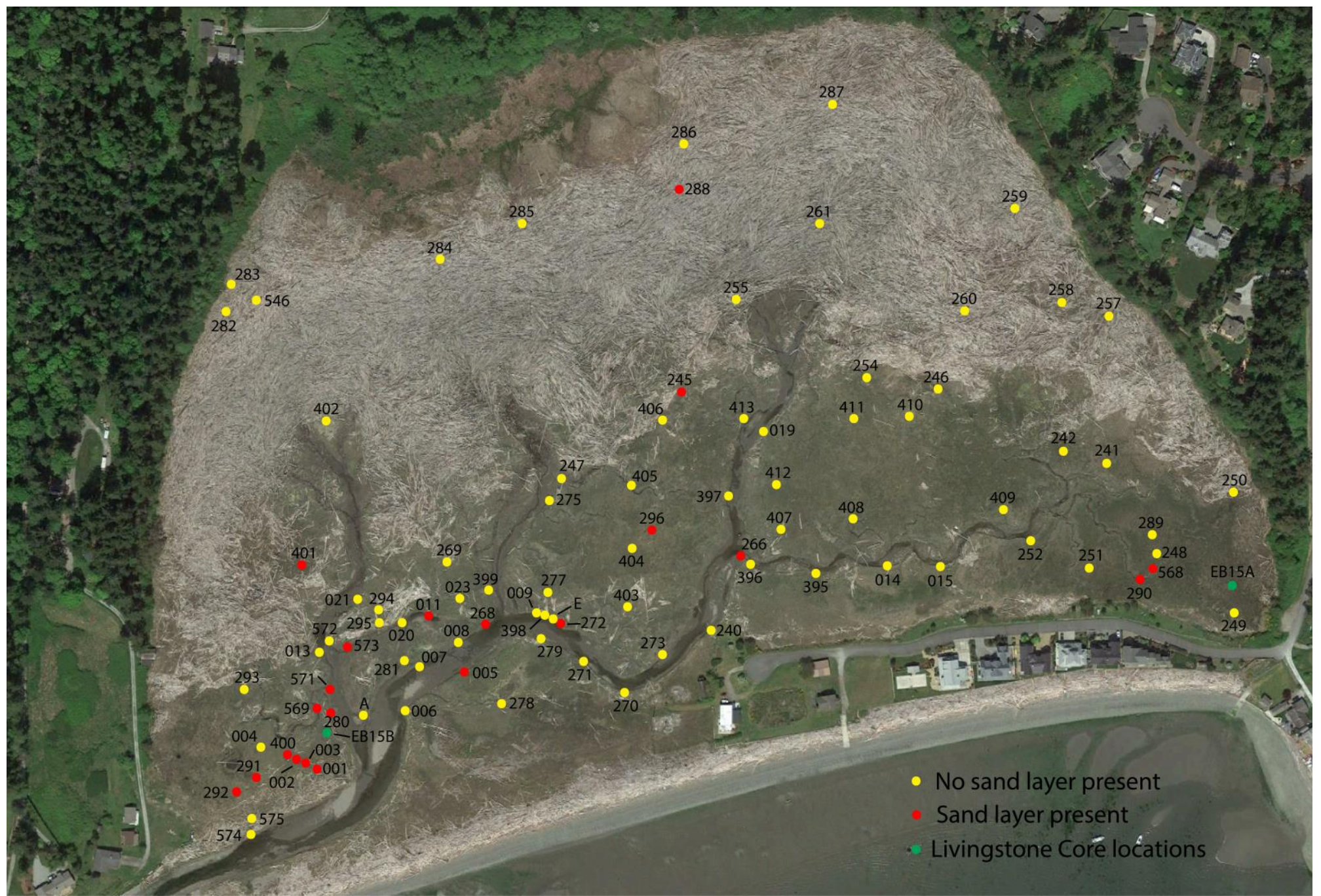

Figure 13 Sand Layers Locations Map. Locations where sand lenses were found (red dot) and where no sand was found (yellow dot). Livingstone cores are shown by a green dot. 


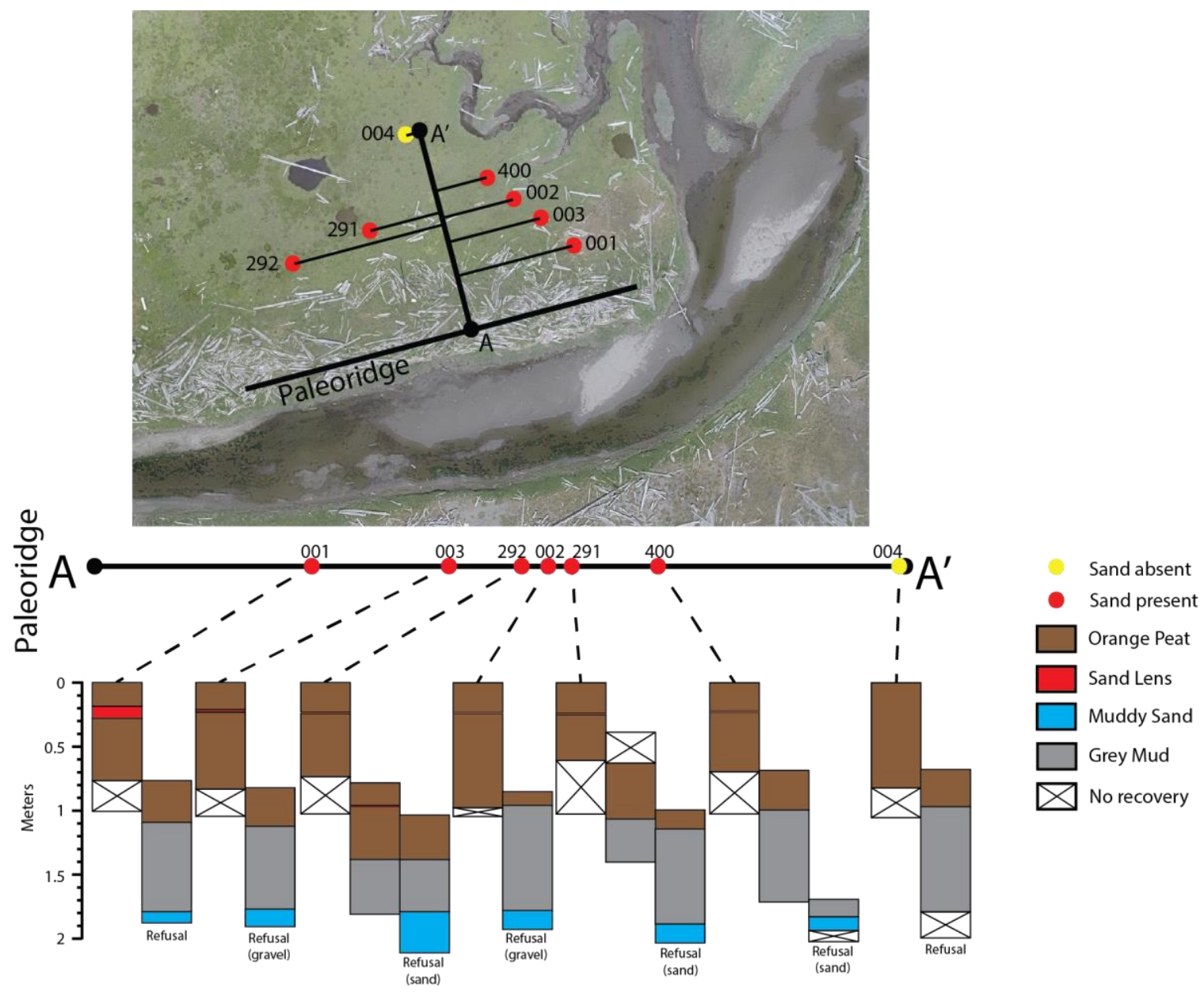

Figure 14 Tsunami Deposit Location and Stratigraphy. Transect that shows a sand layer (interpreted as a tsunami deposit) thinning inland near the mouth of the marsh. The red dots indicate deposit present and the yellow dot indicates no deposit. Marsh image is the orthophoto created from SfM software. In cores 292, 002, 291, and 400, the sand layer is too thin to be drawn red and is indicated by the black lines.

potentially these lenses could be from liquefaction, a known depositional process in Puget Sound (Martin and Bourgeois, 2012). Traceable sand deposits displayed typical tsunami deposit characteristics - they thinned landward, were in the same stratigraphical position in each core, and were well sorted (Morton et al., 2007; Bourgeois and Martin, 2012). See A Tsunami Deposit in Elger Bay section below for a more detailed discussion. 


\section{Radiocarbon Results and Interpretation}

I sent five samples to the DirectAMS laboratory, Bothell, WA for ${ }^{14} \mathrm{C}$ dating from Elger Bay cores 272, 280, 400, 401, and 568 (Figure 15; Table 4). Two samples were Triglochin (samples 272 and 568), two charcoal (samples 280 and 400), and one unidentified seeds (sample 400). The Triglochin samples are most accurate at dating a specific depth because the preserved part of the plant sits right at the marsh surface. Sample 272 was a Triglochin located in the Organic-Rich Mud facies about $8 \mathrm{~cm}$ below a $1 \mathrm{~cm}$ thick lens of sand. This sand layer was untraceable across the cutbank exposure due to an erosional surface interpreted as a meandering tide channel, but could correlate to sand layers in Samples 280 and 400 based on the similar date. Sample 400 was a piece of charcoal that was found within a bulk core sample of Orange Peat taken from $16.5 \mathrm{~cm}$ to $31 \mathrm{~cm}$ depth and is associated with a sand layer at $24 \mathrm{~cm}$ depth that is interpreted to be a tsunami deposit. Compared to other dates in Elger Bay, the date of 1478 - 1664 AD seems old for such a shallow sample. If so, it could be due to the charcoal being reworked material, or a piece of significantly older wood (such as driftwood) relative to the time it was burned and deposited. Sample 280 was a piece of charcoal that was found at $50 \mathrm{~cm}$ depth within the Grey Mud facies, immediately below the deeper of the two sand lenses found in the cutbank. I cannot directly determine which of the two sand layers (if any) in 280 correlated to the traceable sand layer — the date of the lower sand layer is similar to the traceable sand layer's date from 400, however, the lower sand layer is $15-20 \mathrm{~cm}$ deeper while the upper sand layer is of a similar stratigraphic position. 

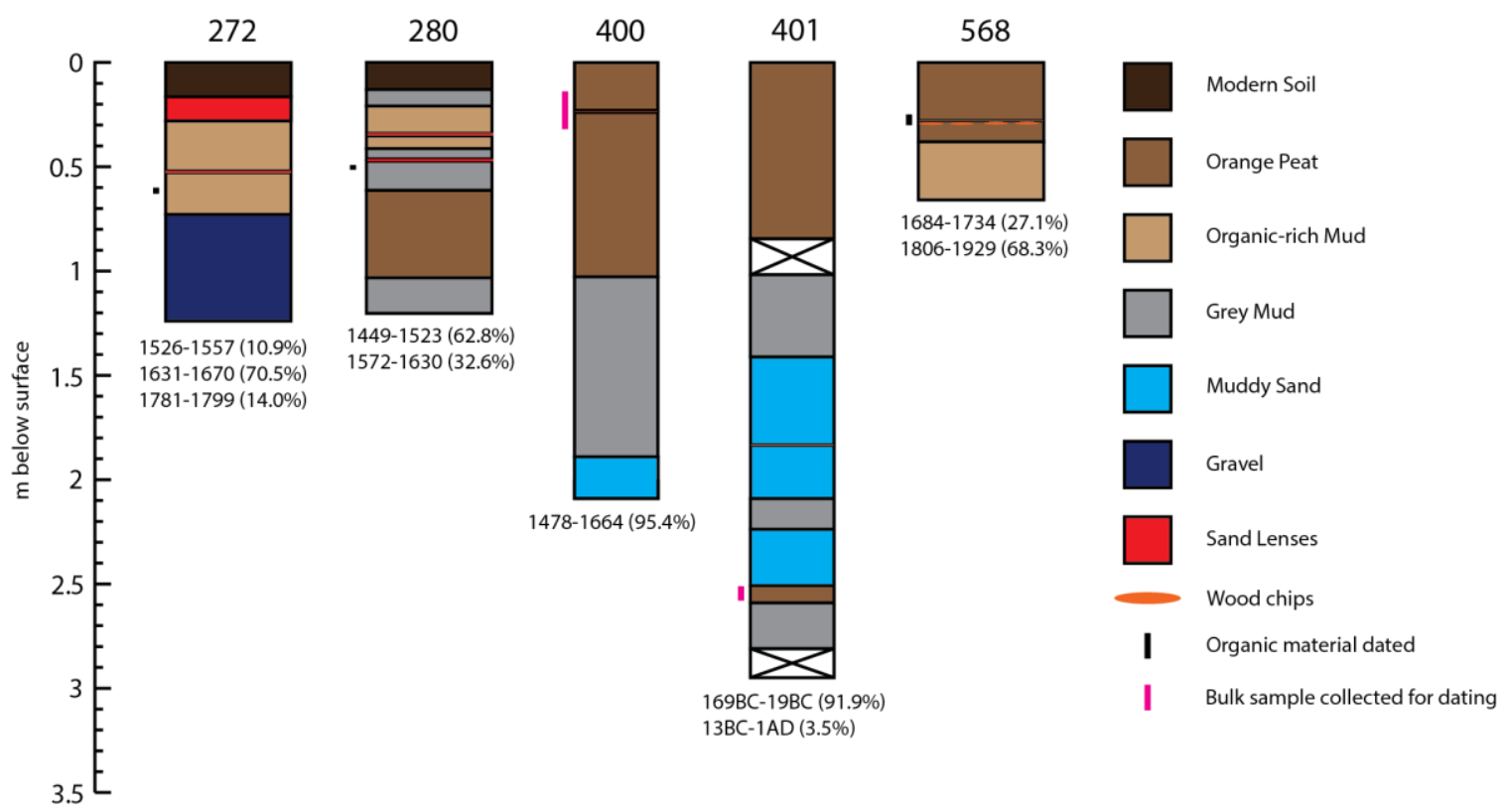

Figure 15 Radiocarbon Dates in Stratigraphy. Stratigraphy and stratigraphic position of all samples dated with ${ }^{14} \mathrm{C}$ in Elger Bay marsh. Core and exposure locations can be found in Figure 5. Dates are shown in cal AD unless otherwise indicated, with probability percentage in parenthesis. Dates calibrated using OxCal v.4.3.2, IntCal13 atmospheric curve.

Table 4 Radiocarbon Dates Data. All ${ }^{14} \mathrm{C}$ data collected in Elger Bay marsh. All dates shown in cal AD unless otherwise indicated, with probability percentage in parenthesis. Dates calibrated using OxCal v.4.3.2, IntCal13 atmospheric curve.

\begin{tabular}{|c|c|c|c|c|}
\hline Sample & Material & Depth & Reason & Date \\
\hline 272 & Triglochin & $30-32 \mathrm{~cm}$ & Below Sand Lens & $\begin{array}{l}1526-1557(10.9 \%) \\
1631-1670(70.5 \%) \\
1781-1799(14.0 \%)\end{array}$ \\
\hline 280 & Charcoal & $50 \mathrm{~cm}$ & Below Sand Lens & $\begin{array}{l}1449-1523(62.8 \%) \\
1572-1630(32.6 \%)\end{array}$ \\
\hline 400 & Charcoal & $16.5-31 \mathrm{~cm}$ & Near Sand Lens & $1478-1664(95.4 \%)$ \\
\hline 401 & Seeds & $251-259 \mathrm{~cm}$ & Min age of marsh & $\begin{array}{l}169 \mathrm{BC}-19 \mathrm{BC}(91.9 \%) \\
13 \mathrm{BC}-1 \mathrm{AD}(3.5 \%)\end{array}$ \\
\hline 568 & Triglochin & $26-30 \mathrm{~cm}$ & At Sand Lens & $\begin{array}{l}1684-1734(27.1 \%) \\
1806-1929(68.3 \%)\end{array}$ \\
\hline
\end{tabular}


Sample 568 was a Triglochin found at $26-30 \mathrm{~cm}$ depth with a sand layer with some driftwood that was at $28 \mathrm{~cm}$. There was also a sand layer found about $10 \mathrm{~m}$ away in core 290 that was about $8 \mathrm{~cm}$ lower than the sand layer in exposure 568 .

Sample 401 was from seeds picked from a bulk gouge auger core sample of organic matter that was at a contact between Grey Mud and Muddy Sand from 251 - 259 $\mathrm{cm}$ depth. This depth is near the maximum depth that we were able to core. This sample estimates the minimum age of the marsh of the cores we took and gives us a rough estimate of when Elger Bay was a lagoonal tide flat.

\section{Environmental Change Through Time at Elger Bay}

Deeper sediments, though still above the basal Gravel, tended to be mud and muddy sand with relatively low amounts of organic material, indicating that about 2,000 years ago Elger Bay "marsh" resembled the lagoonal Triangle Cove today - lowintertidal sediments with little to no vegetation. In this scenario, the area would have been flooded with each high tide and drained completely with each low tide. Over time, the surface accumulated sediment faster than sea level rise in the last few thousand years in Puget Sound, which is a rate of about $0.7 \pm 0.2 \mathrm{~mm} / \mathrm{yr}$ over the last 4,000 years (Englehart et al., 2015) and eventually built up to where the marsh was no longer fully flooded with every high tide. This accumulation through time allowed vegetation colonization and deposition of upper intertidal sediments (Organic-Rich Mud and Orange Peat). Through radiocarbon dating, we know that peat was being deposited here at least 500 years ago, and likely for centuries before. 
For both a lagoonal tide flat or marsh to be present, the spit fronting Elger Bay must have been present for low energy deposition to be possible, however, this spit has not remained stationary over time. During analysis of the SfM images and aerial photos, I discovered remnants of what I interpret as past spit locations (hereafter called paleoridges) that predate the current ridge (Figure 16). The paleoridges can be seen in the field by the change in color of vegetation and the abundance of driftwood lodged on the elevated land. Supporting evidence for a paleoridge is Core 006 located at the western end of the older paleoridge, which consists of only $6 \mathrm{~cm}$ of Modern Soil overlying $64 \mathrm{~cm}$ of Gravel, without any intervening marsh or tide flat facies. The abandonment of the paleoridges could be evidence of pulses of sediment deposition, changes in storminess, or changes in the sea level through time (Weir et al., 2006).
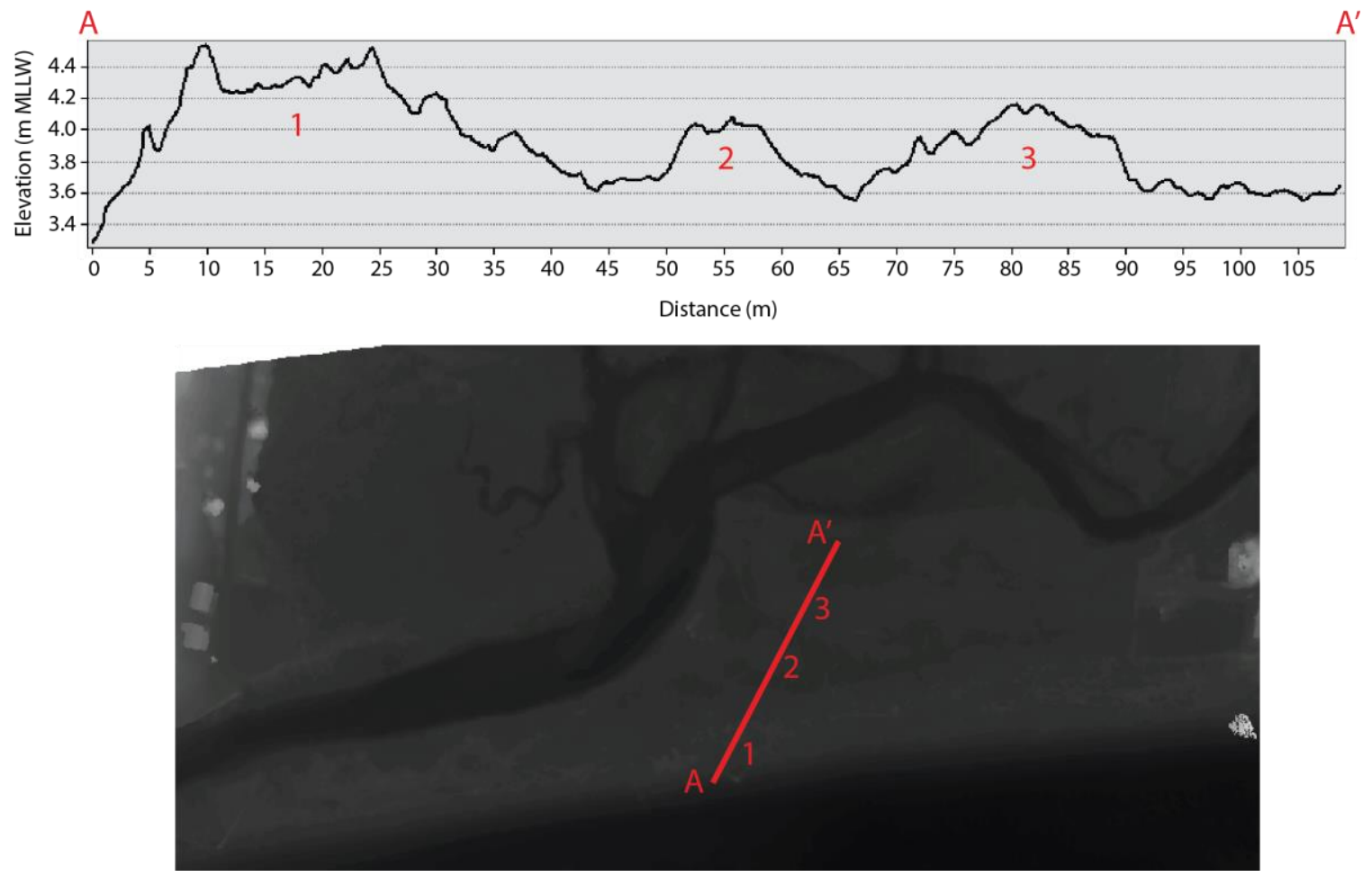

Figure 16 Paleoridges Digital Surface Model. Elevation of the surface across two paleoridges (2 and 3 ) and the present-day ridge (1). Image is a DSM produced using aerial photographs processed with SfM software. 
The two paleoridges are about 0.3 - $0.5 \mathrm{~m}$ lower elevation than the current ridge. One possibility is that they were formed when sea level was lower and they were the same elevation relative to sea level, assuming storminess was the same as today. Another possibility is that storminess has increased since the paleoridges were abandoned, building the current ridge up higher (Weir et al., 2006).

Another paleoridge is found along the northwest side of the inlet (Figure 17). This ridge was the barrier that protected the west side of the marsh from waves before the modern spit grew across the inlet and became the new barrier. We spoke with a person whose family had lived on a plot of land bordering the western side of the marsh for generations. He told us that his grandmother (born in 1906) could recall that the spit did not extend out to the west the way it does today. T-sheets and historical maps support this testimony (Figure 18) and indicate that sometime between 1911 and 1940 the spit grew across the inlet.

Field observations and historical aerial photographs also show that the main tidal channel (light blue line in Figure 19) has changed its path over time. The complex stratigraphy of the southern marsh consisting of lenses of sands that thicken and pinch out over relatively short distances sedimentologically indicates an actively meandering tidal channel system. An example of this can be found at exposure 272 (Figure 20) where we observed a $12 \mathrm{~cm}$ thick sand lens pinch out completely and stratigraphy changes from Muddy Sand and Gravel to Organic-rich Mud over Gravel over a distance of just a few meters (Figure 20). 


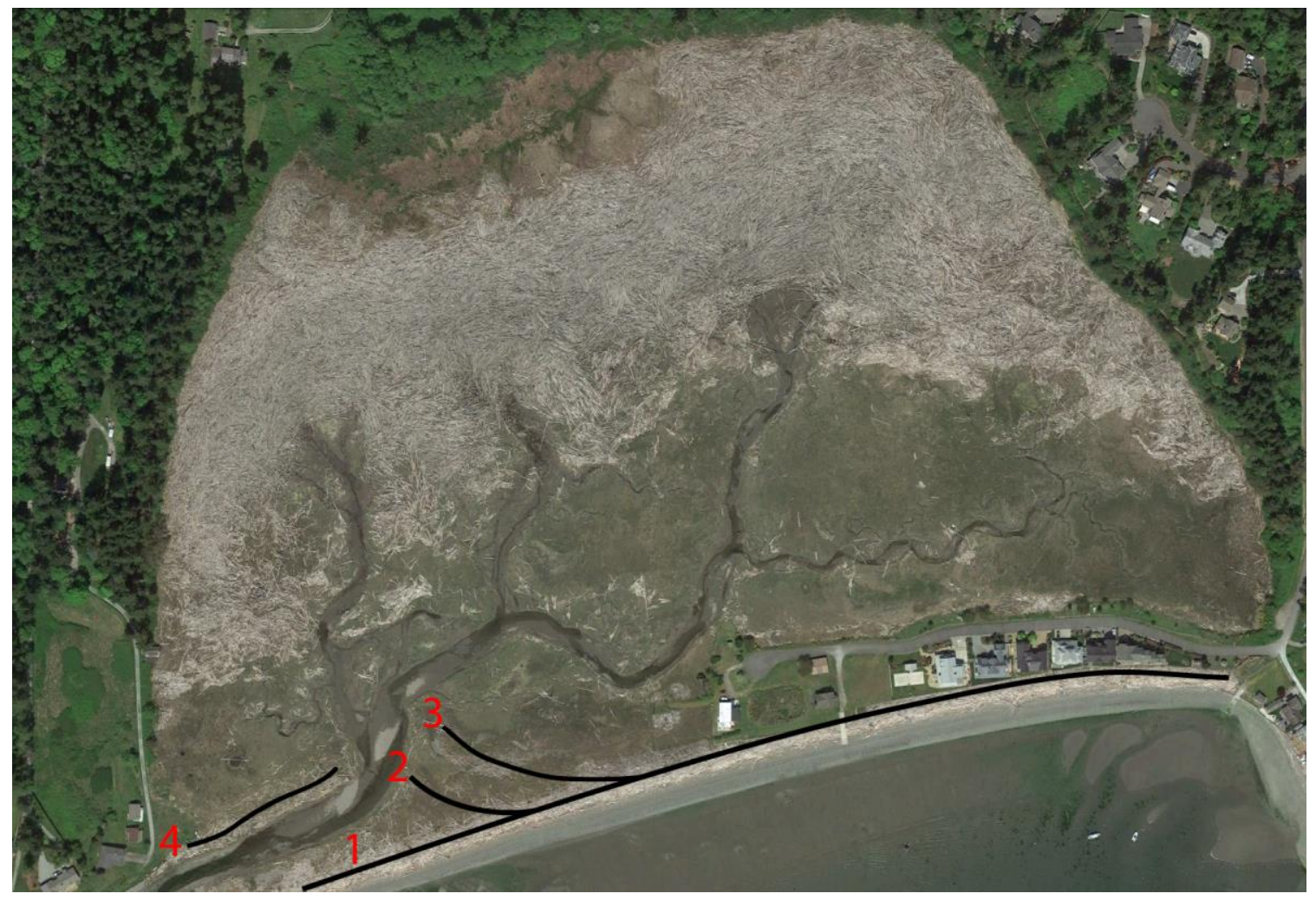

Figure 17 Paleoridges Map. Black lines indicate present-day (1) and paleoridge (2, 3, and 4) locations.
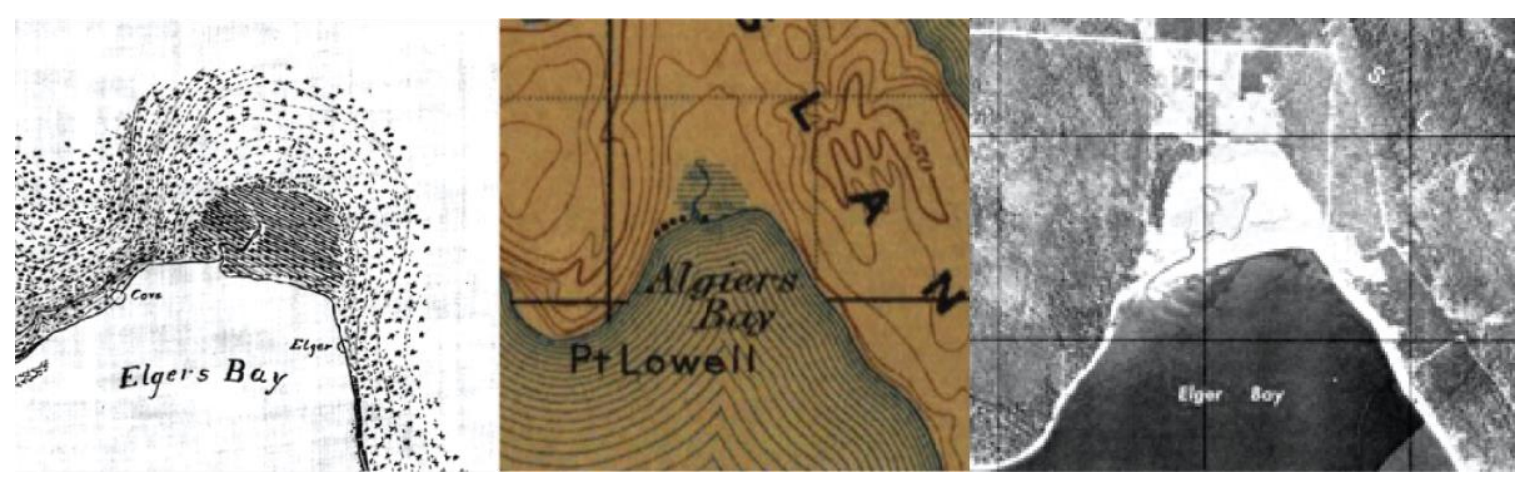

Figure 18 Protective Ridge in Historic Elger Bay Maps and Photographs. 1888 T-sheet of Elger Bay (left; U.S. Coastal \& Geodetic Survey, 1887-88), 1911 map of Elger Bay (center; U.S.G.S., 1911), and 1940 aerial photo provide a time frame for spit growth across the inlet of Elger Bay marsh. 


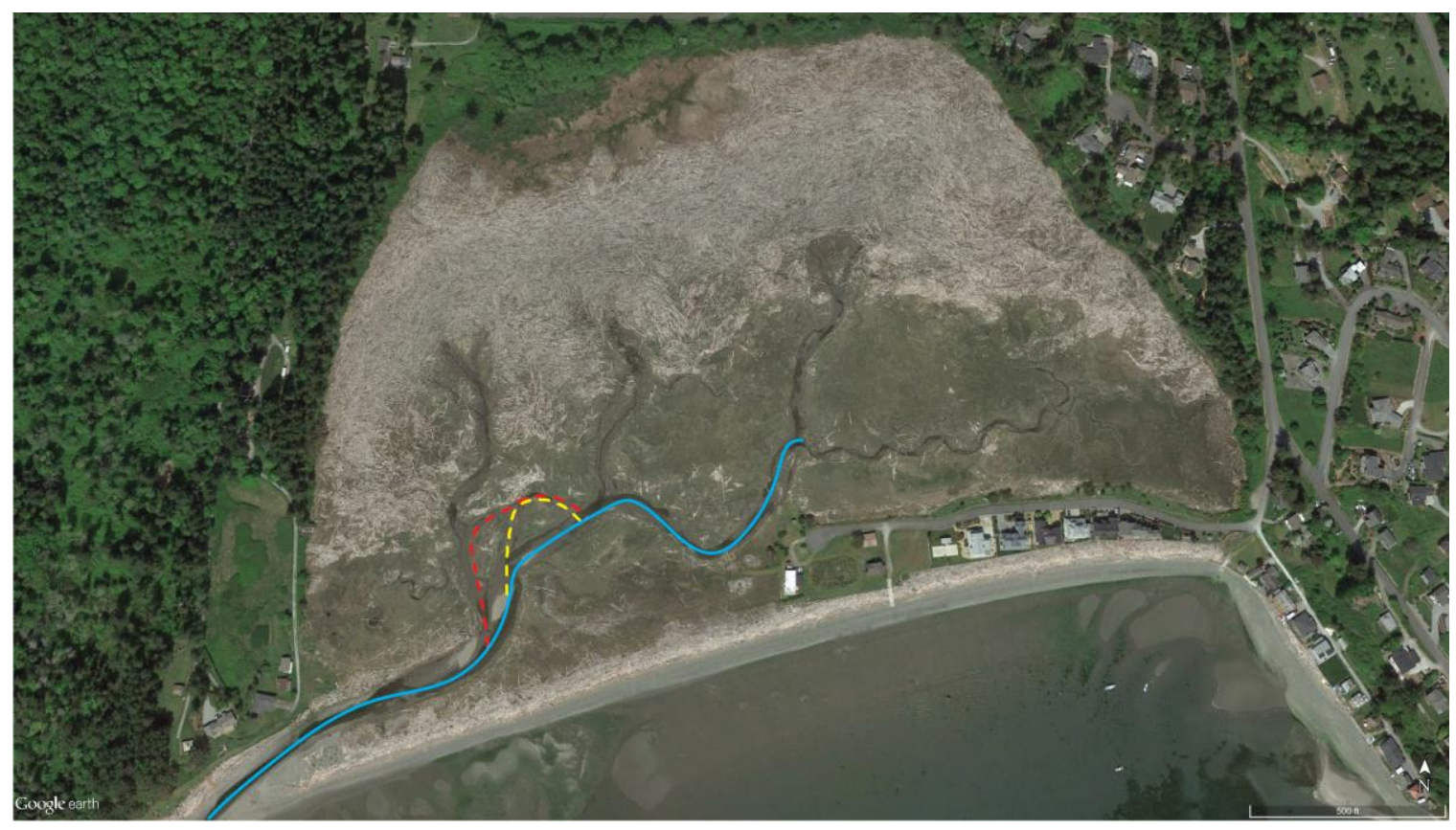

Figure 19 Main Waterflow Channel Locations. The light blue line indicates the location of the main channel, the red dashed line indicates the location of channel 1, and the dark blue dashed line indicates the location of channel 2 .

Historical aerial photographs of the marsh show the main waterflow in and out of the marsh changing channels over time, occupying at least two other channels since 1940 (Figure 21). In 1940 the main tidal water flow appears to use its current path, like today, with little to no water flow in channels 1 and 2. However, a 1954 aerial photograph shows the main flow occupying both its current path and channel 2, while by 1971 only channels 1 and 2 are being used. The 1971 aerial photograph was taken during low tide with water only flowing out of the marsh, but it shows the main channel as having no flow at this water level, although the lack of vegetation in the abandoned main channel in this photo does indicate that there may be some flow at higher tides. A 2006 satellite image shows that there was minimal waterflow through channels 1 and 2, though they are still occupied. Finally, a 2015 satellite image taken at low tide shows vegetation 
inhabiting the end of channels 1 and 2, indicating that there is no longer flow through these channels at normal tide levels.

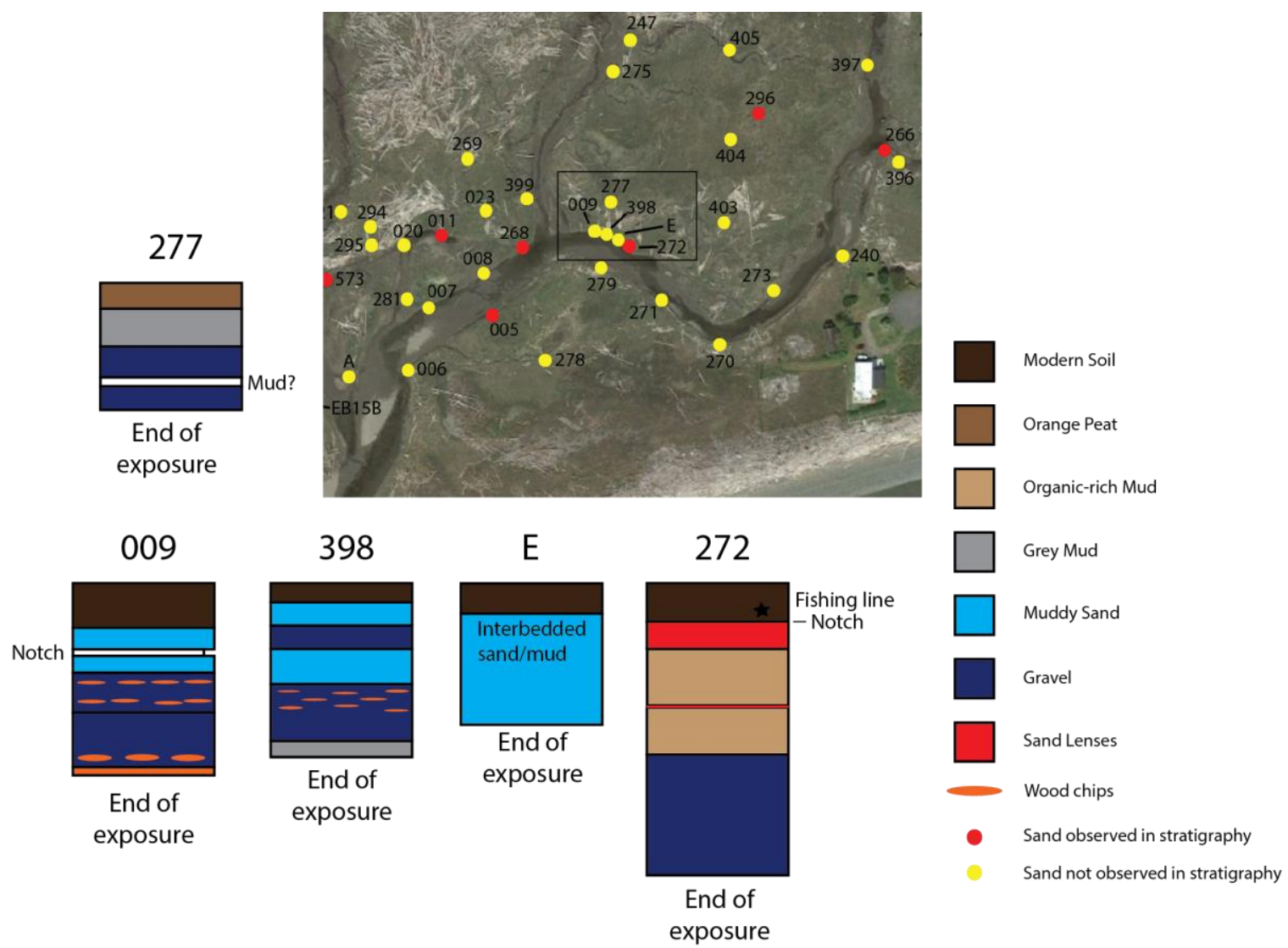

Figure 20 Exposure 272 Surrounding Stratigraphy. Rapid change of stratigraphy over a short distance suggestive of erosion from meandering tide channels. 272 represents a longer record, while 009 to $\mathrm{E}$ are interpreted as recent deposits from a tide channel.

\section{A Tsunami Deposit in Elger Bay}

I interpret one sand layer found near the mouth of the marsh as being deposited by a tsunami. The layer found at approximately $20-25 \mathrm{~cm}$ depth was traceable through multiple locations, was well-sorted, and thinned inland from a thickness of $10 \mathrm{~cm}$ to 0.5 cm (Morton et al., 2007). Other sandy layers were found within the marsh, 

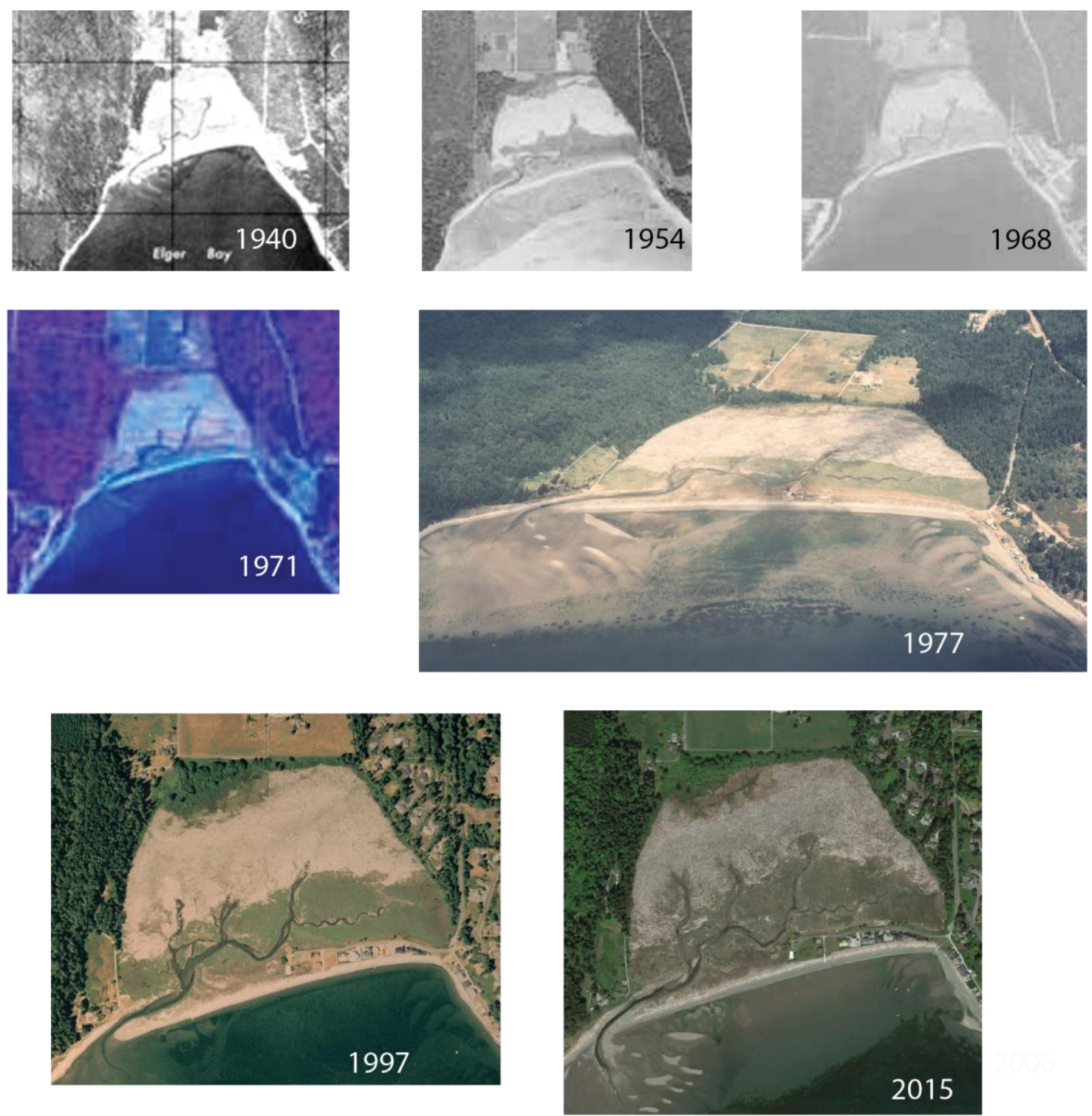

Figure 21 Aerial Photographs of Elger Bay. Aerial photos and satellite imagery of Elger Bay marsh from 1940 to 2015.

with up three sand layers found in any one core or cutbank. However, their thicknesses varied drastically over short distances and were typically challenging to trace in cutbanks as they thinned out quickly, which meant these features are not typical of tsunami deposit geometry (Morton et al., 2007; Martin and Bourgeois. 2012). Additionally, sand lenses are intrinsic to all my interpreted depositional environments except the Orange Peat and Organic-Rich Mud facies. Therefore only sand lenses in those facies are candidates for 
tsunami deposit interpretation. These include sands from cores 011, 288, 290, 291, 292, 568, 569, 571, and 573 (Appendix A). Although many of these sand layers are on the opposite ends of the marsh as those from the traceable sand at the inlet, there are several occurrences of a sand observed between $20 \mathrm{~cm}$ and $40 \mathrm{~cm}$ depth, especially in the central marsh region. While it would take many more ${ }^{14} \mathrm{C}$ dates to accurately correlate the sand layers across the marsh, it is not out of the realm of possibility that some of these sands are from the same event, especially if they are close to the main tide channel at the time. Other possibilities for how sand lenses formed include being deposited anthropogenically (fishing line found just above the sand in exposure 272), in storm deposits, or liquefaction dikes during earthquakes (Martin and Bourgeois, 2012).

The traceable sand near the inlet interpreted as a tsunami deposit is stratigraphically too young to have been deposited by the Seattle fault tsunami. A piece of charcoal near the sand in Core 400 was dated to $1478-1664$ cal AD (95.4\% probability). Two other samples had dates that overlapped with the dates from Core $400-$ the Triglochin from 272 and charcoal from 280 - indicating that they could be deposits from the same event. The date from Core 400, which we interpreted as possibly being too old for its stratigraphic position at least gives us a maximum age of the sand layer. This puts the date of the traceable sand at least 500 years too young to be a result of the Seattle Fault tsunami.

If the deposit is not a result of the 900 AD Seattle fault tsunami, there are other possible tsunami sources that fit within the ${ }^{14} \mathrm{C}$ date range and stratigraphic position. One possibility is the 1820's Camano Head landslide tsunami (Shipman, 2001). According to Snohomish accounts, people were clamming on Camano Island and Hat Island when the 
slide occurred. Those on Hat Island recalled hearing a thunderous noise and noticing a large cloud of "smoke" (dust) where Camano Head was supposed to be. Shortly after they observed a large wave incoming and they retreated to higher ground (Shipman, 2001). When viewed aerially, the slide scarp is easily observed as well as the material that is now under water in Puget Sound (Figure 22). To date there is no known tsunami deposit correlated with this event.

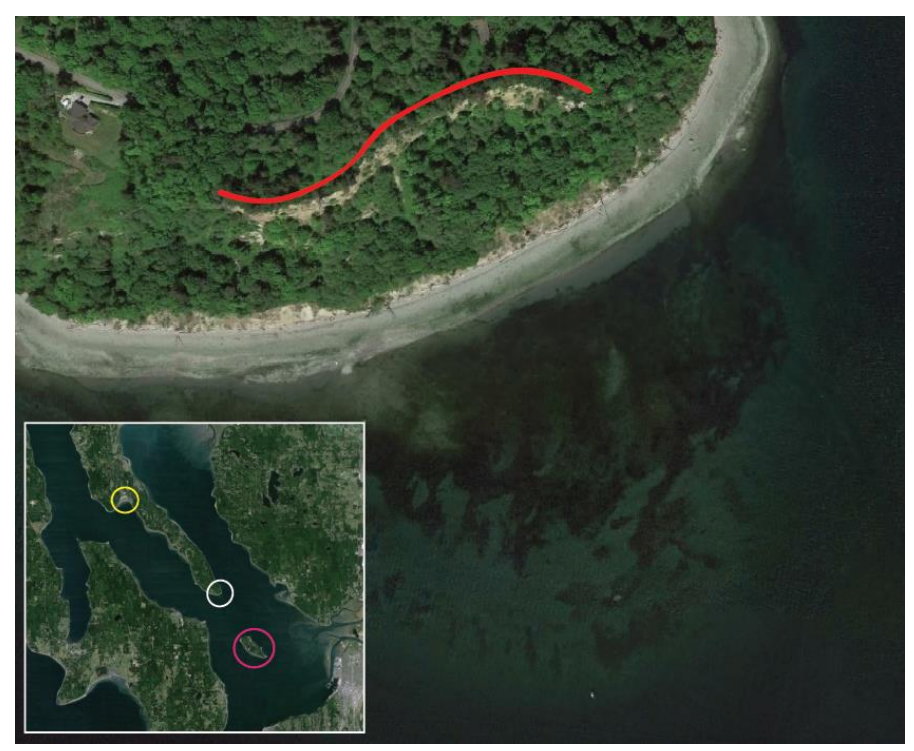

Figure 22 Camano Head Landslide Location. Larger image: Camano Head landslide. Head scarp traced with the red line. You can also see slide material underwater in this image. Inset: location of Elger Bay (yellow circle), Camano Head (white circle) and Hat Island (red circle).

Another possible source within the last 500 years for the deposit is the 1700 Cascadia event. Models of the L1 Cascadia scenario (a larger earthquake and tsunami than the one in 1700) ran at MHW tide levels showed that Elger Bay would be inundated by only $\sim 2 \mathrm{ft}$ of water $(\sim 0.7 \mathrm{~m})$ (Dolcimascolo et al., 2021). Additionally, with such a wide date range for this deposit, other sources without known evidence of a tsunami 
could also be considered, such as the nearby Utsalady Point fault that ruptured $\sim 400$ years ago (Johnson, 2004).

\section{Could We Have Seen a Seattle Fault Tsunami Deposit in Elger Bay If It Was There?}

The $~ 900 \mathrm{AD}$ date for the Seattle fault tsunami is problematic for Elger Bay. Seeds in core 401 at a depth of $251-259 \mathrm{~cm}$ were dated at $169-19 \mathrm{BC}$ or $13 \mathrm{BC}-1 \mathrm{AD}$, which is $~ 1000$ years older than the Seattle fault tsunami. This shows that stratigraphy in Elger Bay includes the time period of the Seattle fault rupture. However, based on this stratigraphy I estimate that the right environment for deposit preservation did not exist 900 AD in Elger Bay. Peat throughout the majority of the marsh did not typically extend beyond $1 \mathrm{~m}$ depth. Data from nine cores at Discovery Bay (Williams et al., 2005) show that accumulation rates in most cores was typically $\sim 1 \mathrm{~mm} /$ year. Using this rate, I calculate that $1 \mathrm{~m}$ of peat would be about $\sim 1000$ years old. This rate puts the Seattle fault rupture right around the limit of the extent of the peat. The deepest we find peat (with the exception of a few small layers of highly organic matter found in Grey Mud and Muddy Sand) is about $142 \mathrm{~cm}$ in core 292. In most cores at this same depth were the lagoonal and intertidal Grey Mud or Muddy Sand facies. The facies associated with these environments typically contain sand, so any sandy layers observed within them are attributed to tide channels or extreme weather events, and are not to be interpreted as a tsunami deposit. The deepest sand observed in Orange Peat or Organic-Rich Mud facies (the depositional setting where tsunami deposits can be recognized) was at about $60 \mathrm{~cm}$ depth. Because I did not obtain material to date at the peat-mud transition, I am not 
certain when it transitioned from a lagoonal environment to a marshy environment, however I estimate that it was after $~ 900 \mathrm{AD}$. 


\section{CHAPTER V \\ TSUNAMI MODELING RESULTS AND DISCUSSION}

\section{Field Sites for Modeling the Seattle Fault Tsunami}

In addition to Elger Bay, tsunami deposit evidence of the 900 AD Seattle Fault tsunami deposit has been found at West Point, Cultus Bay (Atwater and Moore, 1992), and Snohomish Delta (Bourgeois and Johnson, 2001), and preliminary results show the tsunami deposit is at Deer Lagoon (Bruce, 2020).

\section{Seafloor Deformation}

I calculated seafloor deformation from the $900 \mathrm{AD}$ Seattle fault earthquake using the Okada (1985) equations in the GeoClaw program for three different Seattle fault scenarios, as explained in chapter 3.

Koshimura: An earthquake using parameters defined in Koshimura et al. (2002). Venturato: An earthquake using parameters defined in Venturato et al. (2007). Uniform Venturato: An earthquake using averaged parameters of Venturato to make a simplified version with homogenous slip.

Analysis of the seafloor deformation patterns from these earthquakes shows that Venturato has a larger area of deformation compared to Uniform Venturato, which was more localized (Figure 23). The difference between Koshimura and Venturato is that Venturato used six subfaults that reach the surface and Koshimura used 12 subfaults, six shallow and six deep. 
The seafloor deformation in Venturato has two areas of approximately $8 \mathrm{~m}$ uplift along the rupture line, and subsidence of less than $2 \mathrm{~m}$ on the north side.
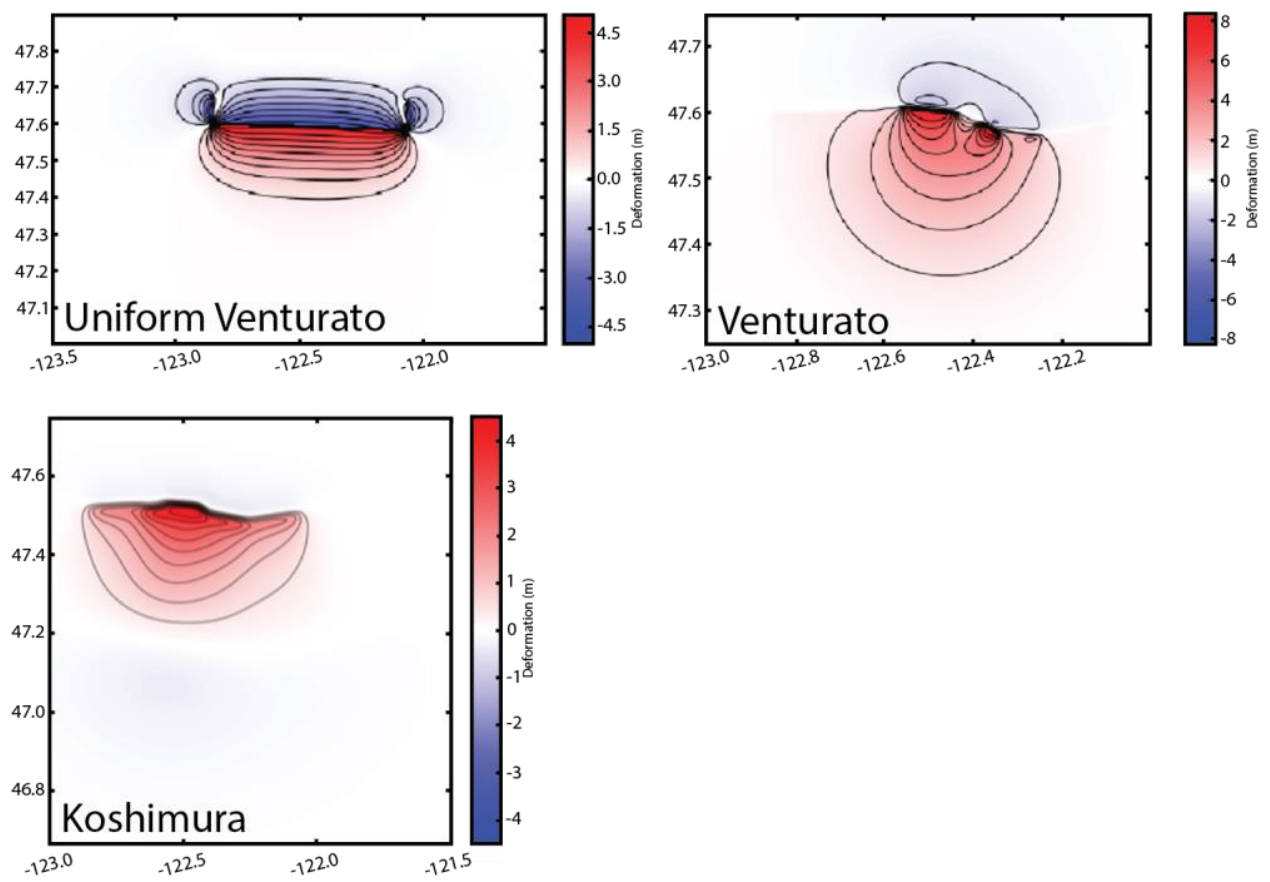

Figure 23 Seafloor Deformation of Three Earthquakes. Plots of the seafloor deformation of the Uniform Venturato earthquake (left), Venturato earthquake (right), and Koshimura (bottom).

Koshimura's seafloor deformation is smaller vertically, with a maximum uplift of about 4 $\mathrm{m}$ along the middle of the rupture plane and minimal subsidence. It is more evenly spread across the fault compared to Venturato that has two subfaults with a large vertical displacement. Seafloor deformation in Uniform Venturato is evenly spread across the extent of the fault rupture with a maximum $4.5 \mathrm{~m}$ of uplift, much larger subsidence than in the other scenarios $(4.5 \mathrm{~m}$ vs $<2 \mathrm{~m})$. 


\section{Snohomish Delta Model Results}

Since gauge 27 is located in the Snohomish River, we are able to see the waveform for all three tidal stages (Figure 24). The Uniform Venturato and Koshimura tsunamis arrive 20 minutes after rupture at MHHW and 23 minutes after rupture at NAVD88 and MLLW tides. Venturato arrives after 28 minutes at MHHW and after 31 minutes at NAVD88 and MLLW tides. Venturato and Uniform Venturato both had initial drawdowns during all three tides while Koshimura did not. All three earthquakes
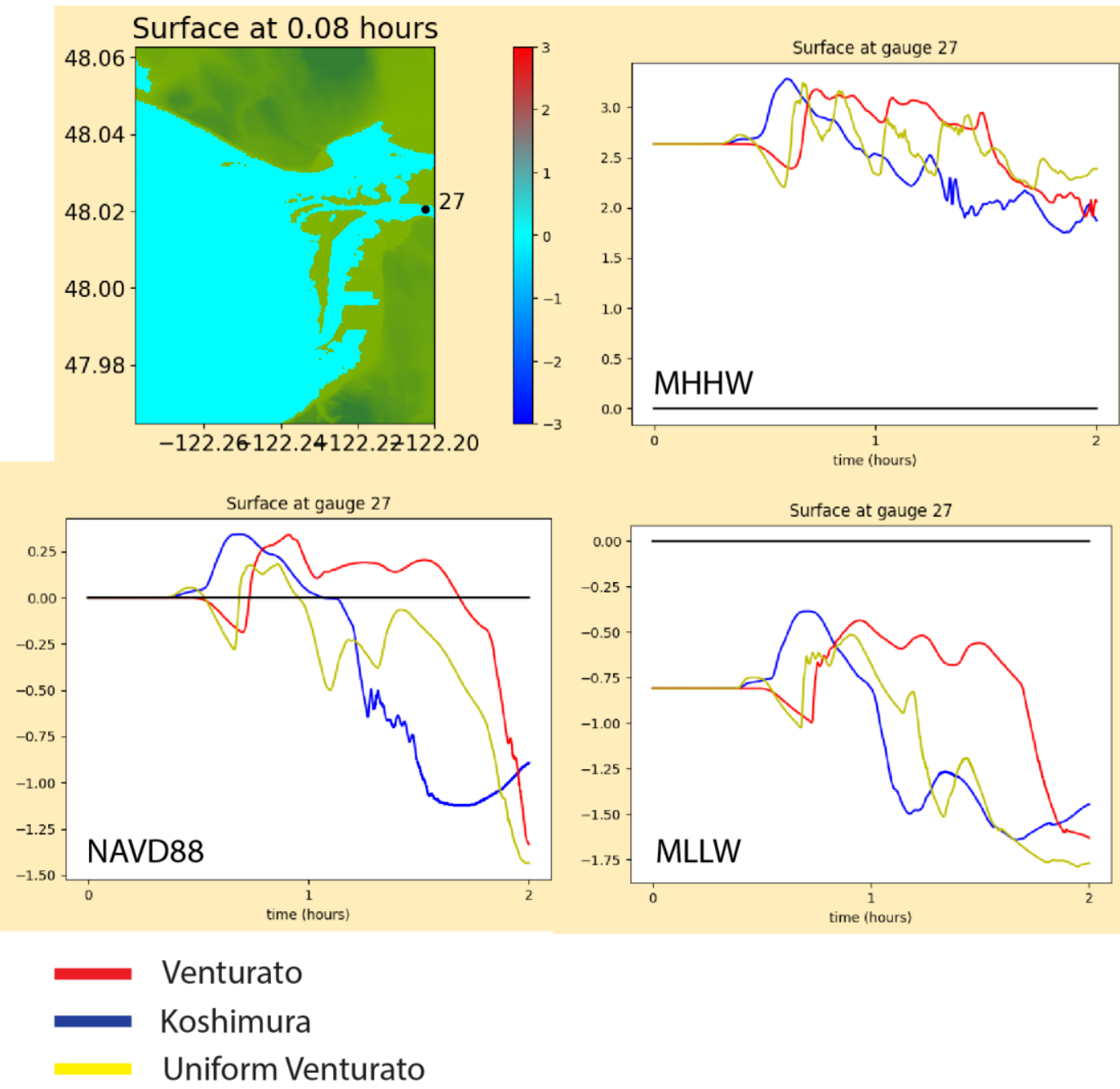

Figure 24 Snohomish Delta Modeling Results. Top left shows Snohomish Delta with Gauge 27 at NAVD88, 4.8 minutes after rupture, before the tsunami has arrived. Top right, waveforms (in m) for the three simulations at MHHW; bottom left, at NAVD88; bottom right, at MLLW. 
produced waves of similar height at MHHW, about $0.6 \mathrm{~m}$ to $0.7 \mathrm{~m}$ above the tidal water surface (Table 5). At NAVD88, Venturato and Koshimura produced waves of similar height at about $0.3 \mathrm{~m}$ while Uniform Venturato was slightly smaller wave height at $0.2 \mathrm{~m}$. At MLLW, Koshimura and Venturato were about $0.4 \mathrm{~m}$ high, while Uniform Venturato's was about $0.3 \mathrm{~m}$.

Table 5 Summary of Tsunami Simulations. Wave heights relative to the tide datum for all simulations.

\begin{tabular}{|l|c|c|c|c|c|c|}
\hline Earthquake & Tide Level & Snohomish Delta & Cultus Bay & Deer Lagoon & West Point & Elger Bay \\
\hline \multirow{4}{*}{ Koshimura } & MLLW & $0.4 \mathrm{~m}$ & No data & $<0.1 \mathrm{~m}$ & $3.75 \mathrm{~m}$ & $0.6 \mathrm{~m}$ \\
\cline { 2 - 7 } & NAVD88 & $0.3 \mathrm{~m}$ & No data & $0.25 \mathrm{~m}$ & $3.25 \mathrm{~m}$ & $0.5 \mathrm{~m}$ \\
\cline { 2 - 7 } & MHHW & $0.7 \mathrm{~m}$ & $1.2 \mathrm{~m}$ & $1 \mathrm{~m}$ & $3.5 \mathrm{~m}$ & $0.5 \mathrm{~m}$ \\
\hline \multirow{4}{*}{$\begin{array}{l}\text { Venturato } \\
\text { Uniform }\end{array}$} & MLLW & $0.4 \mathrm{~m}$ & No data & $<0.1 \mathrm{~m}$ & $1 \mathrm{~m}$ & $0.6 \mathrm{~m}$ \\
\cline { 2 - 8 } & NAVD88 & $0.2 \mathrm{~m}$ & No data & $0.5 \mathrm{~m}$ & $1.25 \mathrm{~m}$ & $0.6 \mathrm{~m}$ \\
\cline { 2 - 7 } & MHHW & $0.6 \mathrm{~m}$ & $1.2 \mathrm{~m}$ & $1 \mathrm{~m}$ & $1.5 \mathrm{~m}$ & $0.6 \mathrm{~m}$ \\
\hline & MLLW & $0.3 \mathrm{~m}$ & No data & $0.2 \mathrm{~m}$ & $2.8 \mathrm{~m}$ & $0.7 \mathrm{~m}$ \\
\cline { 2 - 7 } & NAVD88 & $0.3 \mathrm{~m}$ & No data & $0.5 \mathrm{~m}$ & $2.9 \mathrm{~m}$ & $0.75 \mathrm{~m}$ \\
\cline { 2 - 7 } & MHHW & $0.6 \mathrm{~m}$ & $2 \mathrm{~m}$ & $1 \mathrm{~m}$ & $4 \mathrm{~m}$ & $0.75 \mathrm{~m}$ \\
\hline
\end{tabular}

\section{Cultus Bay Model Results}

Gauge 20 in Cultus Bay is located behind the spit on the northern end of the marsh; the elevation of the site was $1.75 \mathrm{~m}$ above NAVD88. Both Koshimura and Venturato produced wave heights of $1.2 \mathrm{~m}$ above the marsh surface at MHHW (Figure 25) but with differing arrival times (8 and 17 minutes after rupture, respectively). Uniform Venturato formed two waves that were $2 \mathrm{~m}$ above the marsh surface, with an initial arrival time of 8 minutes. All three earthquakes produced tsunamis that were too small to inundate the marsh during NAVD88 and MLLW water levels. 

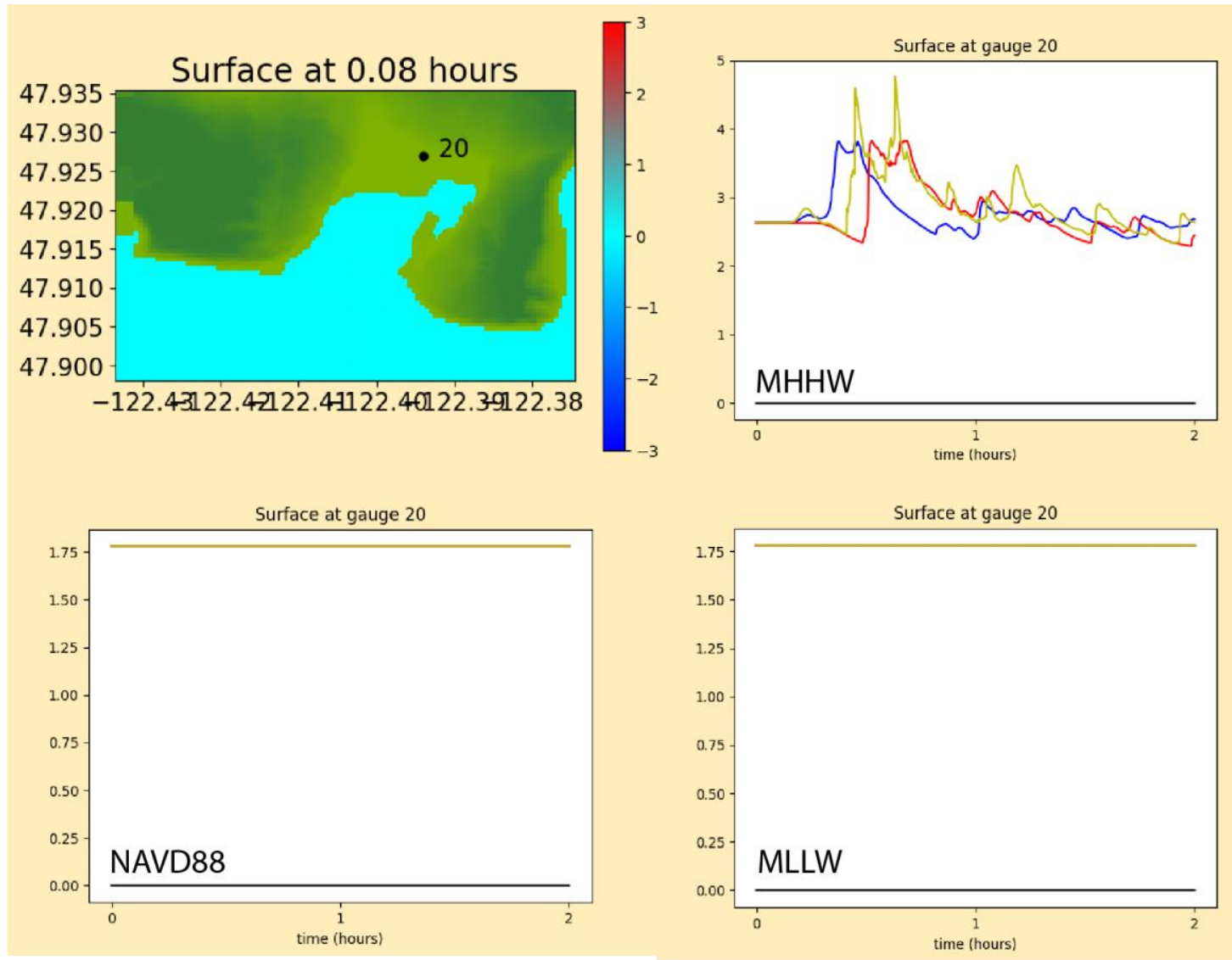

\section{Venturato \\ Koshimura \\ Uniform Venturato}

Figure 25 Cultus Bay Modeling Results. Top left, Cultus Bay showing Gauge 20 location at 4.8 minutes at NAVD88, before the tsunami has arrived. Top right, waveforms (in $\mathrm{m}$ ) for the 3 simulations at MHHW; bottom left, at NAVD88; bottom right, at MLLW. Both NAVD88 and MLLW are displaying the marsh land surface with lines at $\sim 1.75 \mathrm{~m}$; there is no inundation by a tsunami except at MHHW.

\section{Deer Lagoon Model Results}

Gauge 31 was placed in the center of Deer Lagoon (Figure 26), on the intertidal flat, seaward of two manmade dikes. At MHHW, all three models produced tsunamis that were able to flood the tide flat to about $1 \mathrm{~m}$ depth. At NAVD88 Venturato and Uniform Venturato flooded to about $0.5 \mathrm{~m}$ of water at the gauge while Koshimura only flooded to 

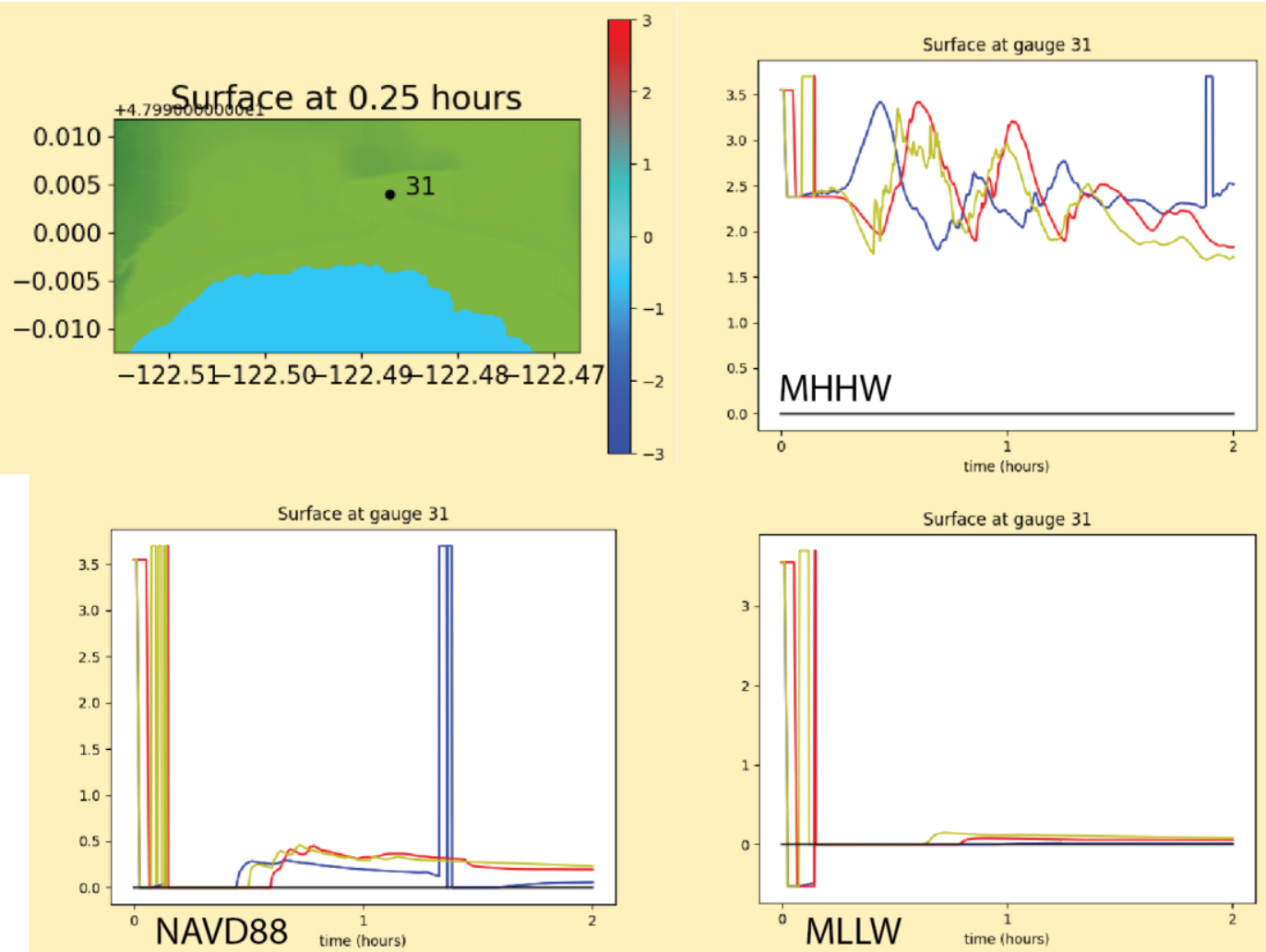

\section{Venturato \\ Koshimura \\ Uniform Venturato}

Figure 26 Deer Lagoon Modeling Results. Top left is a snapshot of Deer Lagoon at NAVD88, 15 minutes after rupture, before the tsunami has arrived. Top right, waveforms (in $\mathrm{m}$ ) for the three simulations at MHHW; bottom left, at NAVD88; bottom right, at MLLW. The vertical spikes in the waveforms should be ignored as they are artifacts of GeoClaw's AMR refinement steps, temporarily affecting the topographic elevation.

about $0.25 \mathrm{~m}$ depth. At MLLW, Uniform Venturato had the deepest flood at about $0.2 \mathrm{~m}$, while Venturato and Koshimura were both $<0.1 \mathrm{~m}$.

The three tide levels had different tsunami arrival times. The shortest time was at MHHW, where all three tsunamis arrived at $~ 15$ min. At NAVD88 Koshimura arrived at $26 \mathrm{~min}$, Uniform Venturato at $30 \mathrm{~min}$, and Venturato at $36 \mathrm{~min}$. At MLLW, Uniform Venturato flooded the tide flat at $38 \mathrm{~min}$ and Venturato at $48 \mathrm{~min}$; Koshimura is nearly indistinguishable from the zero line. The later arrival at lower tide levels relates to water 
height needed to reach the gauge; at MLLW only the maximum peak height of the waveforms reach the gauge.

\section{West Point Model Results}

Gauge 3 at West Point is located just off the southern point (Figure 27). The highest tsunami wave heights of all simulated sites was recorded here, with a maximum reaching $\sim 4 \mathrm{~m}$ above the water surface. All three scenarios maintained a consistent and unique waveform across all tide levels. Both Koshimura and Uniform Venturato wave arrivals were nearly instantaneous at all three tides, with Uniform Venturato's withdrawal being $2+\mathrm{m}$. Koshimura had the highest wave above the water surface at NAVD88 and MLLW levels (3.25 m and $3.75 \mathrm{~m}$ respectively) although interestingly Uniform Venturato was slightly higher than Koshimura at MHHW (4.0 m vs $3.5 \mathrm{~m}$ above the water surface). At MHHW, these maximum wave height exceeded $6 \mathrm{~m}$ above the 0 datum of NAVD88, the highest wave heights in my project. The Venturato tsunami behaved differently than the other two scenarios, with an arrival time of about $5 \mathrm{~min}$ at all tide levels and a smaller series of waves that began with a $0.5 \mathrm{~m}$ withdrawal and had maximum wave heights reaching about $1.5 \mathrm{~m}$ at MHHW, and $1.25 \mathrm{~m}$ at NAVD88, and 1 $m$ at MLLW above the water surface. 

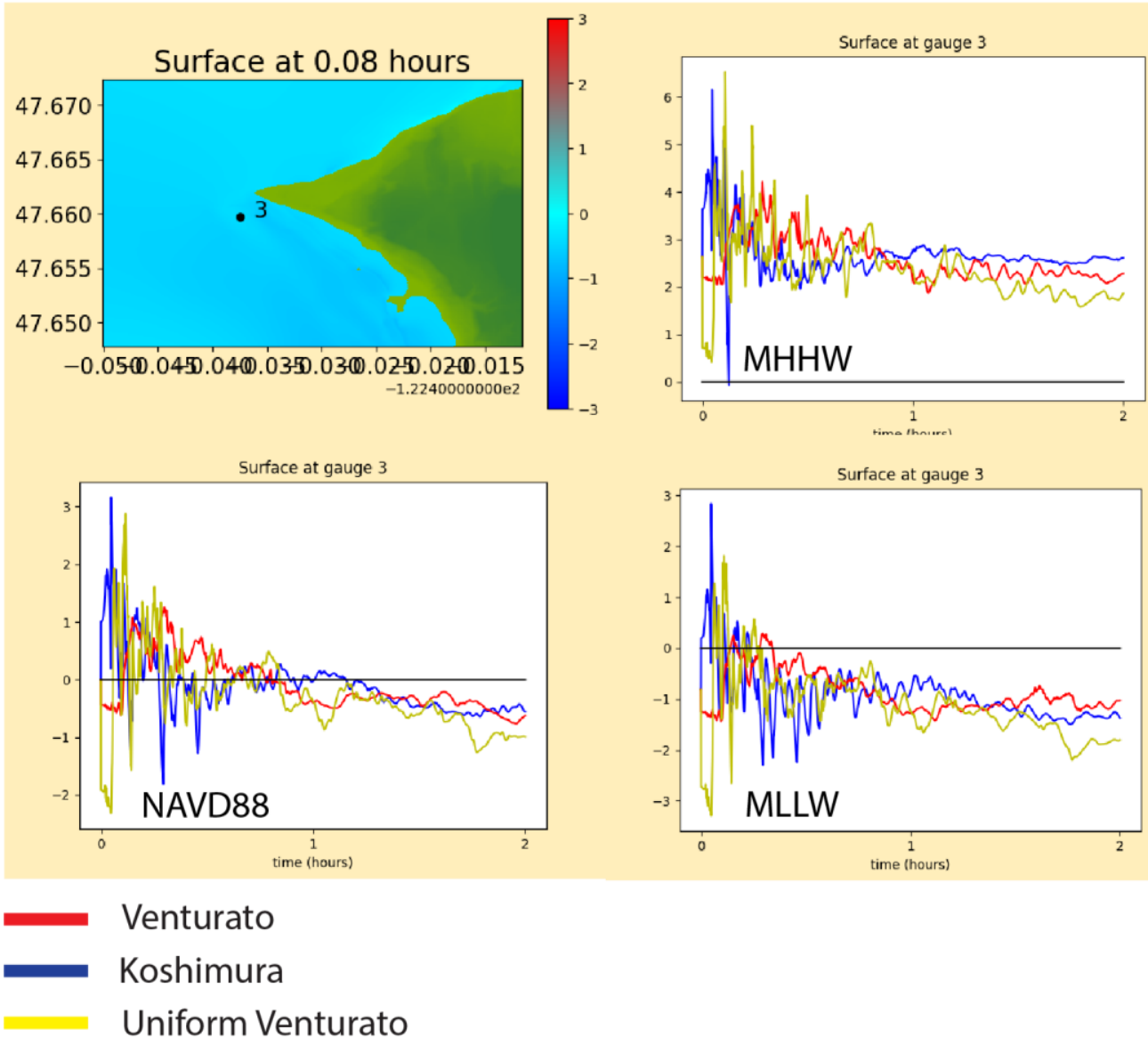

Figure 27 West Point Modeling Results. Top left is a snapshot of West Point at NAVD88, 4.8 minutes after rupture, before the tsunami has arrived. Top right, waveforms (in m) for the three simulations at MHHW; bottom left, at NAVD88; bottom right, at MLLW.

\section{Elger Bay Model Results}

At Elger Bay, gauge 9 was placed offshore, south of the beach within the bay

(Figure 28). The tsunami arrived at the marsh at 23 minutes after the rupture for all three models at all three tide levels. At both MHHW and NAVD88, Uniform Venturato had the highest wave at $0.75 \mathrm{~m}$ above the water surface while Koshimura was smallest at $>0.5 \mathrm{~m}$ and Venturato in the middle at about $0.6 \mathrm{~m}$. MLLW was slightly different with Uniform Venturato still having the largest wave height, but in this case only $0.7 \mathrm{~m}$ above the water surface, while Koshimura and Venturato both were $0.6 \mathrm{~m}$. 


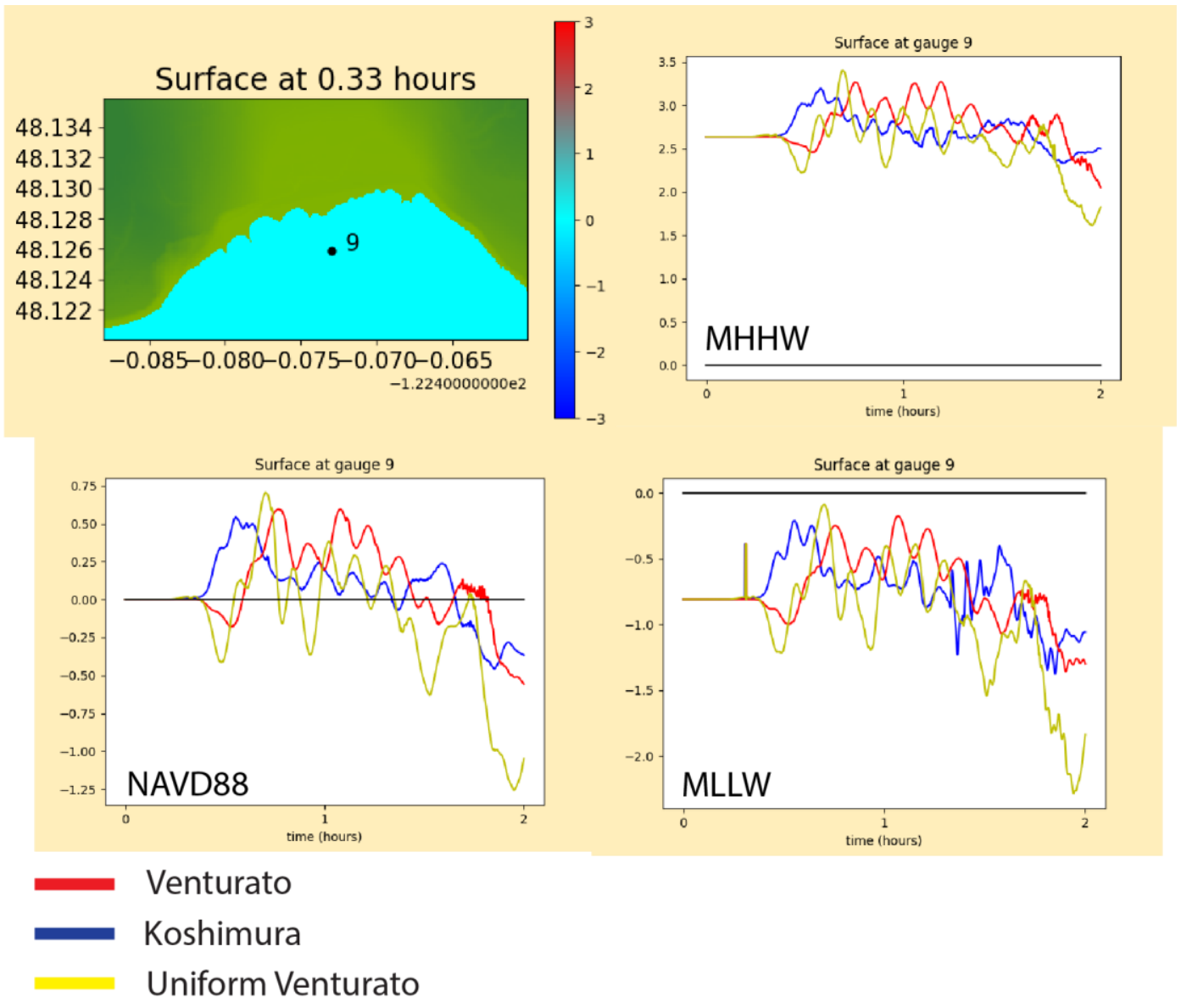

Figure 28 Elger Bay Modeling Results. Top left is a snapshot of Elger Bay at NAVD88, 19.8 minutes after rupture, before the tsunami has arrived. Top right, waveforms (in $\mathrm{m}$ ) for the three simulations at MHHW; bottom left, at NAVD88; bottom right, at MLLW. The vertical spikes in the waveforms of MLLW should be ignored as they are artifacts of GeoClaw's AMR refinement steps, temporarily affecting the topographic elevation.

\section{Discussion of Model Results}

\section{The Seattle Fault Tsunami Occurred Near High Tide}

Based on the modeling and locations of tsunami deposit observations, the Seattle fault tsunami occurred at or near MHHW. All tsunamis would have flooded my coastal sites at MHHW, but would they have likely left a tsunami deposit or not needs discussion. Excluding West Point, none of the tsunamis tested were large enough to 
inundate marshy areas at MLLW or NAVD88. Refer to Table 5 for a summary of these results.

Table 6 Summary of Tsunami Deposit Likelihood. Evaluation of whether or not the simulations suggest that a deposit was likely. $\mathrm{NO}=$ flow depth $<0.5 \mathrm{~m}$; MAYBE $=$ flow depth $0.5-1.0 \mathrm{~m}$; YES = flow depth $>1.0 \mathrm{~m}$.

\begin{tabular}{|l|c|c|c|c|c|c|}
\hline Earthquake & Tide Level & Cultus Bay & Snohomish Delta & Deer Lagoon & West Point & Elger Bay \\
\hline \multirow{4}{*}{ Koshimura } & MLLW & NO & NO & NO & NO & NO \\
\cline { 2 - 7 } & NAVD88 & NO & NO & NO & MAYBE & NO \\
\cline { 2 - 7 } & MHHW & YES & MAYBE & YES & YES & NO \\
\hline \multirow{4}{*}{ Venturato } & MLLW & NO & NO & NO & NO & NO \\
\cline { 2 - 7 } & NAVD88 & NO & NO & NO & NO & NO \\
\cline { 2 - 7 } & MHHW & YES & MAYBE & YES & YES & NO \\
\hline \multirow{3}{*}{$\begin{array}{l}\text { Uniform } \\
\text { Venturato }\end{array}$} & MLLW & NO & NO & NO & NO & NO \\
\cline { 2 - 7 } & NAVD88 & NO & NO & NO & NO & NO \\
\cline { 2 - 7 } & MHHW & YES & MAYBE & YES & YES & NOS \\
\hline
\end{tabular}

Snohomish Delta: At the mouth of the Snohomish River land level is just above MHHW, where it typically is only submerged during extreme high tide events and flooding. Bourgeois and Johnson (2001)'s tsunami deposit in the Snohomish Delta was a sand layer that was $2 \mathrm{~cm}$ thick. Estimating a tsunami's wave height and flow speed based on the deposit left behind requires extra modeling using programs such as TsuSedMod (Jaffe and Gelfenbaum, 2007) or TSUFLIND (Tang and Weiss, 2015), therefore I used the criteria from the Comparing Model Results to Field Data section based on my simulated wave heights. All three scenarios at MHHW produced a tsunami that was $0.6 \mathrm{~m}$ to $0.7 \mathrm{~m}$ higher than MHHW (which is approximately land surface elevation). These tsunamis are considered potentially large enough to leave a widespread deposit, as observed, so they are designated as MAYBE (Table 4). At NAVD88 and MLLW, all of the tsunamis were only $0.25 \mathrm{~m}$ above the water level; they would have to exceed $2.7 \mathrm{~m}$ to exceed the height of MHHW and flood the marsh surface, therefore they could not inundate and were designated NO. 
I interpret that the actual tsunami in the Snohomish Delta, based on deposit observations, was likely larger than my simulations estimated. However, this site still supports the interpretation that the tsunami occurred at or near MHHW. If the actual tsunami was larger than my models, as I am suggesting, it would need to be >10x larger than the height at NAVD88 to flood the Snohomish Delta surface. Another possible explanation for a tsunami deposit with such a small tsunami in the simulation is local liquefaction induced subsidence. Bourgeois and Johnson (2001) concluded that $50-75 \mathrm{~cm}$ of local subsidence occurred at the Snohomish delta. The subsidence paired with the 0.25 $\mathrm{m}$ tsunami wave at that location would then have $>1 \mathrm{~m}$ flow depth at high tide, thus designating it as a YES.

Cultus Bay: At Cultus Bay, all of the scenarios at MHHW were large enough to have produced a tsunami deposit like the one found in Atwater and Moore (1992). Flow depths at Gauge 20, located on the marsh surface ranged between $2.2 \mathrm{~m}$ (Uniform Venturato) and $1.25 \mathrm{~m}$ (Venturato and Koshimura). If flow depths were as deep as $2 \mathrm{~m}$ in the marsh at MHHW, then a lower tide level (within $1 \mathrm{~m}$ of MHHW) would still have flows deep enough in the marsh for deposition.

Deer Lagoon: At Deer Lagoon, MHHW is the only scenario that sees considerable flooding of the tidal flats. Land level at the gauge is at $0 \mathrm{~m}$ and wave height reaches about $1 \mathrm{~m}$ for all three earthquake scenarios. When added to a $2.5 \mathrm{~m}$ column of water at MHHW in the flat the tsunami's flow depth of $3.5 \mathrm{~m}$ would easily be deep enough to leave a deposit, such as the one found by Bruce (2020) and Bourgeois (pers. comm., 
2014) so I designate all three scenarios a YES at MHHW. Because the gauge is sitting on land at $0 \mathrm{~m}$ elevation in the NAVD88 and MLLW tidal scenarios, flow depths are less than $0.5 \mathrm{~m}$ deep for all scenarios and likely would not leave a deposit, which results in a designation of NO for all three scenarios at NAVD88 and MLLW.

West Point: Here Atwater and Moore (1992) found a sandy layer determined to be a tsunami deposit about $100 \mathrm{~m}$ inland that stretched about $200 \mathrm{~m}$ to the northeast. Land level is at $2.8 \mathrm{~m}$ NAVD88, slightly higher than MHHW. The tsunami deposit was observed between about $-0.75 \mathrm{~m}$ NAVD88 on the seaward end of the trench and $0.25 \mathrm{~m}$ on the landward end of the trench. At MHHW, Uniform Venturato and Koshimura would see flood depths reach just below $3.5 \mathrm{~m}$. The much smaller Venturato tsunami still had about $1.3 \mathrm{~m}$ of flow depth, designating all three scenarios as a YES at MHHW. At NAVD88, Koshimura had a flow depth of just over 0.5 m (MAYBE) and Uniform Venturato had a flow depth of about $0.25 \mathrm{~m}(\mathrm{NO})$. Wave height in the Venturato scenario was only about $1.25 \mathrm{~m}$, so it did not reach the required $2.635 \mathrm{~m}$ NAVD88 for flooding to occur, so it is designated as a NO. At MLLW, all three scenarios are designated a NO: Koshimura flow depths were only $0.25 \mathrm{~m}$, Uniform Venturato was nearly $1 \mathrm{~m}$ too small to flood and Venturato even smaller.

Elger Bay: The land level inside the marsh is at $2.7 \mathrm{~m} \mathrm{NAVD88.} \mathrm{At} \mathrm{MHHW,} \mathrm{wave}$ heights reached between $0.6 \mathrm{~m}$ and $0.75 \mathrm{~m}$ above water level for all scenarios. Since gauge 9 is not located inside the marsh, I will use flow depths found in Figure 29 to designate whether a deposit would be expected. For Venturato and Uniform Venturato 

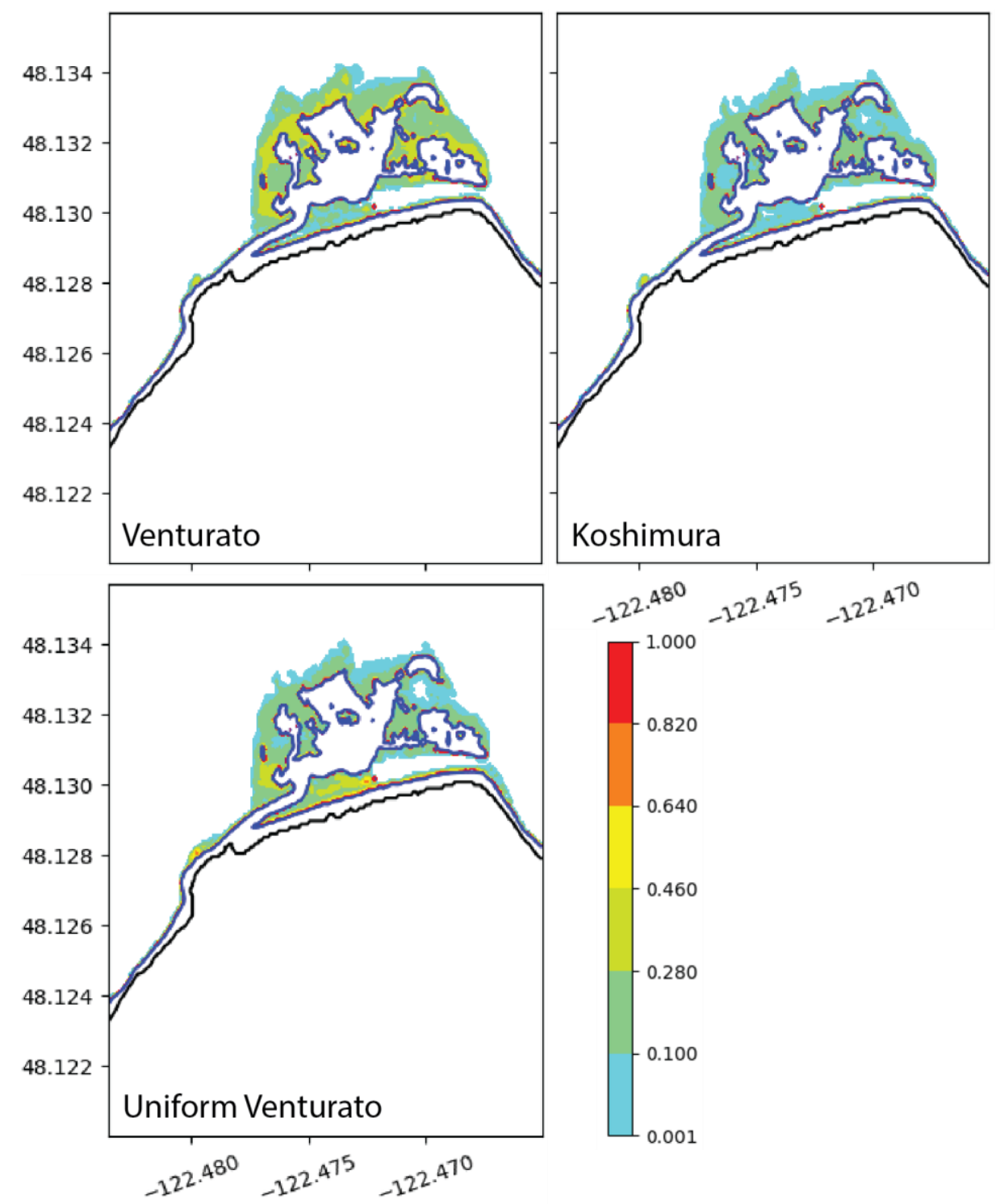

Figure 29 Maximum Flow Depths in Elger Bay. Plots of the maximum flow depth where water is not already present in Elger Bay at MHHW. Scale bar is in meters. Black line is the shoreline. (Top left) Venturato scenario, (Top right) the Koshimura scenario, and (Bottom) the Uniform Venturato scenario.

the maximum flow depth falls in the range of $0.28 \mathrm{~m}$ to $0.46 \mathrm{~m}$ over land $-\mathrm{NO}-$ and the Koshimura maximum flow depth falls in the range of $0.1 \mathrm{~m}$ to $0.28 \mathrm{~m}$ over land - NO. At NAVD88 and MLLW, all earthquakes had tsunamis with wave heights of $0.6 \mathrm{~m}-0.7 \mathrm{~m}$ so they do not reach the required elevation of $2.7 \mathrm{~m}$ NAVD88 to flood the marsh. 
At MHHW, all scenarios overtopped the western half of the protective ridge and flooded the extent of the Elger Bay marsh. The eastern end of the ridge that was not overtopped is where a road and several houses are located. Although Uniform Venturato had the highest amplitude tsunami on the offshore gauge, it did not have the deepest flooding throughout the marsh. Near the inlet, flow depths from Uniform Venturato were in the range of $0.28-0.46 \mathrm{~m}$, but farther back in the marsh they was less than $0.28 \mathrm{~m}$. Venturato had deeper flow depths farther inland within the marsh, with a more extensive area that falls within the $0.28-0.46 \mathrm{~m}$ range. Since these two tsunamis were very close in wave height ( $0.1 \mathrm{~m}$ to $0.2 \mathrm{~m}$ difference) on the gauge, I interpret the deciding factor determining flooding extent must be details of the waveform. Uniform Venturato's large initial wave was followed by several smaller waves $\sim 0.3 \mathrm{~m}$ high. Because the ridge is about $3.4 \mathrm{~m}$ elevation (since MHHW is $2.635 \mathrm{~m}$ above NAVD88, the ridge is $0.765 \mathrm{~m}$ above MHHW), the smaller waves could not have overtopped the ridge again and would have only injected water through the inlet. Conversely, the Venturato tsunami consisted of three waves about $0.6 \mathrm{~m}$ high and all three waves must have overtopped the beach ridge, thus resulting in a larger volume of water in the marsh. However, as an aside, none of the waves should have overtopped the ridge considering the largest wave was only $0.75 \mathrm{~m}$ above MHHW. This discrepancy is likely created because the bathymetry resolution is $1 / 3$ arc second, which is about $10 \mathrm{~m}$. The peak of the ridge was not preserved in the bathymetry because it was averaged with the surrounding (lower) elevations. 


\section{The Koshimura Source Produced a More Accurate Tsunami}

When comparing the tsunami simulations to discern which more closely matched observations, I related flow depths over land to the deposits observed at each site individually. The tsunami from the Koshimura source was a good fit at every site, so therefore I interpret it as the most accurate tsunami. At both Deer Lagoon and Elger Bay, all three earthquake sources produced tsunamis that were similar in height (within 0.25 m), so they cannot be distinguished. At Cultus Bay, Koshimura and Venturato are at nearly the same wave height while Uniform Venturato was $>0.75 \mathrm{~m}$ larger. If the flow depths in Cultus Bay were $\sim 4 \mathrm{~m}$, I predict that a more extensive, thicker deposit should have been observed, so I interpret Uniform Venturato as too large here. At Snohomish Delta Koshimura produced the largest wave, though all three were very similar. Since the waves here are in the MAYBE category, the largest wave is the best fit. At West Point, Koshimura and Uniform Venturato had flow depths of nearly $4 \mathrm{~m}$ while Venturato was only about $1.5 \mathrm{~m}$. Because the elevation of the deposit here varies by about a meter and under the assumption that the marsh surface was near MHHW, I predict that a wave $>1.5$ m must have left the deposit. Thus, Koshimura and Uniform Venturato are a better fit here.

\section{Sources of Error}

Fault parameter errors: Potential issues arise in the Venturato and Koshimura scenarios from overlap of subfaults as they extend normal to the fault strike, which is not a straight line. The zigs and zags of the fault can cause the subfaults to stack on each other which produces an additive seafloor deformation as well as leaves gaps between the subfaults. 
These stacked areas and gaps will affect tsunami size. Additionally, when calculating the location of the subfaults I could have made mathematical errors due to the complex calculations used to find top center of each subfault. Those potential errors would change the location of the seafloor deformation and thus affect the size and behavior of the wave across the bathymetry of Puget Sound.

Bathymetry errors and resolution averaging: The resolution of my bathymetry is $1 / 3$ arc second, which equates to about $10 \mathrm{~m}$. All elevations in a $10 \mathrm{~m}$ x $10 \mathrm{~m}$ square are averaged to assign a value to that grid point. This could artificially smooth out ridges and peaks, such as identified at Elger Bay with the discrepancies in ridge height compared to wave height and overtopping. Additionally, at Elger Bay and the Snohomish Delta, the tide gauges suggest that the Sound is draining towards the end of the calculation. This could potentially be due to an issue dealing with boundary effects in GeoClaw related to the bathymetry.

Tide calculations: The tide level affects the inundation of the tsunami and if calculated wrong would skew wave heights to be higher/lower. Since the scale of the tidal swings in Puget Sound is much greater than the scale of the tsunami size, tide level is the largest factor in determining whether inundation will occur. Rupture during a slightly higher tide at Elger Bay could cause more extensive breaching of the ridge for example. Reconstructions of past marshes: Another issue to consider is the evolution of the coastline and the bathymetry at my sites, which would have evolved over the last 1100 years. Shoreline positions, marsh surface elevations differences, and the presence or 
absence of protective ridges at any of my sites would result in differences in whether a tsunami would inundate and leave deposits. Additionally, the source of sand could be different than today such that so even with deeper flow a deposit would not be found. 


\section{CHAPTER VI}

\section{CONCLUSIONS}

This study consisted of a field study based at Elger Bay marsh on central Camano Island and modeling of the $900 \mathrm{AD}$ Seattle fault earthquake and tsunami at locations north of the fault where the tsunami deposit has been found. At Elger Bay marsh, we used cores and tidal channel cutbanks to interpret the geologic history of the marsh and look for evidence of tsunamis. We found one traceable sandy deposit 20-25 cm deep, but it was dated to $1478-1664 \mathrm{cal} \mathrm{AD}$ through ${ }^{14} \mathrm{C}$ dating - too young to be deposited by the Seattle fault tsunami. Possible sources for the deposit include the 1820's Camano Head landslide tsunami, the 1700 Cascadia event, or an unknown tsunamigenic source. Other sandy layers were found in the southern half of the marsh, but my interpretation is based on what facies they were found in. If they were found in Organic-rich Mud or Orange Peat facies then they were likely to have been liquefaction deposits. If they were found in Grey Mud or Muddy Sand facies then they were interpreted as migrating tide channel deposits.

Elger Bay has not always been a marsh. I used ${ }^{14} \mathrm{C}$ dating paired with stratigraphy and accumulation rates of those types of stratigraphy calculated in other studies in the region to reconstruct its evolutionary history. I determined that for at least 1000 years Elger Bay was a lagoonal or tidal flat environment, up to about 1000 AD. Around that time it transitioned from being completely flooded with each tide to an environment that was not flooded with each tide and allowed vegetation colonization. Elger Bay has been a marsh for about 1000 years now. To have lagoonal and marshy deposits, a protective ridge must have been present. Evidence of protective ridge growth was observed in the 
DSM that I created using aerial photographs processed in SfM software, as well as historic maps and aerial photographs. Two abandoned paleoridges were observed near the inlet in the DSM. Historic maps supported that these ridges were once the active protective ridge to Elger Bay. Between 1911 and 1940 the current protective ridge abandoned the ridge at the inlet and grew across the inlet to its present-day location. Using aerial photographs and recent satellite imagery, I observed the main tidal flow occupying different meanders multiple times as recent as the past few decades.

Modeling consisted of simulating three earthquakes based on parameters from Koshimura (2002), Venturato (2007), and one that I calculated by modifying Venturato's earthquake. Seafloor deformation from each earthquake was used to calculate wave heights at West Point, Cultus Bay, Snohomish Delta, Deer Lagoon, and Elger Bay at MLLW, NAVD88, and MHHW tide levels. The largest takeaway from the results of modeling is that a tsunami resulting from a rupture of the Seattle fault is an inundation threat for low-lying coastal areas if it occurs at or near high tide. Simulations consistently showed that inundation was possible only at or near MHHW levels. Although the large tidal swings in Puget Sound can provide a large buffer to protect the low-lying areas in the region during much of the tidal cycle, it is still hazardous when the conditions line up.

Based on my parameters, all earthquake scenarios show that even at high tide, tsunami flow depths within Elger Bay marsh were unlikely to leave a deposit in present day conditions. My environmental reconstructions from core stratigraphy concluded that Elger Bay was likely a lagoonal tide flat around the time of the Seattle fault rupture, thus a deposit would not be recognizable in the sediment due to higher energy conditions and higher sand content in the environment. 
Future work should focus on the Camano Head landslide from the 1820's. The extent of the tsunami is unknown however, oral histories identify it as flooding Hat Island (Shipman, 2001). A Camano Head landslide tsunami deposit could be preserved in nearby marshes, potentially the tsunami deposit identified in Elger Bay. Field studies at locations such as the marsh at Skiou Point in Tulalip, the marshy area on the NW corner of Hat Island on Sandpoint Way, and a more extensive search near the inlet and along the back side of the protective berm in Elger Bay could give us an insight to the magnitude and extent of a tsunami generated by this landslide. This information could help enhance the knowledge and threat of landslide generated tsunamis in Puget Sound.

Additional future field studies of the Seattle fault tsunami in Puget Sound, are possible at three marshes in the vicinity of Kinney Point State Park - Oak Bay Park, Indian Island County Park, and the marshy area at the south end of Scow Bay - just to the west of Deer Lagoon. All three marshes would have easy access due to nearby roads and have campgrounds. These sites would give data points past Deer Lagoon to further track down the extent of the 900 AD Seattle Fault tsunami, to continue the goals of this project. This study and others like it help the ICDEM and other local agencies to determine the tsunami hazards involved with a Seattle fault rupture. Considering that most sites only flooded at or near high tide, the threat of a future Seattle fault tsunami is not great for the majority of Puget Sound. Another threat to consider though is currents generated by the tsunamis traveling through the Sound. Strong currents can destroy coastal structures, cause rapid erosion of coastal sediments, and are hazardous to people living in low-lying areas. 


\section{REFERENCES}

Adams, J., 1992, A Search for Ancient Earthquakes in Puget Sound: Science, v. 258, no. 5088, p. 1592-1592, doi:10.1126/science.258.5088.1592.

Arcos, M.E.M., 2012, The A.D. 900-930 Seattle-Fault-Zone Earthquake with a Wider Coseismic Rupture Patch and Postseismic Submergence: Inferences from New Sedimentary Evidence: Bulletin of the Seismological Society of America, v. 102, p. 1079-1098, doi:10.1785/0120110123.

Atwater, B.F., 1987, Evidence for Great Holocene Earthquakes Along the Outer Coast of Washington State: Science, v. 236, p. 942-944, doi:10.1126/science.236.4804.942.

Atwater, B.F., and Moore, A.L., 1992, A Tsunami about 1000 Years Ago in Puget Sound, Washington: Science, v. 258, no. 5088, p. 1614-1617, doi:10.1126/science.258.5088.1614.

Berger, M.J., and LeVeque, R.J., 1998, Adaptive Mesh Refinement Using WavePropagation Algorithms for Hyperbolic Systems: SIAM Journal on Numerical Analysis, v. 35, no. 6, p. 2298-2316, doi:10.1137/S0036142997315974.

Berger, M.J., George, D.L., LeVeque, R.J., and Mandli, K.T., 2011, The GeoClaw software for depth-averaged flows with adaptive refinement: Advances in Water Resources, v. 34, no. 9, p. 1195-1206, doi:10.1016/j.advwatres.2011.02.016.

Blakely, R.J., Wells, R.E., Weaver, C.S., and Johnson, S.Y., 2002, Location, structure, and seismicity of the Seattle fault zone, Washington: Evidence from aeromagnetic anomalies, geologic mapping, and seismic-reflection data: GSA Bulletin, v. 114, no. 2 , p. 169-177. 
Bourgeois, J., and Johnson, S.Y., 2001, Geologic Evidence of Earthquakes at the Snohomish Delta, Washington, in the Past 1200 yr: GSA Bulletin, v. 113, no. 4, p. 482-494.

Bruce, D., 2020, Mapping and Modeling the Seattle Fault Tsunami Inundation in Puget Sound [M.S. thesis]: Central Washington University, Ellensburg, WA, 155 p.

Bucknam, R.C., Hemphill-Haley, E., and Leopold, E.B., 1992, Abrupt Uplift Within the Past 1700 Years at Southern Puget Sound, Washington: Science, v. 258, no. 5088, p. 1611-1614, doi:10.1126/science.258.5088.1611.

Dolcimascolo, A., Eungard, D. W. Allen, C., LeVeque, R. J., Adams, L. M. Arcas, D., Titov, V. V., González, F. I., Moore, C., Garrison-Laney, C. E., and Walsh, T. J., 2021, Tsunami Hazard Maps of the Puget Sound and Adjacent Waters-Model Results From an Extended L1 M $\mathrm{w}_{\mathrm{w}}$ 9.0 Cascadia Subduction Zone Megathrust Earthquake Scenario: Washington Geological Survey Map Series 2021-01, 16 sheets, scale 1:48,000, $49 \mathrm{p}$. [https://fortress.wa.gov/dnr/geologydata/tsunami_hazard_maps/ger_ms202101_tsunami_hazard_puget_sound.zip]

Engelhart, S.E., Vacchi, M., Horton, B.P., Nelson, A.R., and Kopp, R.E., 2015, A SeaLevel Database for the Pacific Coast of Central North America: Quaternary Science Reviews, v. 113, p. 78-92, doi:10.1016/j.quascirev.2014.12.001.

Eronen, M., Kankainen, T., and Tsukada, M., 1987, Late Holocene Sea-Level Record in a Core from the Puget Lowland, Washington: Quaternary Research, v. 27, no. 2, p. 147-159, doi:10.1016/0033-5894(87)90073-1. 
Heiri, O., Lotter, A.F., and Lemcke, G., 2001, Loss On Ignition as a Method For Estimating Organic and Carbonate Content in Sediments: Reproducibility and Comparability of Results: Journal of Paleolimnology, v. 25, p. 101-110, doi:10.1023/A:1008119611481.

Jacoby, G.C., Williams, P.L., and Buckley, B.M., 1992, Tree Ring Correlation Between Prehistoric Landslides and Abrupt Tectonic Events in Seattle, Washington: Science, v. 258, no. 5088, p. 1621-1623, doi:10.1126/science.258.5088.1621. Jaffe, B., and Gelfenbaum, G., 2007, A Simple Model For Calculating Tsunami Flow Speed From Tsunami Deposits: Sedimentary Geology, v. 200, no. 3-4, p. 347361doi:10.1016/j.sedgeo.2007.01.013.

Johnson, S.Y., 2004, Evidence for Late Holocene Earthquakes on the Utsalady Point Fault, Northern Puget Lowland, Washington: Bulletin of the Seismological Society of America, v. 94, p. 2299-2316, doi:10.1785/0120040050.

Kagley, A., Zackey, T., Fresh, K., and Beamer, E., 2007, Juvenile Salmon and Nearshore Fish use in Shoreline and Lagoon Habitat Associated with Elger Bay, 2005-2007: Skagit River System Cooperative, 26 p.

Kelsey, H.M., Sherrod, B.L., Nelson, A.R., and Brocher, T.M., 2008, Earthquakes generated from bedding plane-parallel reverse faults above an active wedge thrust, Seattle fault zone: Geological Society of America Bulletin, v. 120, p. 1581-1597, doi:10.1130/B26282.1.

Koshimura, S., Mofjeld, H., González, F., and Moore, A., 2002, Modeling the 1100 BP Paleotsunami in Puget Sound, Washington: Geophysical Research Letters, v. 29, no. 20 , doi:10.1029/2002GL015170. 
LeVeque, R.J., George, D.L., and Berger, M.J., 2011, Tsunami Modelling With Adaptively Refined Finite Volume Methods: Acta Numerica, v. 20, p. 211-289, doi:10.1017/S0962492911000043.

Livingstone, D.A., 1955, A Lightweight Piston Sampler for Lake Deposits: Ecology, v. 36, no. 1, p. 137, doi:10.2307/1931439.

MacLennan, A., 2005, An Analysis of Large Woody Debris in two Puget Sound Salt Marshes; Elger Bay, Camano Island, and Sullivan Minor Marsh, Padilla Bay [M.S. thesis]: Western Washington University, Bellingham, WA, 116 p.

Mandli, K.T., Ahmadia, A.J., Berger, M., Calhoun, D., George, D.L., Hadjimichael, Y., Ketcheson, D.I., Lemoine, G.I., and LeVeque, R.J., 2016, Clawpack: building an open source ecosystem for solving hyperbolic PDEs: PeerJ Computer Science, v. 2, p. e68, doi:10.7717/peerj-cs.68.

Martin, M., and Bourgeois, J., 2012, Vented Sediments and Tsunami Deposits in the Puget Lowland, Washington - Differentiating Sedimentary Processes: Sedimentology, v. 59, p. 419-444, doi:10.1111/j.1365-3091.2011.01259.x. McCaffrey, R., Long, M.D., Goldfinger, C., Zwick, P.C., Nabelek, J.L., Johnson, C.K., and Smith, C., 2000, Rotation and Plate Locking at the Southern Cascadia Subduction Zone: Geophysical Research Letters, v. 27, no. 19, p. 3117-3120, doi:10.1029/2000GL011768.

Mofjeld, H., Venturato, A., Titov, V., González, F., and Newman, J.C., 2002, Tidal Datum Distribution in Puget Sound, Washington, Based on a Tidal Model: NOAA Technical memorandum OAR PMEL-122. Pacific Marine Environmental Laboratory, Seattle, 39 p. 
Morton, R.A., Gelfenbaum, G., and Jaffe, B.E., 2007, Physical Criteria For

Distinguishing Sandy Tsunami and Storm Deposits Using Modern Examples:

Sedimentary Geology, v. 200, no. 3-4, p. 184-207,

doi:10.1016/j.sedgeo.2007.01.003.

Nelson, A.R., Johnson, S.Y., Kelsey, H.M., Wells, R.E., Sherrod, B.L., Pezzopane, S.K., Bradley, L.-A., Koehler, R.D., and Bucknam, R.C., 2003, Late Holocene Earthquakes on the Toe Jam Hill Fault, Seattle Fault Zone, Bainbridge Island, Washington: Geological Society of America Bulletin, v. 115, p. 1388, doi:10.1130/B25262.1.

Nowaczyk, N.R., 2002, Logging of Magnetic Susceptibility, in Last, W.M. and Smol, J.P. eds. Tracking Environmental Change Using Lake Sediments: Kluwer Academic Publishers, Dordrecht, p. 155-170, doi:10.1007/0-306-47669-X_8.

Okada, Y., 1985, Surface deformation due to shear and tensile faults in a half-space: Bulletin of the Seismological Society of America, v. 75, p. 1135-1154, doi:10.1785/BSSA0750041135.

Porter, S.C., and Swanson, T.C., 1998, Radiocarbon Age Constraints on Rates of Advance and Retreat of the Puget Lobe of the Cordilleran Ice Sheet during the Last Glaciation: Quaternary Research, v. 50, no. 3, p. 205-213, doi:10.1006/qres.1998.2004.

Prasse, K., 2006, Camano Island: Images of America, Arcadia Publishing, Washington, $128 \mathrm{p}$.

Sandgren, P., and Snowball, I., 2002, Application of Mineral Magnetic Techniques to Paleolimnology, in Last, W.M. and Smol, J.P. eds. Tracking Environmental 
Change Using Lake Sediments: Kluwer Academic Publishers, Dordrecht, p. 217237, doi:10.1007/0-306-47670-3_8.

Schuster, R.L., Logan, R.L., and Pringle, P.T., 1992, Prehistoric Rock Avalanches in the Olympic Mountains, Washington: Science, v. 258, no. 5088, p. 1620-1621, doi:10.1126/science.258.5088.1620.

Sherrod, B.L., 2001, Evidence for earthquake-induced subsidence about 1100 yr ago in coastal marshes of southern Puget Sound, Washington: Geological Society of America Bulletin, v. 113, p. 1299-1311.

Sherrod, B.L., Bucknam, R.C., and Leopold, E.B., 2000, Holocene Relative Sea Level Changes Along the Seattle Fault at Restoration Point, Washington: Quaternary Research, v. 54, no. 3, p. 384-393, doi:10.1006/qres.2000.2180.

Shipman, H., 2001, The Fall of Camano Head: A Snohomish Account of a Large Landslide and Tsunami in Possession Sound During the Early 1800s: TsuInfo Alert, v. 3, no. 6, p. 13-14.

Shipman, H., 2008, A Geomorphic Classification of Puget Sound Nearshore Landforms: Technical Report 2008-01. Puget Sound Nearshore Partnership, Seattle, 37 p.

Tang, H., and Weiss, R., 2015, A Model For Tsunami Flow Inversion From Deposits (TSUFLIND): Marine Geology, v. 370, p. 55-62, doi:10.1016/j.margeo.2015.10.011.

Thorson, R.M., 1981, Isostatic Effects of the Last Glaciation in the Puget Lowland, Washington: U.S. Geological Survey Open-File Report 81-370, 110 p. 
U.S. Coast \& Geodetic Survey. Topography of Sarasota Passage and Homesí Harbor. Map. 1:20,000. 1887-88. Puget Sound River History Project, University of Washington.

U.S.G.S. Washington Mount Vernon Quadrangle. Map. 1:125,000. 1911. Print.

Venturato, A., Arcas, D., Titov, V., Mofjeld., H., Chamberlin, C., and González, F., 2007, Tacoma, Washington, Tsunami Hazard Mapping Project: Modeling Tsunami Inundation from Tacoma and Seattle Fault Earthquakes: NOAA Technical memorandum OAR PMEL-132, Joint Institute for the Study of the Atmosphere and Ocean, Seattle, 25 p.

Weir, F., Hughes, M., and Baldock, T., 2006. Beach Face and Berm Morphodynamics Fronting a Coastal Lagoon: Geomorphology, v. 82, no. 3-4, p. 331-346, doi:10.1016/j.geomorph.2006.05.015.

Williams, H.F.L., Hutchinson, I., and Nelson, A.R., 2005, Multiple sources for lateHolocene tsunamis at Discovery Bay, Washington State, USA: The Holocene, v. 15, no. 1, p. 60-73, doi:10.1191/0956683605hl784rp. 


\section{APPENDIXES}

\section{APPENDIX A}

\section{STRATIGRAPHY ILLUSTRATIONS}

Map for core locations can be found on page 20 (Figure 3). Cutbanks/exposures are drawn wider, cores are drawn thinner. The offset sections on the core drawings are indicative of multiple drives in a single core location to get deeper as the corer was only 1 $\mathrm{m}$ long. The sections marked with an $\mathrm{X}$ are indicative of no retrieval where the sediment fell out of the core or was not picked up. Refusal is where the core barrel was unable to be pushed deeper. The cause of refusal was interpreted by the sound and feel of the core barrel interacting with it. End of exposure was the lowest point of the wall of sediment that we were able to observe due to standing water or channel bed. 

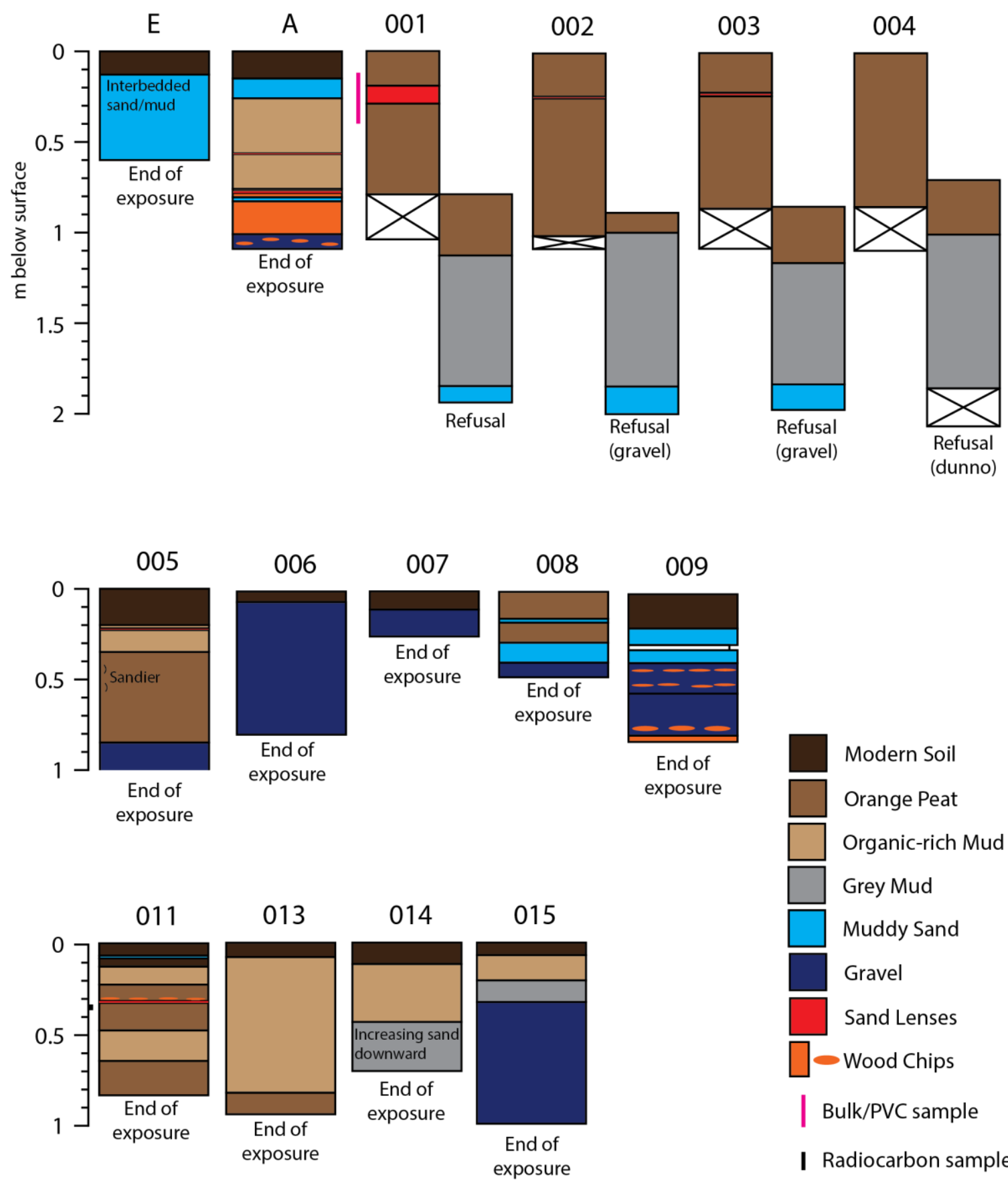

\begin{tabular}{l}
\hline Modern Soil \\
\hline Orange Peat \\
\hline$\square$ Organic-rich Mud \\
\hline$\square$ Grey Mud \\
\hline$\square$ Muddy Sand \\
$\square$ Gravel \\
$\square$ Sand Lenses \\
$\square$ Wood Chips \\
| Bulk/PVC sample \\
I Radiocarbon sample
\end{tabular}



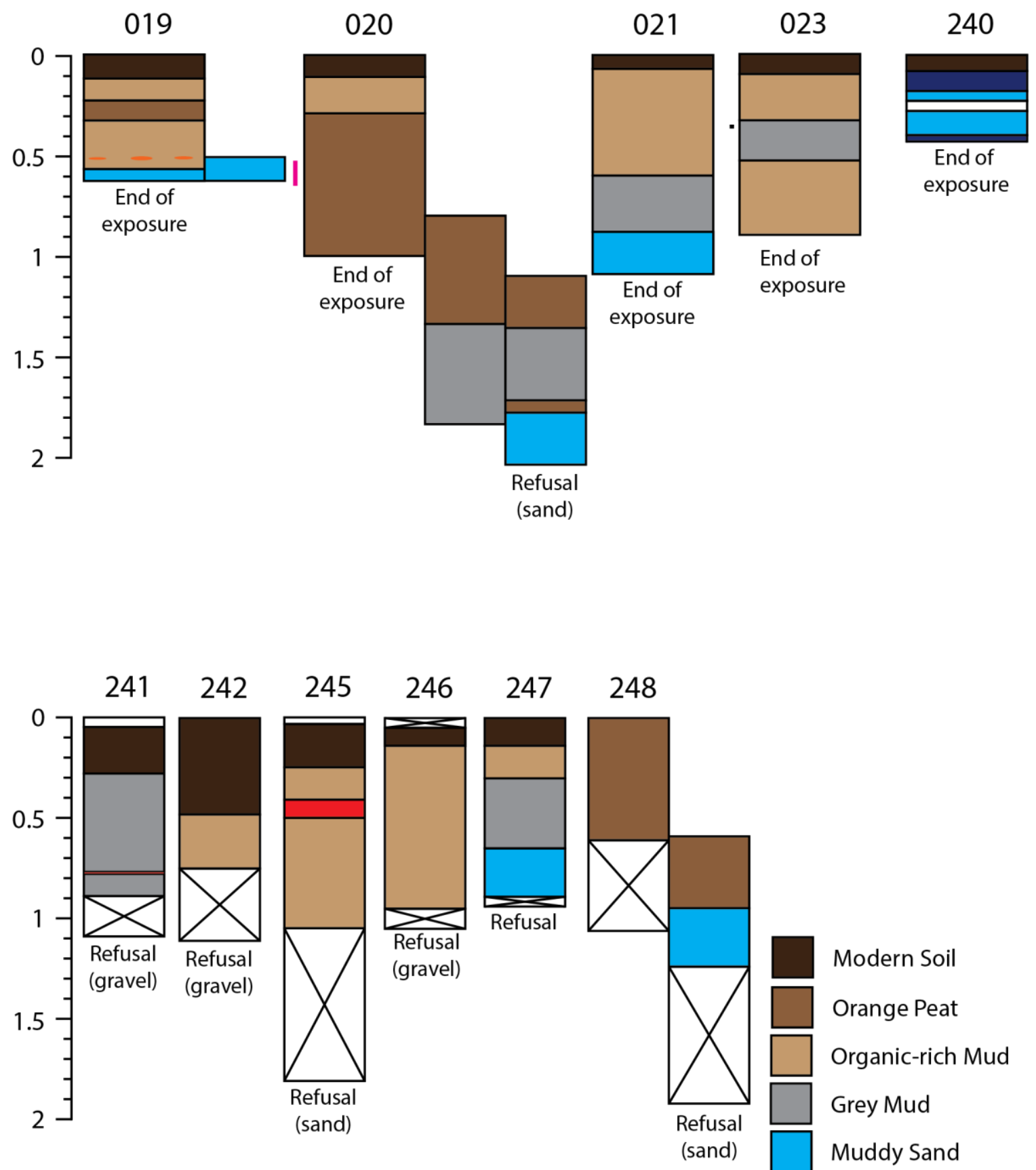

Modern Soil

Orange Peat

Organic-rich Mud

Grey Mud

Muddy Sand

Gravel

Sand Lenses

$\square$ Wood Chips

Bulk/PVC sample

I Radiocarbon sample 


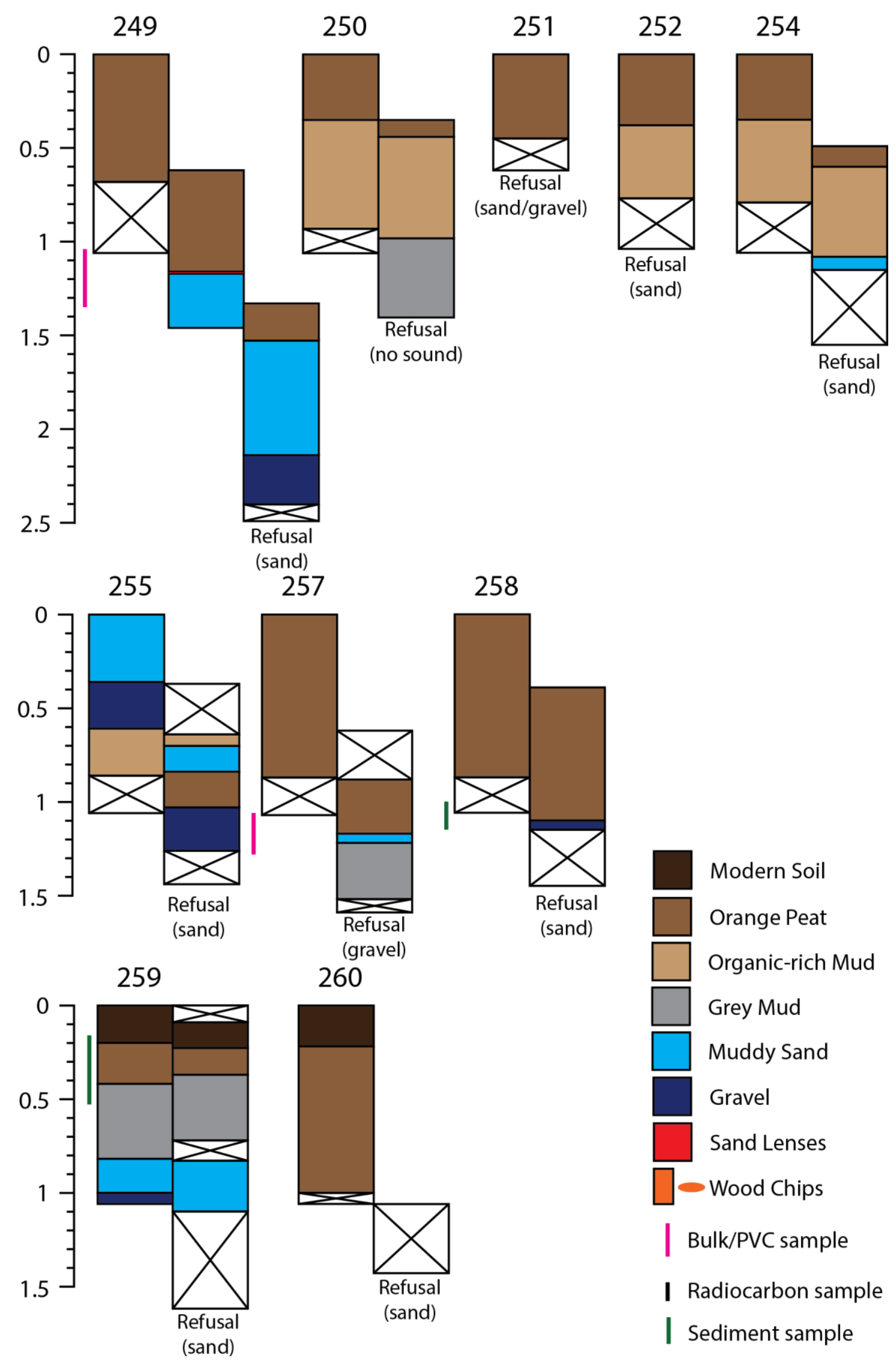



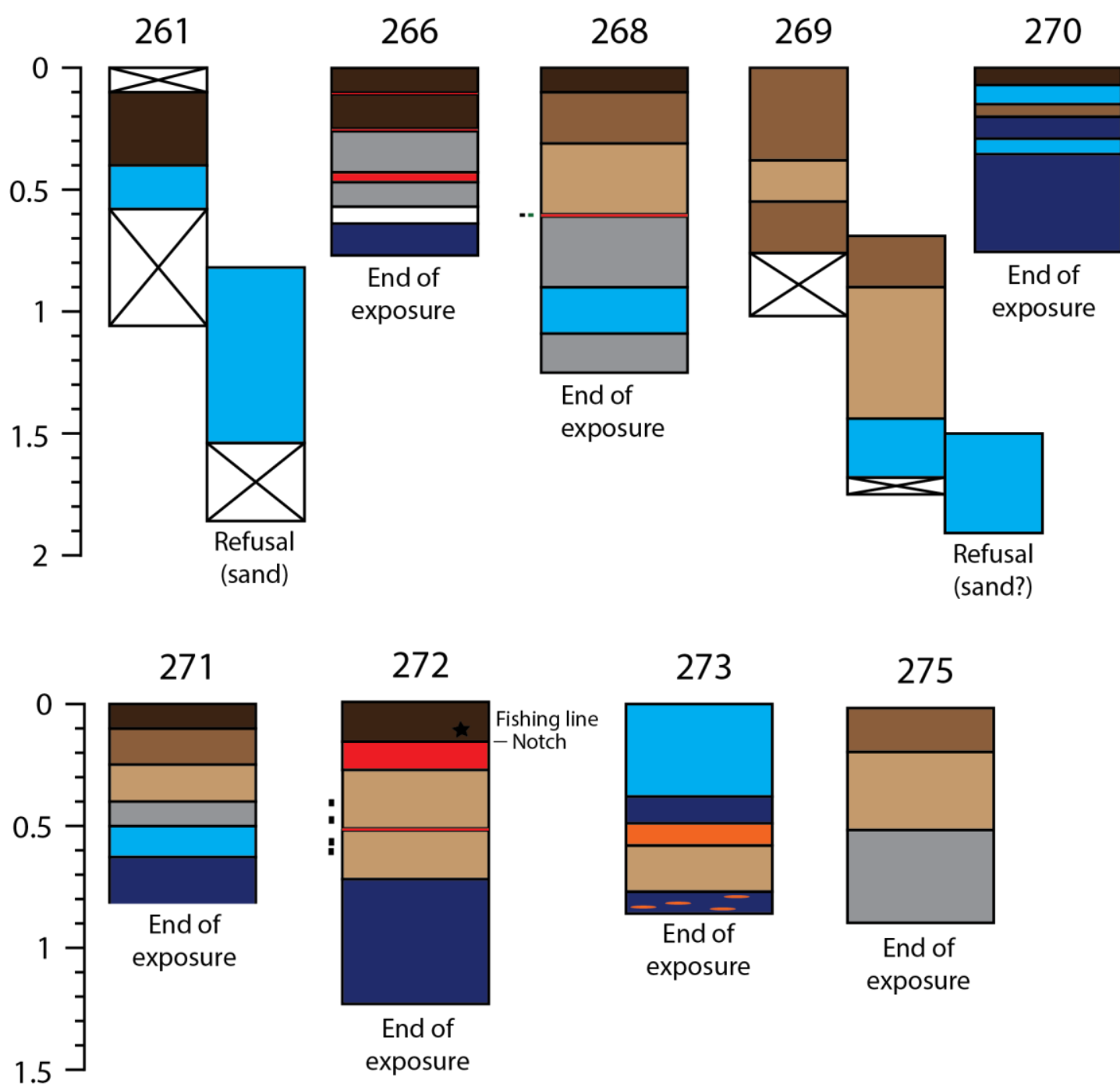

End of exposure
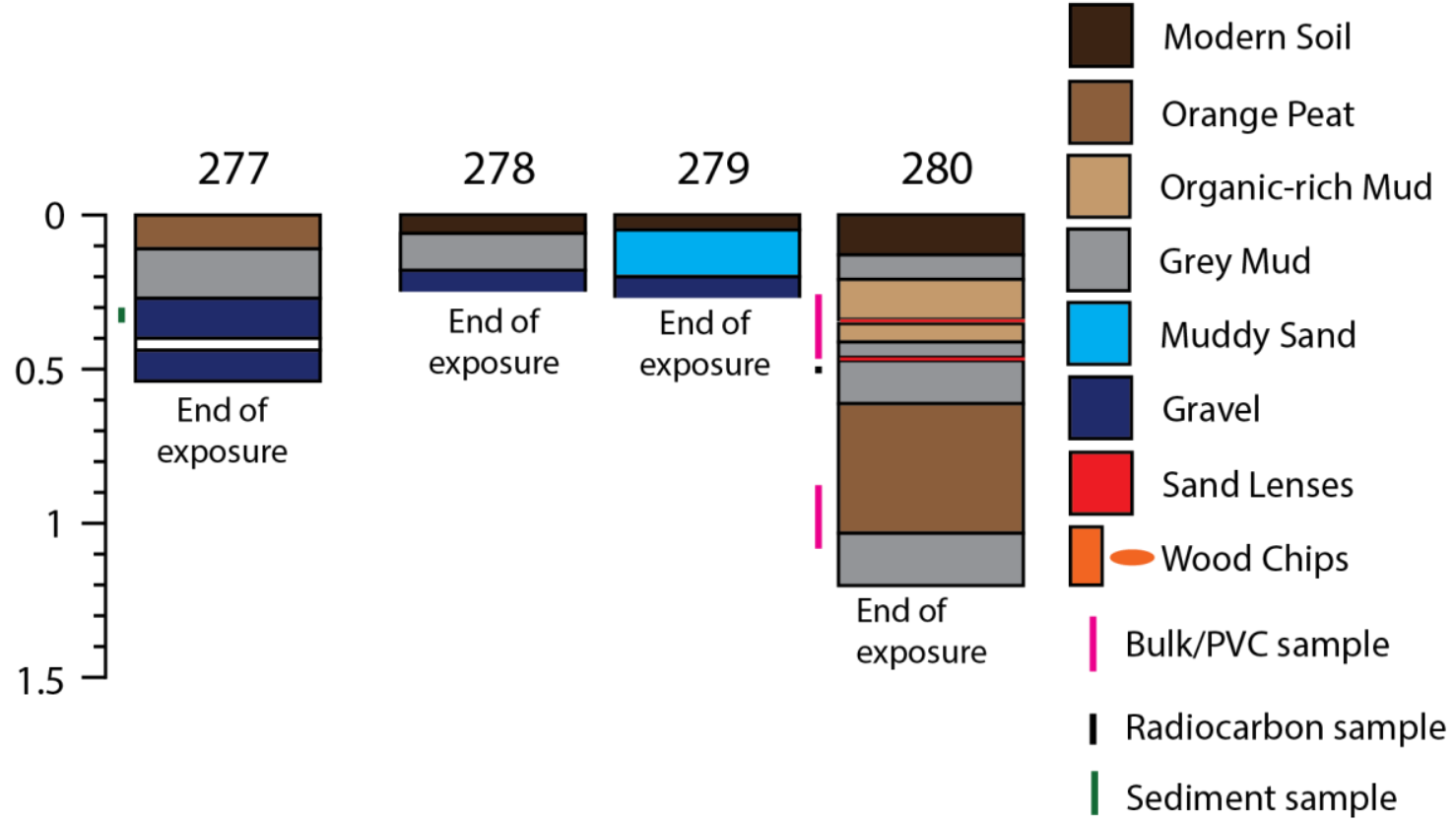

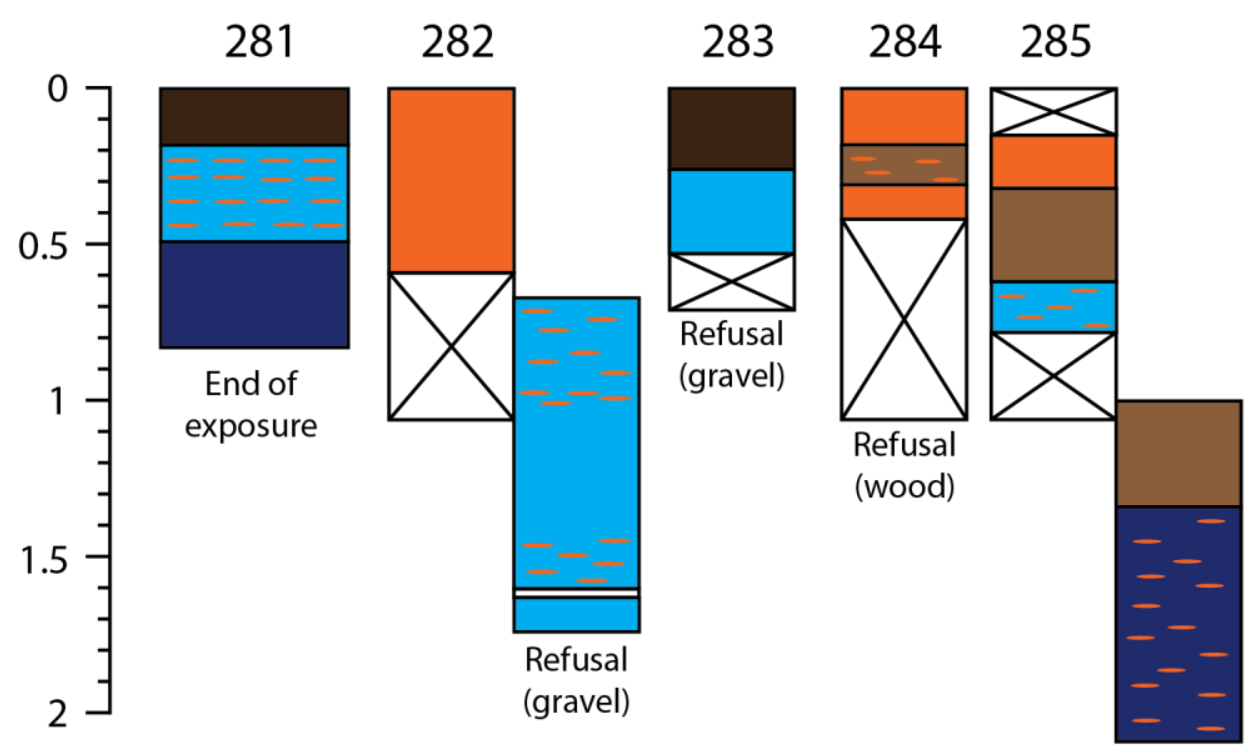

Refusal

(wood)
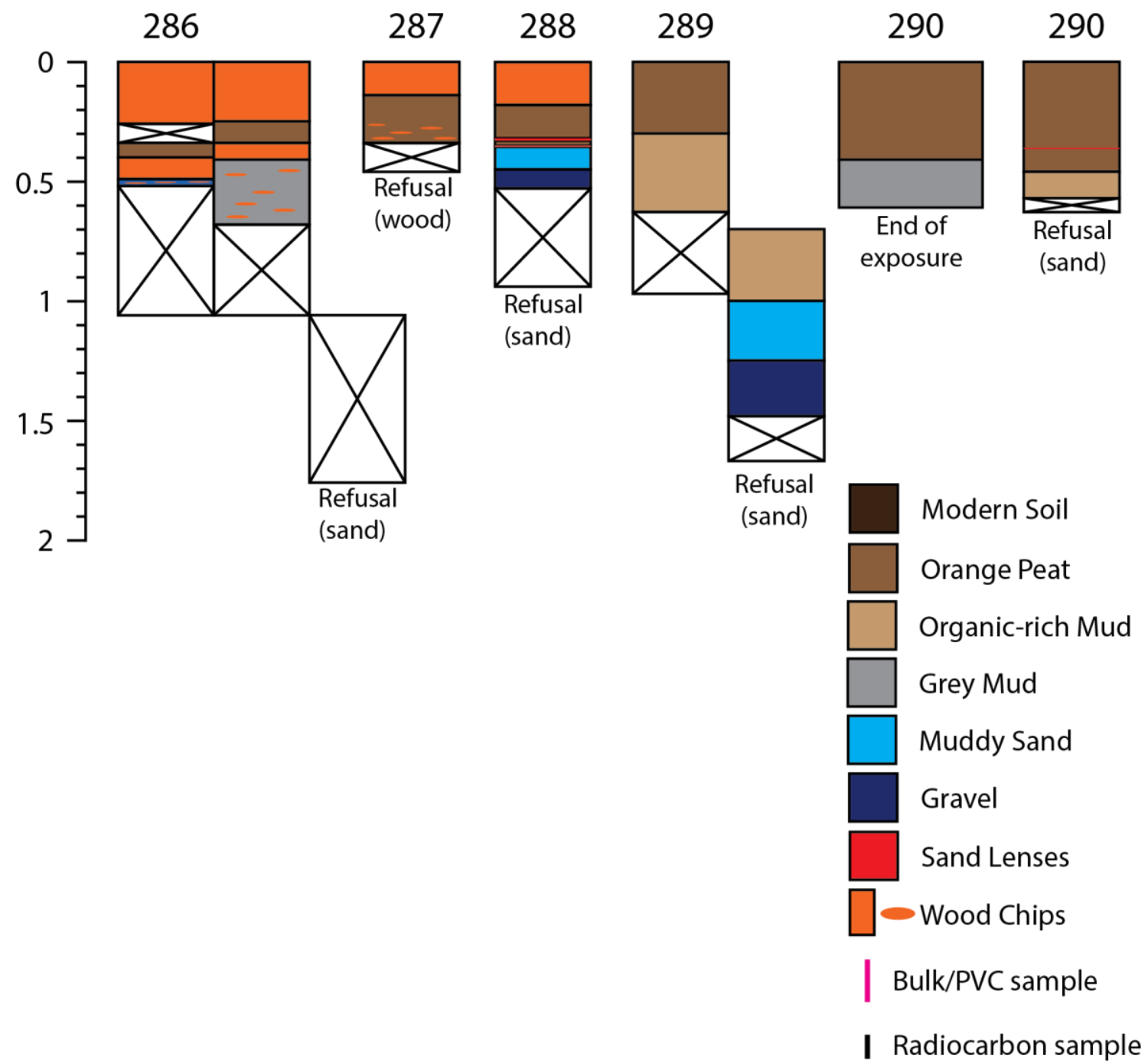

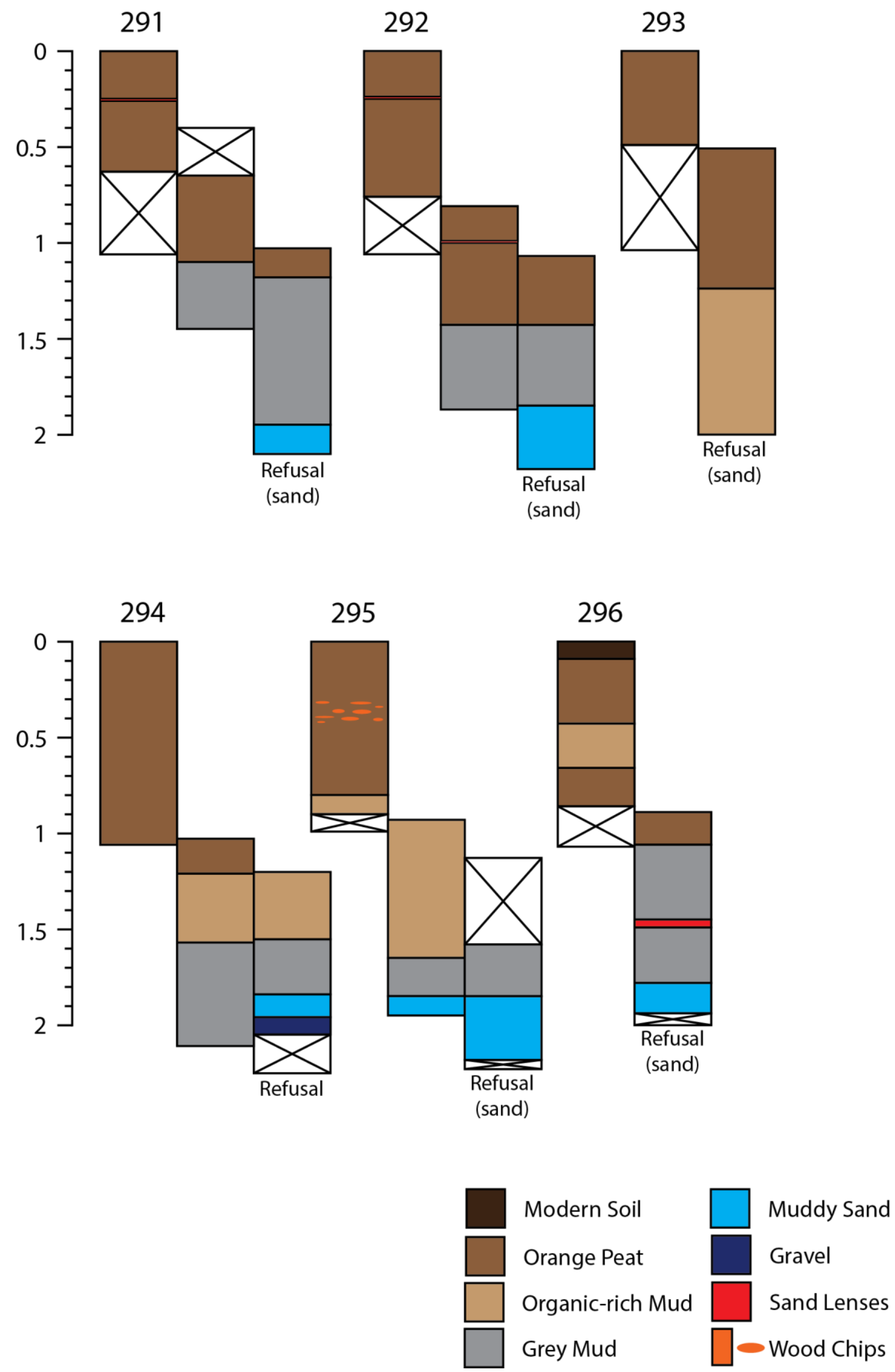

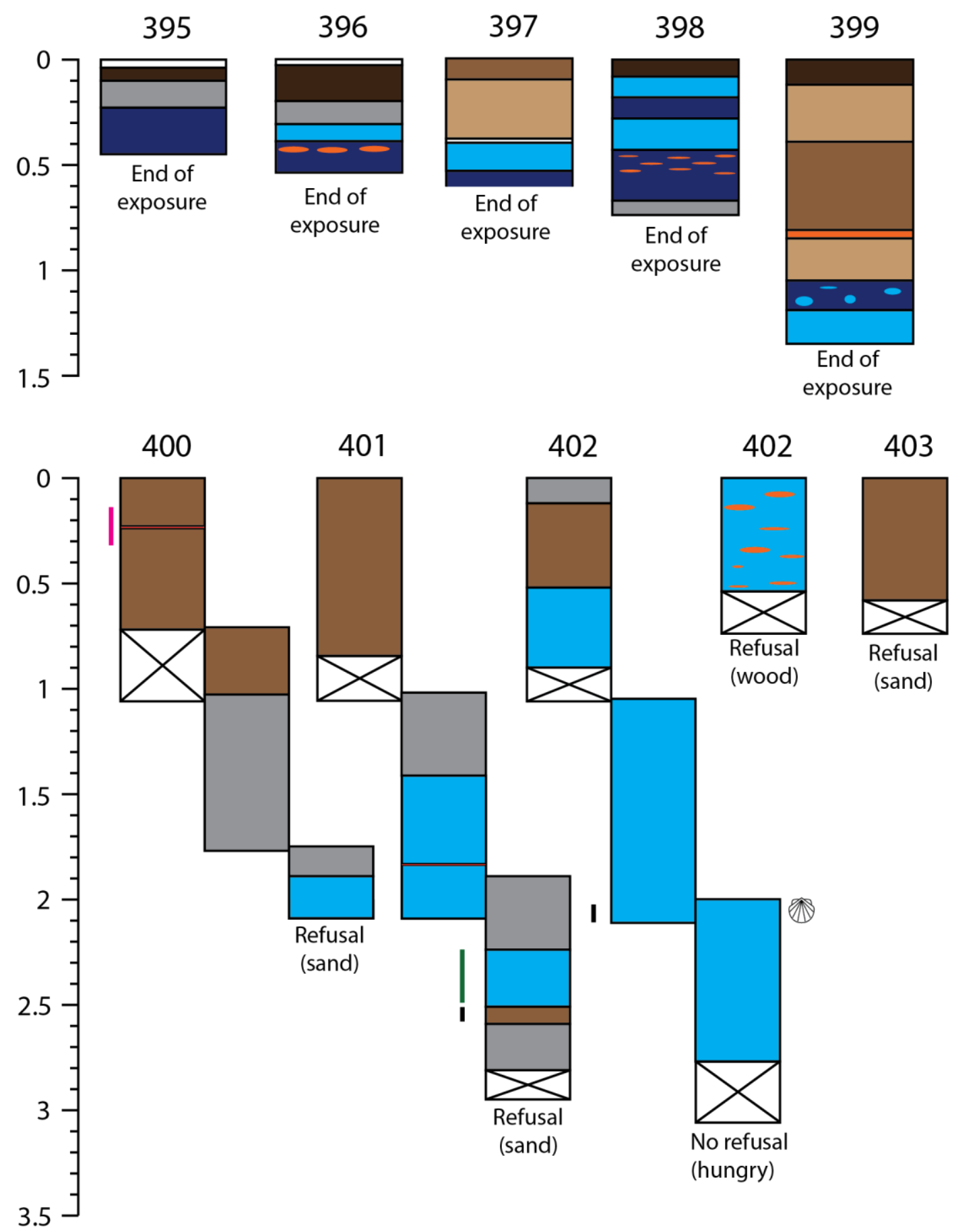

\begin{tabular}{lll}
\hline Modern Soil & $\square$ Muddy Sand & I Bulk/PVC sample \\
\hline Orange Peat & Gravel & I Radiocarbon sample \\
Organic-rich Mud & Sand Lenses & I Sediment sample \\
Grey Mud & $\square$ Wood Chips & Shells
\end{tabular}



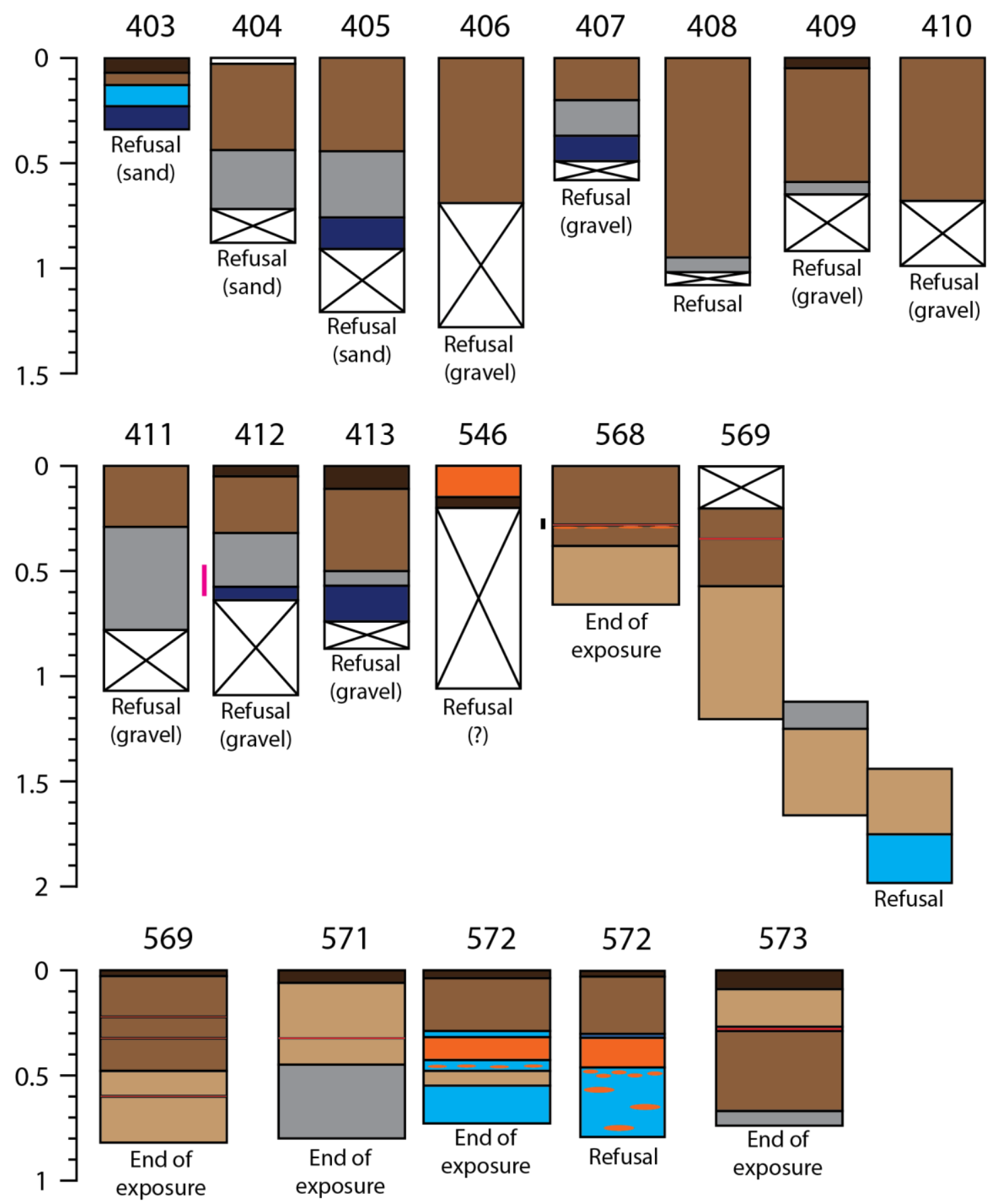

569
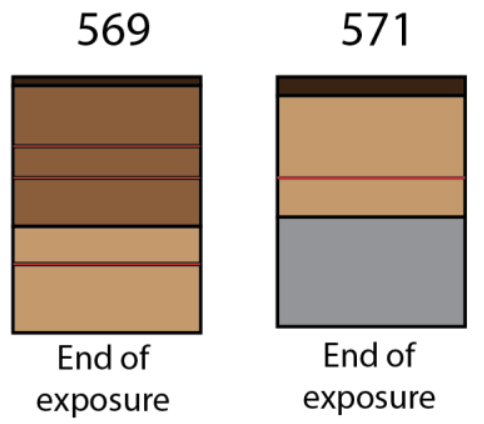

572

572

573
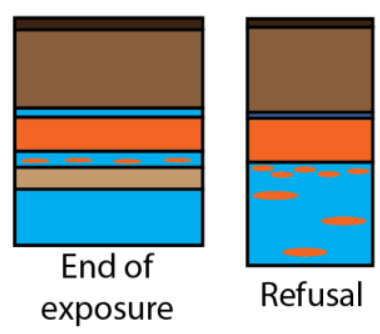

Refusal

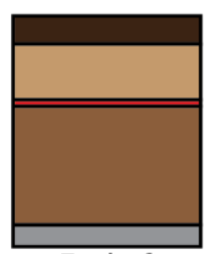

End of

exposure

Modern Soil

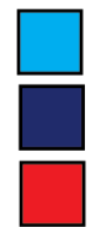

Muddy Sand

Bulk/PVC sample

Orange Peat

Gravel

I Radiocarbon sample

Organic-rich Mud

Sand Lenses

Grey Mud

$\square$ Wood Chips 


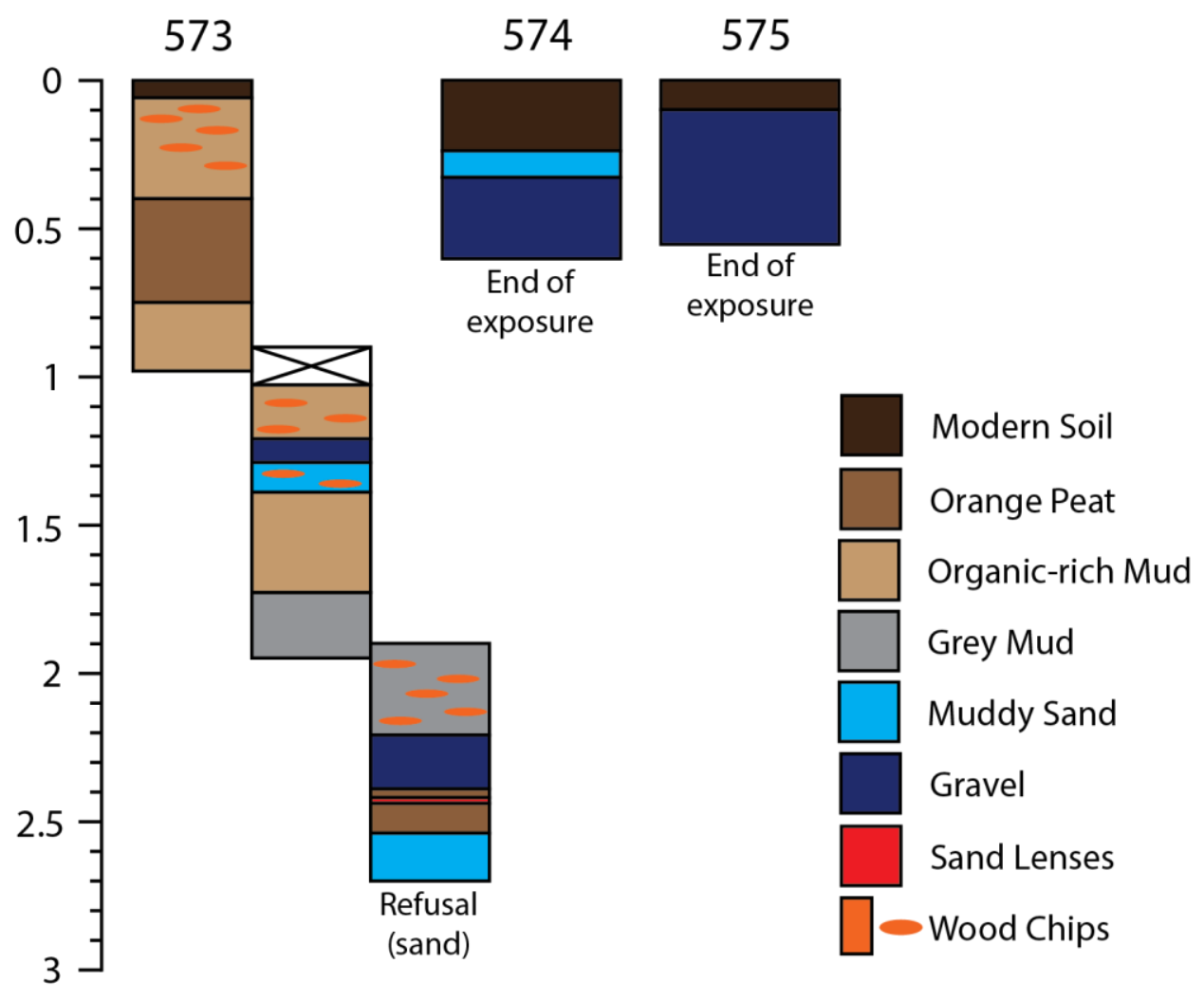




\section{APPENDIX B}

${ }^{14} \mathrm{C}$ PLOTS

Plots created during calibration of radiocarbon dates. I used OxCal v4.3.2 and

IntCal13 atmospheric curve. Refer to pages 34-36 (Figure 15 and Table 4).
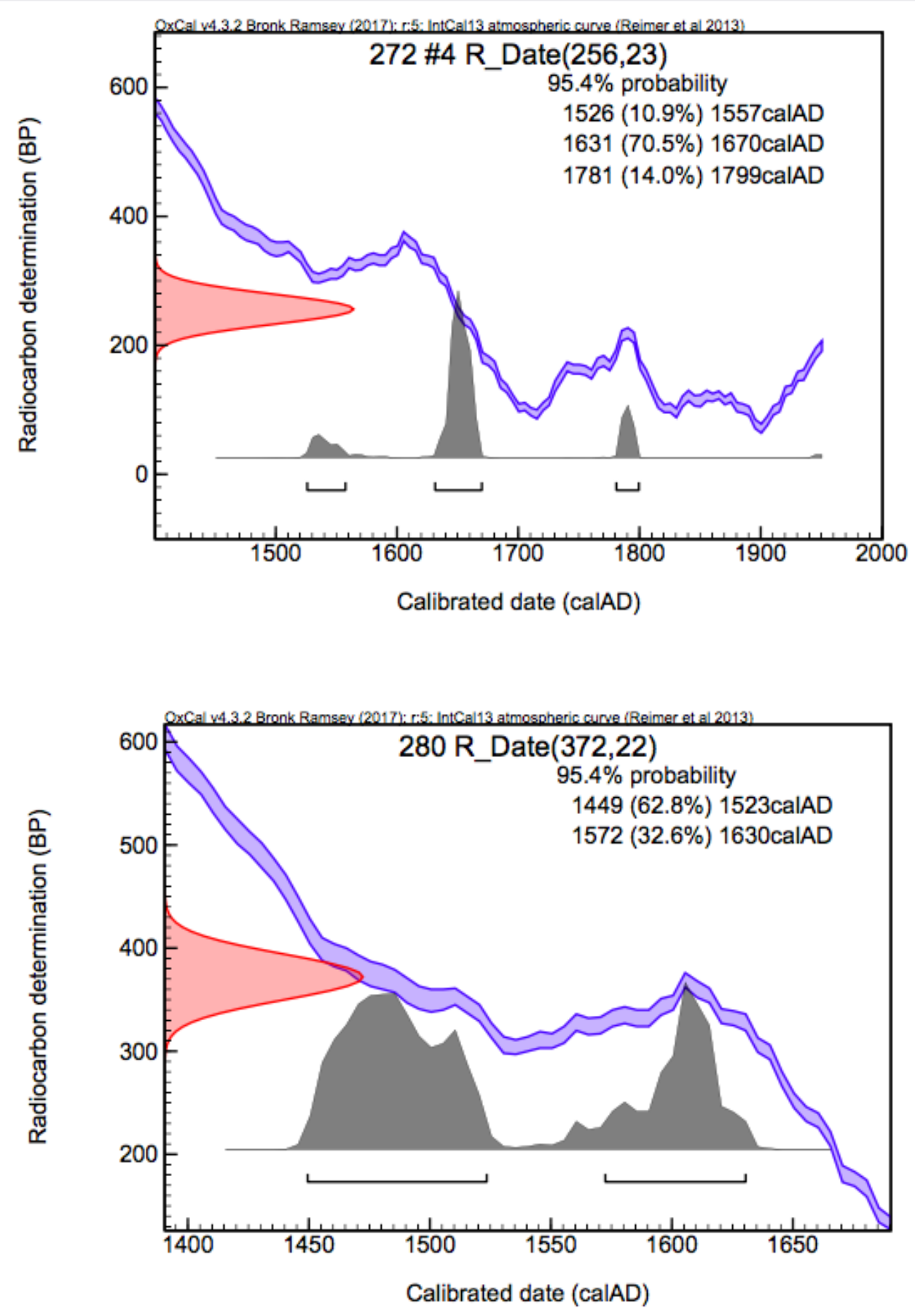

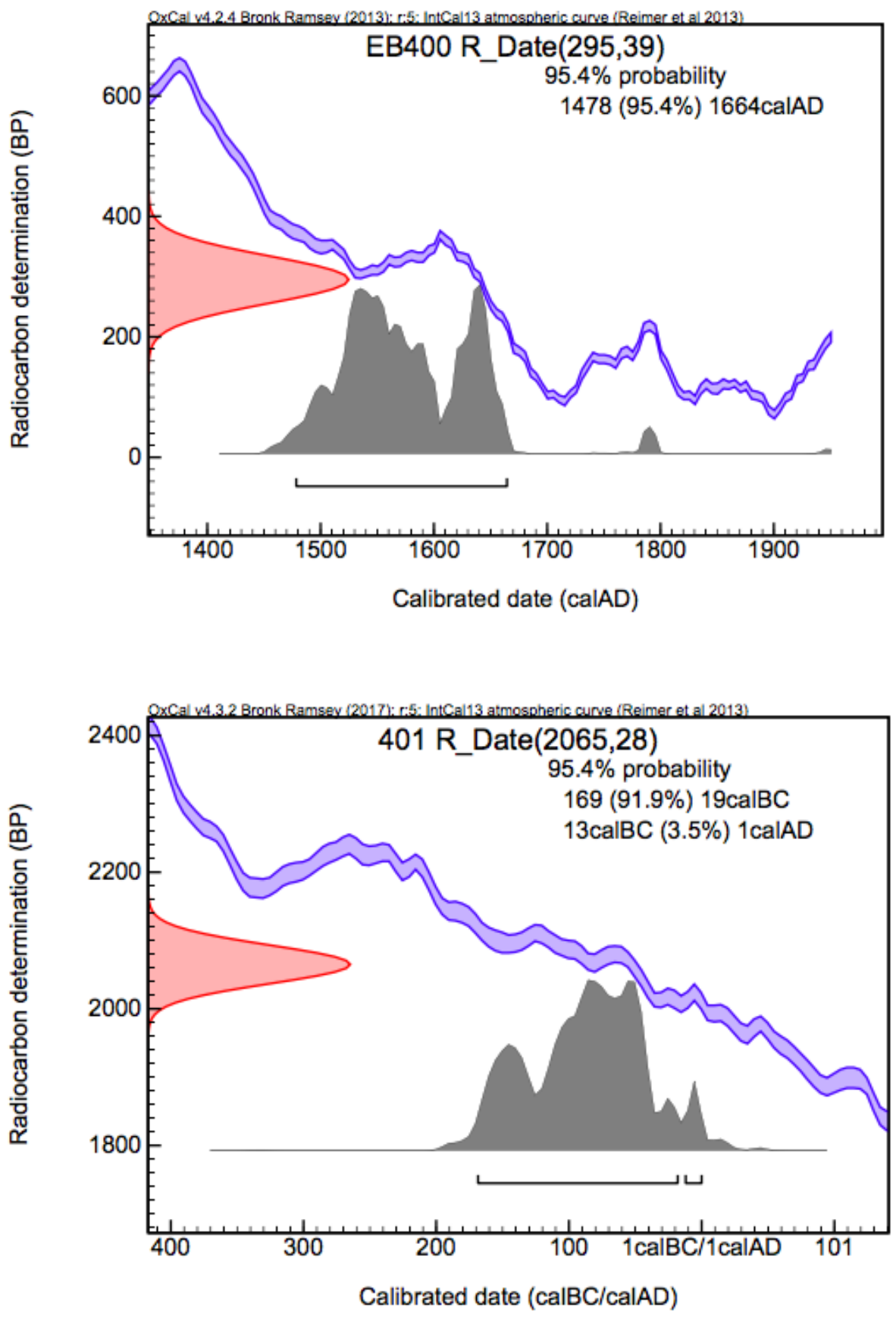


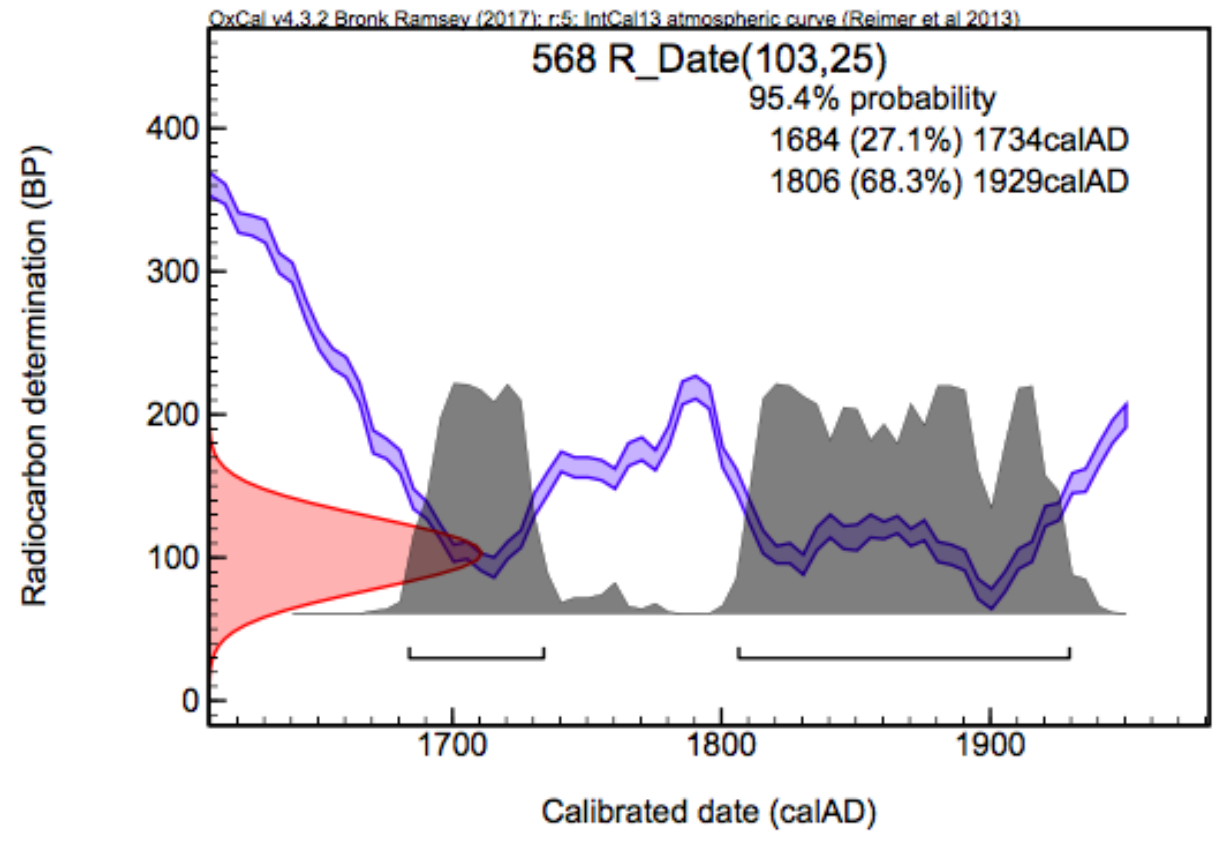

